\title{
PODRIDÃO MOLE EM MADEIRA DE Tabebuia sp. (IPÊ) EM TORRE DE RESFRIAMENTO DE ÁGUA: IDENTIFICAÇÃO E AVALIAÇÃO DA CAPACIDADE DE DEGRADAÇÃO DOS FUNGOS E ALTERAÇÕES NA ESTRUTURA
}

ANATÔMICA DA MADEIRA

\section{SÉRGIO BRAZOLIN}

Biólogo

Orientador: Prof. Dr. MÁRIO TOMAZELLO FILHO

Dissertação apresentada à Escola Superior de Agricultura "Luiz de Queiroz", Universidade de São Paulo, para obtenção do título de Mestre em Ciências, Área de Concentração: Ciência e Tecnologia de Madeiras.

PIRACICABA

Estado de São Paulo - Brasil

Novembro - 1997 


\section{Dados Internacionais de Catalogação na Publicação (CIP) \\ DIVISÃO DE BIBLIOTECA E DOCUMENTAÇÃO - Campus “Luiz de Queiroz"/USP}

\section{Brazolin, Sérgio}

Podridâo mole em madeira de Tabebuia sp. (ipê) em torres de resfriamento de água: identificação e avaliação da capacidade de degradação dos fungos e alterações na estrutura anatômica da madeira / Sérgio Brazolin - - Piracicaba, 1998.

140 p.: il. 1998.

Dissertação (mestrado) - - Escola Superior de Agricultura Luiz de Queiroz, Bibliografia.

1. Anatomia vegetal 2. Madeira de ipê 3. Podridão mole I. Título 


\title{
PODRIDÃO MOLE EM MADEIRA DE Tabebuia sp. (IPÊ) EM
} TORRE DE RESFRIAMENTO DE ÁGUA:

\author{
IDENTIFICAÇÃO E AVALIAÇÃO DA CAPACIDADE DE \\ DEGRADAÇÃO DOS FUNGOS E ALTERAÇÕES NA ESTRUTURA \\ ANATÔMICA DA MADEIRA
}

\author{
SÉRGIO BRAZOLIN
}

Aprovada em: 05 de fevereiro de 1998

Comissão julgadora:

Prof. Dr. Antonio Tadeu de Lelis

Prof. Dr. Mário Tomazello Filho

Prof. Dra. Veronica Angyalossy Alfonso

Prof. Dr. Mário Tomazello Filho

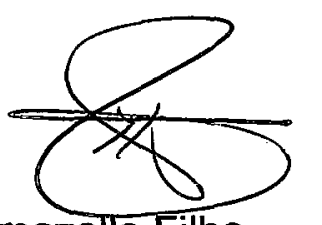
orientador 
À Cláudia e ao Pedro,

que diariamente me ensinam os segredos da felicidade. 


\section{AGRADECIMENTOS}

Ao Prof. Dr. Mário Tomazello Filho, cuja orientação, paciência e auxílio permitiram a realização deste trabalho.

Ao Prof. Dr. Amantino Ramos de Freitas ex-diretor da Divisão de Produtos Florestais do Instituto de Pesquisas Tecnológicas do Estado de São Paulo - IPT, por estimular o ingresso no curso e pelo apoio prestado.

Ao Prof. Dr. Marcio Augusto Rabelo Nahuz, diretor da Divisão de Produtos Florestais do IPT, pelo apoio e incentivo.

Ao Prof. Dr. Antonio Tadeu de Lelis, chefe do Agrupamento Preservação de Madeiras do IPT, pelo apoio, estímulo e longos sábados e domingos.

À Petroquímica União S.A. por ter permitido a realização deste trabalho.

À Fundação Coordenação de Aperfeiçoamento de Pessoal de Nível Superior - CAPES, pelo auxilio financeiro.

Aos professores do Instituto de Pesquisas Tecnológicas do Estado de São Paulo-IPT e da Escola Superior de Agricultura "Luiz de Queiroz" - ESALQ, pela dedicação e auxilio.

À Dra. Iracema Helena Schoenlein-Crusius, aos Biólogos Christian Wellbaum e José Ivanildo de Souza, do Instituto de Botânica do Estado de São Paulo, e à Profa. MSc Marilene da Silva Cavalcanti, da Universidade Federal de Pernambuco - Recife, pela identificação dos fungos isolados.

Ao Dr. Rubens Dias Humphreys pelo auxilio nas análises estatísticas e revisão do documento e ao Prof. Dr. Décio Barbin e Cristian A. Carranza do Departamento de Estatística e Matemática da ESALQ/USP pelas discussões sobre estatística. 
Ao Antônio Carlos F. Barbosa pelas lâminas e pelo estímulo nas conversas de corredor.

Aos colegas do IPT, em especial para ao Geraldo, Gonzalo, Gregório, João, Lígia, Paulinho, Raquel, Reginaldo e Zezé pelo incentivo e auxílio.

À Bea, irmã de espírito, e à Adriana, irmã mais nova. Muito obrigado!

Aos meus pais que me permitiram chegar neste ponto. 


\section{SUMÁRIO}

Página

LISTA DE FIGURAS ............................................................................ viii

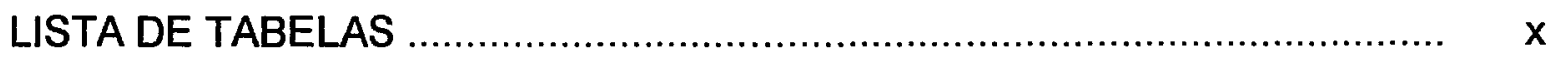

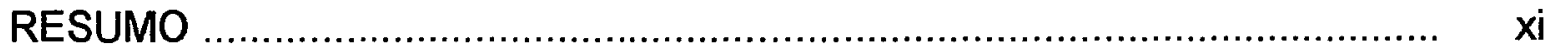

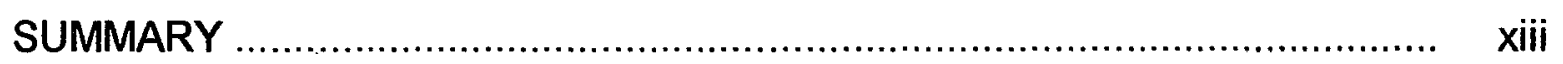

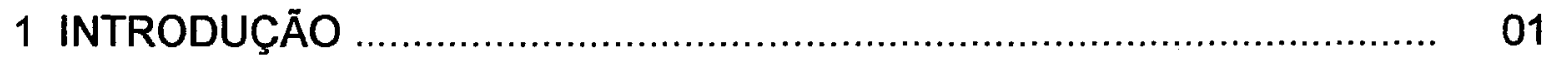

2 REVISÃO DE LITERATURA ….......................................................... 04

2.1 Fungos de podridão mole ............................................................... 04

2.1.1 Classificação taxonômica ................................................................. 05

2.1.2 Condições de desenvolvimento na madeira ...................................... 06

2.1.3 Aspecto macro e microscópico da madeira com podridão mole .......... 07

2.2 Torres de resfriamento de água: estrutura e princípio

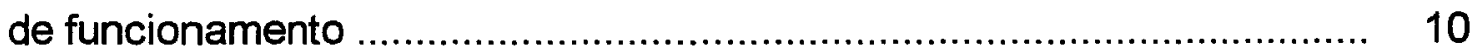

2.3 Fungos de podridão mole em torres de resfriamento de água ............... 12

2.4 Controle da podridão mole em torres de resfriamento de água .............. 26

2.5 Torres de resfriamento de água no Brasil ......................................... 29

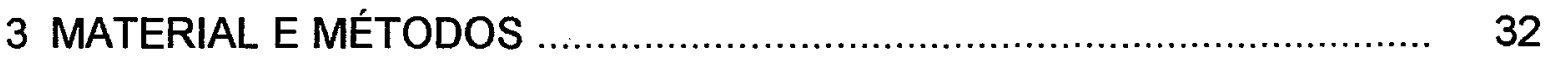

3.1 Localização e características da torre de resfriamento de água estudada ........................................................................... 32

3.2 Coleta das amostras de madeira .................................................... 34

3.3 Identificação da madeira ................................................................... 35

3.4 Avaliação da ocorrência de podridão mole na madeira .......................... 36

3.5 Isolamento e identificação de fungos ................................................... 37

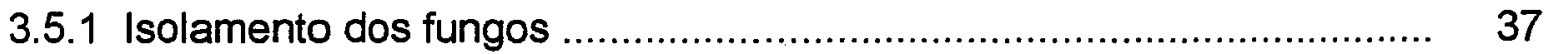

3.5.2 Identificação dos fungos isolados .................................................. 38

3.6 Avaliação da capacidade de degradação dos fungos isolados ............... 39

3.6.1 Ensaio acelerado de podridão mole ................................................. 40 
3.6.2 Confirmação do ataque de podridão mole nas madeiras

3.6.3 Análise estatística ......................................................................... 43

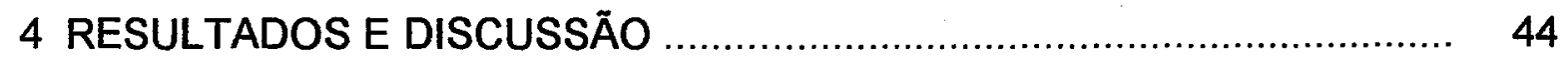

4.1 Identificação da madeira ................................................................. 44

4.2 Avaliação da ocorrência de podridão mole na madeira ......................... 46

4.2.1 Análise macroscópica ............................................................... 49

4.2.2 Análise microscópica ................................................................ 55

4.3 Isolamento e identificação dos fungos .............................................. 62

4.4 Avaliação da capacidade de degradação dos fungos isolados ............... 71

4.4.1 Confirmação do ataque dos fungos de podridão mole ....................... 75

4.4.2 Ensaio acelerado - fungos de podridão mole ................................... 79

5 CONCLUSÕES ............................................................................. 86

REFERÊNCIAS BIBLIOGRÁFICAS ................................................. 88

APÊNDICE 1 - Tabelas de resultados do ensaio acelerado de podridão mole .............................................................. 98

APÊNDICE 2 - Análises estatísticas ................................................. 127 


\section{LISTA DE FIGURAS}

1 - Desenho esquemático de uma torre de resfriamento de água com circulação mecânica e tiragem induzida - corte transversal.

2 - Torre de resfriamento EF-901 da Petroquímica União S.A. situada no município de Santo André - Estado de São Paulo.

3 - Aspecto macroscópico de uma amostra de madeira de Tabebuia sp. do eliminador de respingos com podridão mole; $(A)$ face superior e $(B)$ inferior (escala $=1 \mathrm{~cm}$ ).

4 - Aspecto macroscópico de uma amostra de madeira de Tabebuia sp. do enchimento com ataque químico; $(A)$ face superior $e(B)$ inferior (escala = $1 \mathrm{~cm})$.

5 - Amostras de madeira de Tabebuia sp. do eliminador de respingos. (A) madeira sadia e (B) com ataque de fungos de podridão mole (escala $=$ $1 \mathrm{~cm})$.

6 - Vista geral da secção transversal do xilema, mostrando as regiões superficial (S), intermediária (I) e interna (IN), com diferentes intensidades de alterações causadas pelos fungos de podridão mole (escala $=200 \mu \mathrm{m}$ ).

7 - Detalhe da secção transversal do xilema na região superficial (S) da amostra, mostrando as células severamente afetadas e degradadas pelos fungos de podridão mole (escala $=20 \mu \mathrm{m}$ ).

8 - Detalhe da secção transversal do xilema na região intermediária (I) da amostra, mostrando fibras com as paredes intactas (A) e atacadas por fungos de podridão mole (B) - escala $=20 \mu \mathrm{m}$.

9 - Detalhe da secção transversal do xilema na região interna (IN) da amostra, mostrando células com paredes sem ataque de fungos de podridão mole (escala $=20 \mu \mathrm{m}$ ).

10 - Secção transversal do xilema mostrando hifas pigmentadas e septadas no lume do vaso (escala $=10 \mu \mathrm{m})$. 
11 - Secção longitudinal radial do xilema mostrando hifas pigmentadas e septadas no lume das células do parênquima radial $(A)$ e do parênquima axial $(B)-$ escala $=30 \mu \mathrm{m}$.

12 - Secção transversal do xilema mostrando hifas dos fungos no lume das fibras $(A)$ e a passagem fibra-a-fibra através das pontoações $(B)$ - escala $=$ $5 \mu \mathrm{m}$.

13 - Secção transversal do xilema mostrando a presença de cavidades, formadas por fungos de podridão mole na parede das fibras (escala = $5 \mu \mathrm{m})$.

14 - Secção transversal do xilema mostrando o ataque das hifas dos fungos na parede das fibras $(A)$ em relação às paredes intactas dos vasos $(B)$, das células dos raios $(C)$ e das células do parênquima axial $(D)$ - escala $=$ $30 \mu \mathrm{m}$.

15 - Secção longitudinal tangencial do xilema, sob luz polarizada, mostrando cavidades alongadas, cilíndricas, com as pontas cônicas e com formato rombóide na parede celular das fibras (escala $=10 \mu \mathrm{m}$ ).

16 - Secção longitudinal tangencial do xilema, sob luz polarizada, mostrando cavidades curtas, bicônicas com forma de diamante na parede celular das fibras (escala $=10 \mu \mathrm{m}$ ).

17 - Secção longitudinal tangencial do xilema, sob luz polarizada, mostrando a interligação das cavidades na parede celular e o ângulo formado com o eixo principal das fibras (escala $=20 \mu \mathrm{m}$ ).

18 - Espécies de fungos isolados das amostras de madeira de Tabebuia sp. da torre de resfriamento de água, e suas freqüencias relativas de ocorrência (\%).

19 - Valores médios da perda de massa (\%) de corpos-de-prova de madeira $E$. grandis e $P$. elliottii causada por fungos de podridão mole. 


\section{LISTA DE TABELAS}

1. Relação das espécies de fungos observadas ou isoladas de madeiras em torres de resfriamento de água e suas respectivas referências bibliográficas.

2. Análises macro e microscópicas das amostras de madeira de Tabebuia sp. do eliminador de respingos e do enchimento para detecção da podridão mole.

3. Espécies de fungos isoladas das amostras de madeira de Tabebuia sp., da torre de resfriamento de água, e suas freqüencias relativas expressas em porcentagem.

4. Valores médios da perda de massa (\%) e a análise da estrutura anatômica dos corpos-de-prova de madeira de Eucalyptus grandis e Pinus elliottii submetidos à ação dos fungos isolados.

5. Ensaio acelerado de podridão mole - Valores de perda de massa (\%) da madeira de Eucalyptus grandis.

6. Ensaio acelerado de podridão mole - Valores de perda de massa (\%) da madeira de Pinus elliottii. 


\title{
PODRIDÃO MOLE EM MADEIRA DE Tabebuia_sp. (IPÊ) EM TORRE DE RESFRIAMENTO DE ÁGÜA: IDENTIFICAÇÃO E AVALIAÇÃO DA CAPACIDADE DE DEGRADAÇĀO DOS FUNGOS E ALTERAÇÕES NA ESTRUTURA ANATÔMICA DA MADEIRA
}

\author{
Autor: SÉRGIO BRAZOLIN \\ Orientador: Prof. Dr. MÁRIO TOMAZELLO FILHO
}

RESUMO

A madeira de Tabebuia sp. - ipê - é considerada de alta durabilidade natural aos fungos apodrecedores, sendo freqüentemente utilizada em ambientes agressivos, como torres de resfriamento de água de indústrias químicas e petroquímicas brasileiras. As análises macro e microscópicas de amostras de madeira de Tabebuia sp. do eliminador de respingos e do enchimento de uma torre de resfriamento, com cerca de 23 anos em operação, revelaram a colonização por fungos de podridão mole. $O$ ataque ocorreu de forma generalizada no madeiramento da torre, embora mais intenso e evidente, sob macroscopia, nos seus níveis inferiores.

Sob microscopia, o ataque na madeira foi identificado como podridão mole tipo 1, confirmado pela formação de cavidades na parede celular, com diferentes formas e tamanhos. Este ataque restringiu-se às fibras, não sendo observado nas células dos parênquima radial e axial e nos vasos.

Foram isolados 51 fungos da madeira de Tabebuia sp., pertencentes à Subdivisão Deuteromycotina e aos gêneros Acremonium, Fusarium, Gliocladium, Penicillium, Phialophora, Pullularia, Tipo-Moniliella, Trichoderma e Verticillium. Os fungos dos gêneros Acremonium, Phialophora e Trichoderma foram os mais freqüentes. 
Corpos-de-prova de Eucalyptus grandis e Pinus elliottii foram inoculados com os fungos isolados para avaliar sua capacidade de degradação. A análise da estrutura microscópica desses corpos-de-prova mostrou que os fungos Fusarium oxysporum, Gliocladium spp., Tipo-moniliella, Penicillium sp. Pullularia pullulans, Trichoderma spp. e Verticillium sp. não formaram cavidades típicas de podridão mole nas paredes das células do lenho. Por outro lado, Acremonium sp., A. kiliense, Phialophora sp. e Phialophora butyrii causaram podridão mole nas madeiras de $E$. grandis e $P$. elliottii, constituindo-se em importantes organismos deterioradores na torre de resfriamento.

A avaliação da perda de massa (\%) das madeiras submetidas aos fungos de podridão mole mostrou que $O E$. grandis foi mais susceptivel do que $\circ P$. elliottii, corroborando resultados de pesquisas que comprovaram a susceptibilidade das madeiras de folhosas aos fungos de podridão mole em relação às de coníferas. Dos fungos isolados, 2 cepas de $A$. kiliense apresentaram maior capacidade de degradação dessas madeiras, sugerindo-se sua utilização na avaliação da durabilidade natural de madeiras de coníferas e folhosas, em condições laboratoriais. 


\title{
SOFT-ROT IN Tabebuia sp. WOOD (IPÊ) IN COOLING TOWER: IDENTIFICATION AND DEGRADING CAPACITY OF THE FUNGI AND CHANGES IN THE ANATOMIC STRUCTURE OF THE WOOD
}

\author{
Author: SÉRGIO BRAZOLIN \\ Adviser: Prof. Dr. MÁRIO TOMAZELLO FILHO
}

\section{SUMMARY}

Tabebuia sp. wood (ipê) is considered of high natural resistance to fungi decay, and has been used in harsh environments, such as cooling towers installed in chemical and petrochemical industries. Macro and microscopic analyses of Tabebuia sp. wood samples collected from the drift eliminator and filling of a cooling tower in operation for 23 years, revealed colonisation by soft-rot fungi. The attack in the cooling tower occurred in all wood exposed to water, although macroscopically, more intense and evident in its inferior level.

Microscopically, the wood attack was identified as soft-rot type 1 , confirmed by the formation of cavities in the cell wall, with different sizes and shapes. This attack was restricted to the fibers and was not observed in the radial and axial parenchyma cells and vessels.

Fifty-one fungi were isolated from Tabebuia sp. wood, belonging to the Subdivision Deuteromycotina and the genus Acremonium, Fusarium, Gliocladium, Penicillium, Phialophora, Pullularia, Tipo-Moniliella, Trichoderma and Verticillium. The fungi Acremonium, Phialophora e Trichoderma were the most frequent. 
Specimens of Eucalyptus grandis and Pinus elliottii woods were inoculated with the isolated fungi, in order to evaluate their degrading capacity. The microscopic analyses showed that the fungi Fusarium oxysporum, Gliocladium spp., Tipo-moniliella, Penicillium sp. Pullularia pullulans, Trichoderma spp. and Verticillium sp. were not able to produce typical soft-rot cavities in the cell wall of the xylem cells. On the other hand, Acremonium sp., A. kiliense, Phialophora sp. and Phialophora butyrii caused soft-rot in $E$. grandis and $P$. elliottii woods, becoming important deterioration organisms in the cooling tower.

The analyses of weight loss (\%) of the wood inoculated with the isolated fungi showed that $E$. grandis was more susceptible than $P$. elliottii, agreeing with research results which confirmed that hardwoods are less resistant to soft-rot attack than conifers. Two strains of $A$. kiliense showed the best degrading capacity and were recommended to be used in the evaluation of the natural resistance of hardwoods and softwoods, under laboratory conditions. 


\section{INTRODUÇÃO}

As torres de resfriamento de água são equipamentos indispensáveis e utilizados por um grande número de indústrias nos setores químico, petroquímico e siderúrgico. A madeira é um material empregado na construção desses equipamentos sendo que, as torres mais antigas eram totalmente fabricadas de madeira. Nas mais recentes, a madeira constitui as peças estruturais e não estruturais internas e o concreto compõe a parte estrutural externa.

Após alguns anos de contínua utilização das torres, evidenciase a deterioração da madeira por fungos apodrecedores e, normalmente, os usuários e os construtores de torres no Brasil desconhecem as formas de ataque dos fungos, além de não disporem de informações quanto à durabilidade das espécies de madeira utilizadas.

Em torres de resfriamento de água foram descritos três tipos de apodrecimento: podridão branca, parda e mole (Brown, 1964; Hutton, 1978 e Neves et al., 1989). As podridões branca e parda, conhecidas como ataque interno ou profundo, ocorrem em peças de madeira ocasionalmente umedecidas, não sendo encontradas nas peças submersas em água. A podridão mole, conhecida como ataque superficial, ocorre de forma generalizada nas peças de madeira submersas e não submersas em água, sendo que Price (1957) afirmou ser a principal causa de deterioração da madeira no enchimento de torres de resfriamento nos Estados Unidos da América - E.U.A.. 
Eaton (1972), Eaton \& Irvine (1972), Eaton \& Jones (1971a) e Savory (1954) sugeriram que os custos de manutenção de uma torre de resfriamento de água são afetados pela ocorrência de fungos que causam apodrecimento interno e superficial nas madeiras. Segundo Eaton, citado por Natarajan \& Udaiyan (1978), o estudo dos fungos apodrecedores nas peças de madeira de torres de resfriamento nos E.U.A., Inglaterra, Alemanha, U.R.S.S. e Austrália indicou a sua importância em termos de economia de operação destes equipamentos e Hutton (1978) afirmou que os problemas causados podem atingir milhares de dólares a uma planta industrial, traduzidos em perdas de produção e homens-hora.

De acordo com Eaton \& Jones (1971a), são poucas as investigações ecológicas da biodeterioração da madeira em equipamentos industriais, sendo que, levantamentos detalhados dos microrganismos (fungos e bactérias) que atacam a madeira nas torres não têm atraido a atenção, em comparação com as pesquisas de métodos de prevenção e de tratamento de madeiras (Udaiyan \& Manian, 1991).

Nos E.U.A., o Cooling Tower Institute-CTI (1959 e 1963) realizou estudos sobre a durabilidade natural e a eficiência de produtos preservantes de madeira em torres de resfriamento, elaborando normas que, atualmente, estabelecem a utilização de madeiras de coniferas tratadas sob pressão, com produtos preservantes hidrossolúveis, oleosos ou oleossolúveis.

No Brasil, as informações sobre as espécies de madeira, produtos preservantes e processos de tratamento das madeiras de torres de resfriamento são provenientes de inspeções realizadas com o objetivo de detectar peças atacadas por fungos. Verificou-se que as madeiras de ipê (Tabebuia spp. - Família Bignoniaceae) e de maçaranduba (Manilkara spp. Familia Sapotaceae) foram utilizadas na construção de algumas torres e, apesar de apresentarem alta durabilidade natural ao ataque de fungos apodrecedores no solo, não têm sido avaliadas em sistemas de resfriamento de água. Ressalta-se, também, que nenhuma pesquisa foi realizada no Brasil 
para a caracterização da micota presente nas madeiras das torres de resfriamento.

Destaca-se, portanto, a importância e necessidade de estudos para a identificação da micota e para a caracterização da podridão mole em madeiras de folhosas - utilizadas em torres de resfriamento de água. Esses estudos permitirão a compreensão da biodeterioração da madeira e a adoção de medidas de controle mais eficazes.

Pelo exposto, o presente estudo foi realizado com o objetivo de avaliar a ocorrência de fungos de podridão mole em madeira de Tabebuia sp. de uma torre de resfriamento de água, descrevendo a ação desses fungos na madeira, no nível macro e microscópico. Além disso, identificar a micota existente e os fungos causadores de podridão mole, avaliando sua capacidade de degradação em madeira de Eucalyptus grandis (Família Myrtaceae) e Pinus elliottii (Família Pinaceae). 


\section{REVISÃO DE LITERATURA}

\subsection{Fungos de podridão mole}

Segundo histórico apresentado por Levy (1978), a presença de cavidades na parede celular de células vegetais associadas com hifas de fungos foi primeiro descrita em 1863 pelo botânico alemão Schact. Entretanto, somente em 1937 foi dada atenção especial a este tipo de degradação, quando Bayley \& Vestal observaram que microfungos eram responsáveis pela formação destas cavidades nas células do lenho e Tamblyn detectou este tipo de ataque em madeira de torres de resfriamento. Em 1950, foi constatada por Findlay \& Savory a importância dos fungos das Subdivisões Ascomycotina e Deuteromycotina na deterioração de madeiras em torres de resfriamento de água.

Somente a partir dos estudos de Savory (1954), com madeiras de torres de resfriamento de água, foi aplicado o termo podridão mole ("softrot"), reconhecendo-se a importância e a vasta ocorrência deste tipo de ataque. 


\subsubsection{Classificação taxonômica}

A podridão mole em madeiras é causada por fungos pertencentes às Subdivisões Ascomycotina e Deuteromycotina (Levy, 1978; Nilsson, 1988 e Savory, 1954).

Corbett, citado por Wilcox (1973), considerou que os fungos de podridão mole são intermediários entre os fungos manchadores/emboloradores de madeiras e os fungos que causam podridão branca/parda, por apresentarem características dos dois grupos.

Os fungos manchadores, assim como os emboloradores pertencem à Subdivisões Ascomicotyna e Deuteromycotina e se nutrem de materiais de reserva presentes nas células das madeiras não danificando, nos estágios iniciais de ataque, a parede celular. Os fungos de podridão branca e parda, pertencentes à Subdivisão Basidiomicotyna, degradam as moléculas de celulose, hemicelulose e lignina que constituem as paredes das células da madeira (Eaton \& Hale, 1993).

Muitos fungos de podridão mole são considerados manchadores e emboloradores nos estágios iniciais do ataque à madeira, quando existem substâncias de fácil assimilação disponíveis no lume das células. Com a gradativa diminuição de carboidratos livres e facilmente metabolizáveis, os fungos de podridão mole utilizam os carboidratos da parede celular, como o fazem os fungos de podridão branca e parda (Oliveira et al., 1986).

Käärik, citada por Oliveira et al. (1986), com base na atividade 
enzimática classificou, também, os fungos de podridão mole como um grupo intermediário entre os fungos manchadores e emboloradores de madeira e os fungos de podridão branca e parda, por possuírem capacidade limitada de degradação das paredes celulares.

A formação de cavidades na parede celular, característica de fungos de podridão mole, foi também observada para alguns fungos da Subdivisão Basidiomycotina. Desta forma, este tipo de ataque à parede celular foi considerado, por alguns autores, como caracteristico de um grupo de fungos que hidroliza a celulose independentemente da classificação taxonômica dos fungos apodrecedores (Wilcox, 1973).

Atualmente, é aceita a definição proposta por Nilsson (1988), que considera a podridão mole como uma forma de apodrecimento da madeira causado por fungos pertencentes às Subdivisões Ascomycotina e Deuteromycotina.

\subsubsection{Condições de desenvolvimento na madeira}

Duncan (1960) demonstrou, em condições de laboratório, que espécies de fungos que causam podridão mole, podem tolerar condições ambientais extremas:

a) com relação à temperatura, $40 \%$ dos fungos tiveram um ótimo crescimento micelial a $34^{\circ} \mathrm{C}$ e $6 \%$ a $38^{\circ} \mathrm{C}$ - temperaturas consideradas acima das verificadas, normalmente, para basidiomicetos apodrecedores;

b) com relação ao $\mathrm{pH}$, o crescimento micelial máximo foi obtido com pH próximo de 6 para muitos fungos de podridão mole, coincidente com $\circ$ 
dos basidiomicetos apodrecedores; cerca da metade dos fungos mantiveram o crescimento máximo em pH 7 e até 8; em pH 9 o crescimento foi reduzido, mas não paralisado;

c) com relação à disponibilidade de oxigênio, os fungos apresentaram uma maior tolerância à ambientes com aeração restrita e com deficiência em oxigênio do que os basidiomicetos apodrecedores;

d) com relação à tolerância a produtos preservantes, utilizados no tratamento de madeiras, estes fungos apresentaram igual ou maior tolerância em comparação com basidiomicetos apodrecedores.

Eaton \& Hale (1993) citam que os fungos de podridão mole ocorrem na madeira em condições de altos teores de umidade, baixos teores de oxigênio disponivel e na presença de produtos preservantes elou extrativos na madeira. Nessas condições, o crescimento e a atividade dos basidiomicetos que causam podridão branca e/ou parda pode ser retardado ou inibido. Fatores como elevadas temperaturas e concentrações de nitrogênio solúvel podem favorecer a ocorrência de podridão mole.

Esses estudos explicam a predominância de fungos de podridão mole e a ausência de fungos de podridão branca e parda nas madeiras das áreas submersas em água das torres de resfriamento.

\subsubsection{Aspecto macro e microscópico da madeira com podridão mole}

Macroscopicamente, a madeira úmida quando atacada por fungos de podridão mole, apresenta sua camada superficial amolecida, escurecida e facilmente removivel e a camada imediatamente abaixo da área 
atacada encontra-se sadia. Quando a madeira seca, surgem pequenas fissuras superficiais paralelas e transversais às fibras, conferindo à peça um aspecto craqueado (Savory, 1954).

Corbett, citado por Wilcox (1973), descreveu, em nível microscópico, dois tipos de ataque na madeira: tipo 1 , no qual ocorre a formação de cavidades na camada $S_{2}$ da parede secundária da célula; e tipo 2, com a erosão da parede celular, a partir do lume das células.

0 ataque tipo 1 é a forma clássica de deterioração da madeira atribuída aos fungos de podridão mole. Segundo Levy (1978), em um corte transversal da madeira as cavidades aparecem como buracos na camada $\mathrm{S}_{2}$ da parede secundária das células, podendo destruí-la totalmente, mas, raramente atingem a camada $S_{3}$ da parede celular. Nos cortes longitudinais estas cavidades estão unidas e alinhadas formando uma cadeia.

Hale \& Eaton, citados por Eaton \& Hale (1993), ao estudarem a penetração transversal das hifas de fungos na parede celular e o processo de formação e desenvolvimento das cavidades com técnicas de filmagem - "timelapse" - distinguiram cinco etapas: (i) penetração transversal de uma fina hifa (0,3 a 0,5 $\mu \mathrm{m}$ de diâmetro) em ângulo reto com a parede celular; (ii) realinhamento da fina hifa em disposição paralela às microfibrilas de celulose na camada $S_{2}$, com ramificação da hifa em forma de "T" ou "L" até certa extensão após o que, cessa o crescimento apical da hifa; (iii) dissolução enzimática da parede celular ao redor da hifa e formação de uma cavidade com pontas cônicas; (iv) início de novo crescimento apical da hifa ( $2^{\mathrm{a}}$ fase) com a formação de uma fina hifa (probóscide), a partir da ponta cônica da cavidade, na direção das microfibrilas de celulose; após certa extensão, a probóscide 
inicia a produção de enzimas para degradação da parede celular; (v) formação de cadeias de cavidades pelo crescimento apical intermitente das hifas e pela dissolução enzimática da parede celular ao longo do comprimento da fina hifa.

Segundo Corbett, citado por Wilcox (1973), o ataque tipo 2 ocorre predominantemente em madeiras de folhosa de baixa resistência natural, consistindo na erosão das camadas da parede celular ao redor das hifas que estão crescendo no lume da célula. Dos padrões de erosão da parede celular pela ação das hifas, o mais simples observado consiste na formação de cavidades em forma de "V"; Nilsson e Leighthey \& Eaton, citados por Eaton \& Hale (1993), observaram formas mais difusas de erosão ocorrendo a uma certa distância da hifa.

Segundo Nilsson (1988), foi sugerido por vários pesquisadores que o termo podridão mole deveria ser restrito às espécies de fungos que formam cavidades no interior da parede celular. Na prática, o ataque tipo 1 parece ser a forma mais encontrada; entretanto, esta restrição excluiria fungos apodrecedores importantes pertencentes aos gêneros Daldinia e Hypoxylon.

Os fungos de podridão mole causam alterações na composição química da parede celular da madeira. De maneira geral, estes fungos degradam primariamente os polissacarídeos, sendo a celulose e hemiceluloses (pentosanas) removidas em taxas similares. Já a degradação da lignina é mais lenta, dependendo da espécie de fungo e da madeira atacada. (Eaton \& Hale, 1993; Eriksson \& Wood, 1985; Nilsson,1988 e Wilcox, 1973). 
2.2 Torres de resfriamento de água: estrutura e principio de funcionamento

As torres de resfriamento de água constituem-se em equipamentos fundamentais e necessários, pois são responsáveis pelo resfriamento de toda a água utilizada nos processos industriais. O tamanho e a complexidade construtiva desses equipamentos dependem da necessidade de cada indústria, podendo ser pequenos, com cerca de $2 \mathrm{~m}$ de altura, ou grandes chegando a cerca de $100 \mathrm{~m}$ de altura (Eaton, 1972). A Figura 1 apresenta um esquema de uma torre de resfriamento de água, indicando seus principais componentes.

Nas torres de resfriamento, a água de refrigeração é bombeada para as bacias de distribuição situadas no alto e nebulizada sobre milhares de ripas de madeira que formam o enchimento (região de respingos), para maior fracionamento das gotículas de água. À medida que a água cai ao longo da torre, entra em contato com o ar e resfria-se. A água resfriada é acumulada na bacia coletora e bombeada para ser reutilizada.

Segundo a forma de entrada do ar na torre, podemos classificar as torres em: circulação natural e mecânica (Drew Produtos Químicos, 1979).

As torres de circulação natural, são construídas com grandes alturas e posicionadas em ângulo reto em relação ao vento dominante, para se conseguir um eficiente resfriamento da água. Nessas torres, ocorrem perdas relativamente grandes de água, pois as gotículas são dispersas através das venezianas laterais que controlam também a entrada do ar. 


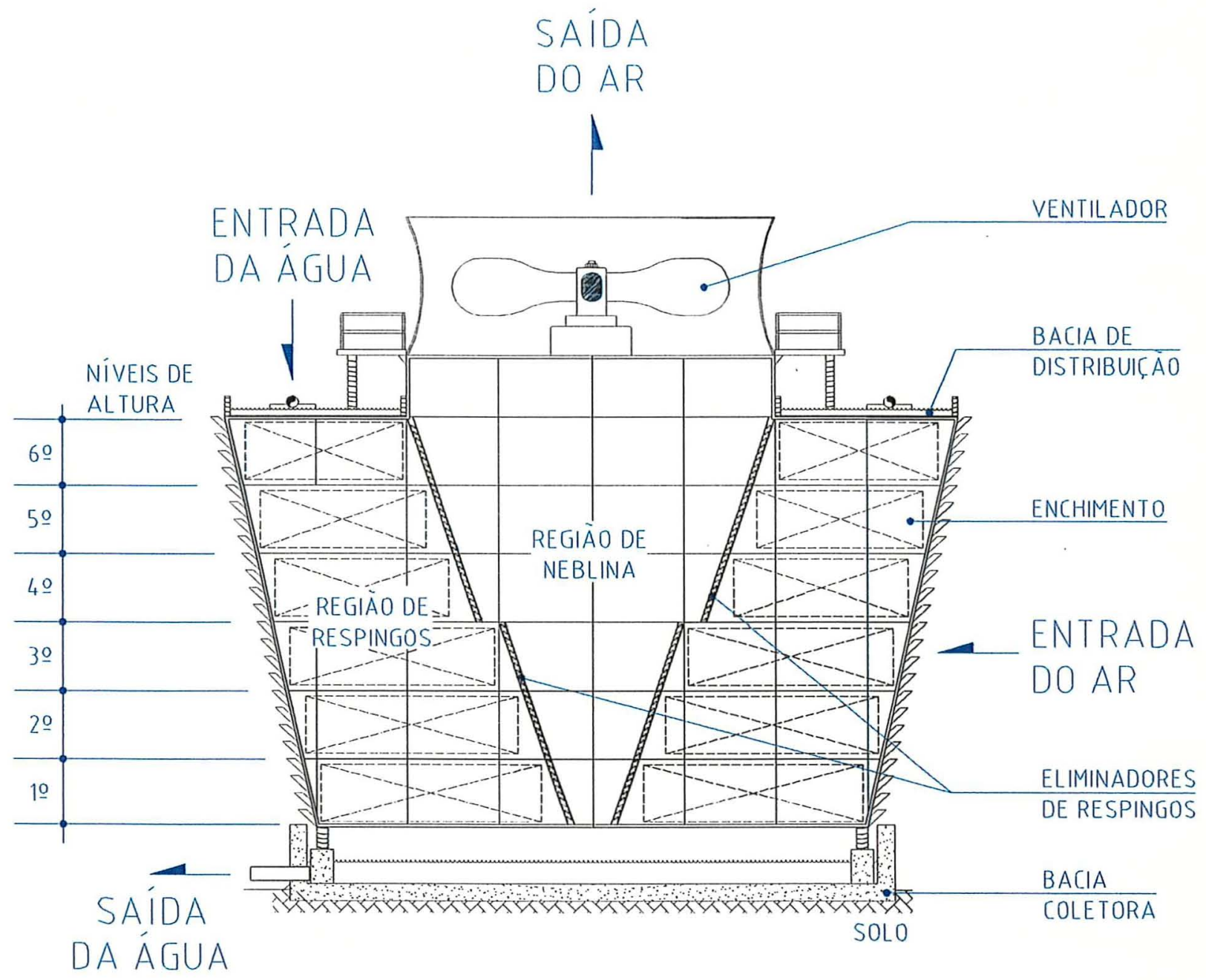

Figura 1 - Desenho esquemático de uma torre de resfriamento de água com circulação mecânica e tiragem induzida - corte transversal. 
As torres de circulação mecânica são equipamentos mais modernos, onde o ar é introduzido por um dos dois métodos: tiragem forçada e induzida. As torres de tiragem forçada utilizam ventiladores, situados na base ou nos lados da torre, para forçar o ar a entrar horizontalmente e depois subir para encontrar as gotículas de água descendentes. As torres de tiragem induzida (Figura 1) aspiram o ar para dentro através de ventiladores localizados no topo. Para direcionar o ar que passa pelo enchimento da torre e minimizar a perda de água arrastada pela corrente de ar, são construídos eliminadores de gotículas ou respingos; constituídos por venezianas compostas por ripas de madeira.

\subsection{Fungos de podridão mole em torres de resfriamento de água}

O número de gêneros e espécies de fungos que se desenvolvem nas madeiras em torres de resfriamento de água é significativo.

Segundo Eaton \& Jones (1971a), a colonização em madeiras do enchimento de torres de resfriamento poderia ocorrer por três grupos de fungos:

a) o primeiro grupo incluiria os fungos que estão presentes durante o período inicial de exposição da madeira e são estimulados a frutificar devido à disponibilidade de nutrientes solúveis nas regiōes superficiais da madeira e à relativa ausência de microrganismos competidores; o seu desaparecimento estaria associado com mudanças na textura das camadas superficiais da madeira e com a colonização ou esporulação de outros fungos; 
b) o segundo grupo incluiria os fungos que aparecem muitas semanas após a infestação inicial e o desenvolvimento da podridão mole; sua colonização e esporulação poderia estar relacionada ao desaparecimento dos colonizadores iniciais;

c) o terceiro grupo incluiria os fungos que ocorrem esporadicamente na madeira não demonstrando nenhum padrão de colonização.

A Tabela 1 traz uma relação de fungos observados ou isolados de madeira em torres de resfriamento e suas respectivas referências bibliográficas. Nessa tabela observamos que predominam os fungos pertencentes às Subdivisões Ascomycotina e Deuteromycotina, sendo os gêneros mais citados: Acremonium, Aspergillus, Chaetomium, Fusarium, Graphium, Monodictys, Paecilomyces, Penicillium, Phaeonectriella, Phialophora, Phoma, Savoryella, Sporormia, Stachybotrys, Torula, Trichoderma e outros. Entretanto, devemos ressaltar que apenas Eaton \& Jones (1971a) e Morrel \& Smith (1988) confirmaram a capacidade de alguns fungos isolados causarem podridão mole nas madeiras. 
Tabela 1. Relação das espécies de fungos observadas ou isoladas de madeiras em torres de resfriamento de água e suas respectivas referências bibliográficas.

Espécie de fungo

Absidia cylindrospora

Acremonium sp. (= Cephalosporium sp.)

Acrogenospora sphaerocephala

Allomyces arbuscula

Alternaria sp.

A. alternata

A. longissima

A. tenuissima

Arthrinium phaeospermum

Arthrobotrys arthobotryoides

Ascochyta sp.

A. vulgaris

Aspergillus sp.

A. flavipes

A. fumigatus

A. japonicus

A. niger

A. sydowi

\section{Referência bibliográfica}

(9)

(1); (3); (2); (4); (8); (9)

(9)

(9)

(7)

(6); (5); (9)

(9)

(6)

(6); (9)

(7)

(9)

(8); (9)

(9)

(5); (8); (9)

(6); (9) 

A. terreus
A. versicolor
A. wentii

(8); (9)

(9)

(9)

Asteromella sp.

(1); (3); (2); (4)

Bactrodesmum sp.

(1); (8)

Blodgettia sp.

(9)

Botrydiplodia theobromae

(9)

Cephaliophora tropica

Ceratocystis sp.

Ceratosphaeria lampadophora

(1); (3); (2); (4)

Chaetomium abuense

(8); (9)

C. biapiculatum

C. brasiliense

C. brevipillium

(9)

C. cochlioides

C. cupreum

C. elatum

(1); (7)

C. funicola

C. funicolum

(9)

C. globosum

(1); (3); (2); (7); (4); (8); (9)

C. incomptum

C. lunasporium 

C. olivaceum
C. spirale
C. undulatum

Chaetopis sp.

Chalaropsis sp.

Chrysosporium pannorum

(9)

Chytrids sp.

(1); (3); (4)

Cirrenalia macrocephala

(1); (4)

Cladosporium cladosporioides

(8); (9)

C. oxysporum

(9)

C. sphaerospermum

(8); (9)

Clasterosporium caricium

(1); (3); (2)

Clypeosphaeria mamillana

(1); (4)

Codinea parva

(3); (2); (4)

Coeloanguillospora appalachiensis

(9)

Coniella sp.

(2); (4)

Coniochaeta discospora

(1)

C. tetraspora

(9)

Coniothyrium sp.

(1); (3); (2); (7); (4)

Coprinus lagopus

(8); (9)

Cordana sp.

(7)

Coriolus versicolor

(8); (9) 
Corollospora maritima

(1)

Culciralna achraspora

(1)

Curvularia lunata

(6); (8); (9)

C. pallescens

(9)

C. senegalensis

(6)

C. tuberculata

(9)

Cytospora sp.

Dactylaria sp.

Debaryella sp.

Delitschia bispora

Dendryphion fumosum

(1); (3); (2); (4)

Diccocum uniseptatum

$D$. asperum

Dictyosporium pelagica

Didymosphaeria sp.

(4); (9)

Didymostilbe sp.

(6)

Ditopella sp.

(4)

Doratomyces microsporus

(1); (3); (2); (4)

D. purpureofuscus

(1); (3); (2); (4)

$D$. stemonitis

Drechslera australiense

D. halodes 

D. hawaiiense
D. miyakei

Dyctyosporium pelagica

Emericella nidulans

Epicoccum niger

E. nigrum

Fusarium sp.

F. lateritium

F. oxysporum

F. semitectum

F. solani

Gangliophragma sp.

Gliocladium penicillioides

G. virens

Gonytrichum sp.

Graphium sp.

G. penicillioides

G. putredinis

Griphosphaeria corticola

Haligena alaterophora

Halosphaeria appendiculata

H. mediosetigera

H. tubilifera
(6); (9)

(6); (9)

(1)

(1); (3); (2); (7); (4)

(9)

(6)

(9)

(6); (8); (9)

(9)

(6); (8); (9)

(8); (9)

(9)

(1); (3); (2); (7); (4)

(8); (9)

(6); (8); (9)

(1); (3); (2); (4)

(3); (2); (4)

(1)

$(1) ;(3) ;(2) ;(4)$

(1) 
Helicoma maritimum

(7)

Helicoon sessile

(1); (4)

Heliscus lugdunensis

(4)

Humicola alopallonella

(1); (3); (2); (4)

Hyalopus sp.

Hypomyces sp.

(7)

Leptosphaeria sp.

Luiworthia floridana

Mammaria achinobotryoides

(1); (3); (2); (4)

Melanospora sp.

(7)

Melogramma sp.

(1); (2); (4)

Microascus lunasporus

(8); (9)

Microthelia sp.

(1); (2); (4)

M. maritima

(1); (3)

Mollisia sp.

Monacrosporium bembicoides

Monascus ruber

Moniliella sp.

(8); (9)

Monocilium indicum

Monodictys sp.

M. levis

M. pelagica

M. putredinis

(1); (3); (2); (4); (8); (9) 
Mucor sp.

(4)

M. racemosus

(9)

Mucoraceous sp.

(7)

Mycelia sterilia

Mycosphaerella sp.

(9)

Nais inornata

(3); (2)

Nigrospora sphaerica

(8); (9)

Nodulisporium rubiginosum

Oospora sp.

Orbicula parietina

Paecilomyces inflatus

$P$. variottii

(6); (5); (7); (8); (9)

Paeosphaeria eustoma

(1); (2); (4)

Penicillium sp.

(1); (4)

P. adametzi

$P$. funiculosum

P. lapidosum

$P$. nigricans

P. rubrum

(6); (8); (9)

$P$. sclerotiorum

$P$. stoloniferum

(8); (9)

P. tardum

Periconia sp. 
Pestalozzia sp.

Petriella setifera

Peurophomella sp.

Phaeoisaria clematidis

Phaeonectriella lignicola

Phanerochaete chrysosporium

Phialophora sp.

P. bubakii

P. melinii

P. phaeopora

$P$. richardsiae

Phoma sp.

P. glomerata

Phyllostictina sp.

Pleurophomella sp.

Pleurophragmium sp.

Podospora setosa

Polyschema congolensis

Pseudoeurotium multisporum

Pullularia pullulans (= Aureobasidium pullulans)

Pyrenochaeta sp.

Remispora maritima

Rhizopus nigricans
(7)

(6); (9)

(1)

(6)

(1); (3); (2); (4); (9)

(8); (9)

(1); (3); (5); (2); (7); (4)

(5)

(5); (8); (9)

(1); (3); (2); (7); (4)

(7); (9)

(1); (3); (2); (4)

(3); (2); (4)

(1); (3)

(1); (4)

(9)

(1); (3); (2); (4)

(5); (7)

(1); (3); (2); (4)

(1); (3); (2); (4)

(9) 
Savoryella lignicola

(1); (3); (2); (4); (8); (9)

Sclerotium sp.

(9)

Scopulariopsis candida

(8); (9)

Scytalidium thermophilum

Septonema sp.

(1); (3); (2); (4)

Spicaria divaricata

Sporormia minima

(1); (3); (2); (4); (9)

Sporosmiella pilosella

Sporotrichum pulverulentum

Stachybotrys sp.

S. atra

(1); (3); (2); (4)

Staganospora sp.

Stemphylium sp.

Sterigamtobrotrys macrocarpa

(1); (3); (2); (4)

Stysanus sp.

Syncephalastrum racemosum

Tetraploa aristata

Thermomyces lanuginosus

Thielavia terricola

Torula caligans

(9)

T. herbarum

(1referência); (6); (3); (2); (4); (8)

Trematosphaeria pertusa

(1); (3); (2); (4)

Triangularia karachiensis

Trichocladium sp. 
Espécie de fungo

Trichoderma harzianum

T. koningii

T. piluliferum

T. pseudokoningii

$T$. viride

Trichurus terrophilus

Tricladium splendens

Veronaea botryosa

Verticillium candelabrum

Zalerion maritima

Zopfiella latipes

\section{Referência bibliográfica}

(8); (9)

(1); (9)

(6); (9)

(6); (9)

(6); (7)

(7)

(1)

(9)

(1) Eaton (1972); (2) Eaton \& Irvine (1972); (3) Eaton \& Jones (1971a); (4) Eaton \& Jones (1971b); (5) Morrel \& Smith (1988); (6) Natarajan \& Udaiyan (1978); (7) Savory (1954); (8) Udaiyan \& Manian (1990); (9) Udaiyan \& Manian (1991)

Em um estudo realizado por Eaton \& Jones $(1971 a, b)$ em 2 torres de resfriamento na Grã Bretanha, utilizando corpos-de-prova de madeira de Fagus sylvatica (Família Fagaceae) e Ocotea rodiaei (Família Lauraceae) não tratados e Pinus sylvestris (Familia Pinaceae) tratado com arseniato de cobre cromatado - CCA e não tratado, foram isoladas 45 espécies de fungos pertencentes às Subdivisões Ascomycotina e Deuteromycotina, sendo similares para as 2 torres. Eaton (1972) em um estudo da micota existente em 16 torres 
de resfriamento, também na Grã Bretanha, isolou 71 espécies de fungos das madeiras dos enchimentos das torres e de corpos-de-prova de $F$. sylvatica e $P$. sylvestris (não tratados) instalados, sendo que muitas destas espécies já haviam sido reportadas por Eaton \& Jones (1971a,b).

Eaton \& Irvine (1972) também observaram essa mesma similaridade de espécies de fungos em madeiras de 2 torres de resfriamento, sugerindo a existência de uma micota comum. A presença de outras espécies de fungos pode ser condicionada pela localização da torre. Em uma torre de resfriamento instalada em Connahs'Quay - Inglaterra, que recebe água do estuário do rio Dee, foi reportada a presença de ascomicetos marinhos Haligena elaterophora, Nais inornata, Remispora maritima e Halosphaeria mediosetigera.

Eaton \& Jones (1971a) observaram que os fungos isolados demonstravam preferências de colonização dependendo da espécie de madeira dos corpos-de-prova. Doratomyces sp., Plyllostictina sp., Trematosphaeria pertusa e um certo número de fungos esporádicos, foram isolados apenas de F. sylvatica e os fungos Chaetomium globosum, Graphium sp. e Sporosmia minima foram isolados de $F$. sylvatica e $P$. sylvestris, com preferência por madeira de F. sylvatica. Sterigmatobotrys macrocarpa, Griphosphaeria corticola e Halosphaeria mediosetigera cresciam somente em madeira de $P$. sylvestris. Os fungos Septonema spp. e Melagramma $\mathrm{sp.} \mathrm{foram} \mathrm{mais}$ freqüentes em $P$. sylvestris do que em $F$. sylvatica. Esses autores demonstraram que em madeira de $F$. sylvatica o crescimento de fungos foi 3 vezes maior do que em madeira de $P$. sylvestris. 
Essa preferência por madeira de Fagus sp. também foi observada no trabalho de Courtois, citado por Eaton \& Jones (1971a), que verificou uma preferência de espécies de fungos de podridão mole por madeiras de folhosas do que por madeiras de coníferas.

Eaton (1972) observou uma variação considerável no número de ascomicetos em corpos-de-prova de madeira de $F$. sylvatica e $P$. sylvestris não tratados, instalados em 16 torres de resfriamento. Em algumas torres, os ascomicetos foram totalmente ausentes nos corpos-de-prova de $P$. sylvestris. Chaetomium globosum, Savoryella lignicola, Trematosphaeria pertusa, Ceratosphaeria lampadophora, Melanogramma sp. e uma forma não estromática de Sillia ferruginea, foram os colonizadores mais freqüentes na madeira de F. sylvatica, enquanto que, S.lignicola, Melanogramma sp., Phaeonectriella lignicola e Remispora maritima foram os mais freqüentes na madeira de $P$. sylvestris. C. globosum e C. lampadophora apresentaram preferência por madeira de F. sylvatica. Esta preferência já havia sido verificada anteriormente por Eaton \& Jones (1971a). Dos deuteromicetos isolados de madeira de F. sylvatica, 25 espécies pertenciam à ordem Moniliales; em madeira de $P$. sylvestris foram encontradas 18 espécies de Moniliales indicando, portanto, uma preferência dos fungos pertencentes à ordem Moniliales pela madeira de $F$. sylvatica.

Já Natarajan \& Udaiyan (1978), estudando a micota existente em uma torre de resfriamento na Índia, observaram maior número de espécies de fungos em madeira de conifera (Pinus patula) em relação à madeira de folhosa (Fagus ramnifolia). Isolaram 25 espécies, pertencentes a 19 gêneros, 
de ascomicetos e deuteromicetos a partir de corpos-de-prova ( $P$. patula e $F$. ramnifolia) e de madeiras em serviço ( $P$. longifolia e $P$. roxburghii). Nas madeiras em serviço, tratadas com o produto preservante arseniato de cobre cromatado - CCA, verificou-se a tolerância das espécies Alternaria alternata, Monacrosporium bembicoides, Paecilomyces inflatus, $P$. varioti, Phaeoisaria clematidis, Torula herbarum, Sporormiella pilosella e Moniliella sp..

Concluindo, pode-se afirmar que a localização da torre de resfriamento de água, as espécies de madeira utilizadas e o uso de madeira tratada com produtos preservantes são alguns dos fatores que influenciam na micota existente nestes sistemas.

\subsection{Controle da podridão mole em torres de resfriamento de água}

$\mathrm{Na}$ década de 50, o Cooling Tower Institute - CTI iniciou, nos E.U.A., um estudo sistemático com o objetivo de caracterizar a deterioração da madeira em 103 torres de resfriamento, sendo avaliado, também, o desempenho de algumas espécies de madeira não tratadas e tratadas sob pressão com diversos produtos preservantes de madeira, após 7 e 11 anos de exposição.

Nesses estudos (CTI, 1959 e 1963) foi constatado que a podridão mole caracterizava-se pelo ataque superficial da madeira nas áreas extremamente molhadas como $\circ$ enchimento e eliminadores de respingos. Foram necessários vários anos de lixiviação dos corpos-de-prova antes de ser notado 0 ataque dos fungos. Nas torres em que foi feito o 
tratamento da água de resfriamento, 0 ataque de fungos de podridão mole foi bastante brando tanto nas madeira dos corpos-de-prova tratados como nos não tratados, indicando que a manutenção da qualidade dessa água foi a forma mais efetiva de controle da podridão mole. A eficiência dos produtos preservantes testados foi verificada nas torres onde o tratamento da água não era apropriado. As espécies de madeira testadas diferiram quanto à resistência natural ao ataque dos fungos. Pelo exposto, o CTI recomendou a utilização das melhores combinações entre as espécies de madeira e os produtos preservantes para a construção de torres.

Os resultados da avaliação dos produtos preservantes feita pelo CTI (1963) mostrou que o óleo creosoto, o ácido cúprico cromatado (ACC), o arseniato de cobre cromatado (CCA), e o arseniato de cobre amoniacal (ACA), destacaram-se no controle de fungos. Desses produtos preservantes, apenas o óleo creosoto e o CCA são comercializados no Brasil.

Segundo Eaton (1972), as torres de resfriamento de água na Grã-Bretanha. freqüentemente construídas com madeira de coniferas, têm sido tratadas, desde a década de 40 , com produtos preservantes hidrossolúveis. Problemas de deterioração biológica do enchimento de madeira não tratada, após 7 anos de funcionamento, levou ao uso extensivo do produto preservante CCA.

Na Índia a madeira de Pinus longifolia e de $P$. roxburghii foi tratada com CCA e utilizada no enchimento de torres de resfriamento (Natarajan \& Udaiyan, 1978). 
Em um levantamento realizado por Puckorius (1985) em 196 torres de resfriamento nos E.U.A., com 1 a 18 anos em operação, verificou-se que $80 \%$ foram construídas com madeira de Pseudotsuga menziesii - "douglasfir" - tratada com CCA ou ACC e $20 \%$ com madeira de Sequoia spp. "redwood" - com a metade tratada e a outra metade sem qualquer tratamento preservante.

Atualmente, nos E.U.A., é recomendada a utilização de madeira de conífera tratada sob pressão para torres de resfriamento de água. As normas da "American Wood Preservers' Association - AWPA", entidade reconhecida na área de preservação de madeiras, definem as espécies de madeira, os produtos preservantes e o tipo de tratamento adequado para torres de resfriamento.

A norma AWPA C 30-96 "Lumber, timber and plywood for cooling towers - preservative treatment by pressure processes", recomenda as seguintes madeiras de coníferas: Pinus spp.; Pinus ponderosa; Pseudotsuga menziesii; Tsuga heterophylla e Sequoia spp., tratadas com creosoto e com produtos preservantes hidrossolúveis de comprovada eficiência em contato com o solo. Nenhuma madeira de folhosa de alta durabilidade natural, com ou sem tratamento preservante, é recomendada para torres de resfriamento de água.

As normas AWPA C2-96 "Lumber, timber, bridge, ties and mine ties - preservatives treatment by pressure processes" e AWPA P1/P13-91 "Standard for coal tar creosote for land and fresh water and marine (coastal water use)" estabelecem os produtos preservantes, os valores de retenção e as formas de tratamento. 


\subsection{Torres de resfriamento de água no Brasil}

Em levantamento bibliográfico foram localizados 4 trabalhos técnicos sobre deterioração biológica de madeiras em torres de resfriamento de água no Brasil.

Kotchetkoff (1967) realizou inspeções periódicas em uma torre de resfriamento, construída com madeira de ipê (Tabebuia sp.) e peroba-rosa (Aspidosperma polyneuron), pertencente à Refinaria Presidente Bernardes, Cubatão - SP. Após 2 anos de funcionamento, observou a ocorrência de podridão mole, descrita como ataque superficial, no madeiramento dos eliminadores de respingos e enchimento da torre. As madeiras não haviam recebido tratamento preservante, sendo que, as peças com alburno encontravam-se seriamente atacadas; a madeira de peroba-rosa mostrou-se mais susceptivel do que a de ipê. O tratamento curativo, com o pincelamento de pentaclorofenol e a aplicação de um produto impermeabilizante ("neutrol"), não retardou $\mathrm{O}$ ataque de fungos. $\mathrm{O}$ autor recomendou: (i) a substituição das peças estruturais por madeira de cerne de ipê e o restante do madeiramento por madeira de pinho-do-Paraná tratada sob pressão com creosoto; (ii) a pulverização semestral do madeiramento com pentaclorofenol e; (iii) a aplicação de pentaclorofenato de sódio na água de circulação. Estas recomendações foram baseadas nos estudos do $\operatorname{CTI}(1959,1963)$.

Em 1973, o Instituto Brasileiro de Petróleo - IBP publicou o Guia No. 10 , sobre os procedimentos para inspeção em torres de resfriamento, os tipos de torres existentes, os ataques biológicos/químicos ocorrentes e seus controles. O Guia encontra-se desatualizado com relação aos grupos de 
fungos que causam apodrecimento na madeira, sua forma de ataque e danos causados, não sendo feita menção da utilização de madeira preservada sob pressão na construção de torres e/ou substituição de peças.

Cavalcante (1985) em revisão sobre biodeterioração de madeiras em torres de resfriamento, citou a utilização das madeiras de ipê (Tabebuia spp.) e maçaranduba (Manilkara spp.) na construção desses equipamentos, relatando, entretanto, um alto grau de ataque por fungos apodrecedores após 6 anos para a maçaranduba e 10 anos para o ipê. A podridão mole é descrita como a principal causa do apodrecimento da madeira do enchimento, também ocorrendo nos eliminadores de respingos, junto com os fungos de podridão branca e parda. As madeiras de pinho-do-paraná (Araucaria angustifolia) e pinus (Pinus spp.) tratadas com creosoto, CCA e formulações à base de sais de cobre, cromo e boro (CCB) foram utilizadas na substituição de peças.

Neves et al. (1989) em inspeção no madeiramento da torre de resfriamento da COPENE em Camaçari - BA, descreveram a ocorrência de fungos de podridão mole na madeira de Tabebuia $\mathrm{sp}$. dos eliminadores de respingos e enchimento. Nesse trabalho são recomendadas madeiras de coníferas tratadas com produtos preservantes oleossolúveis ou hidrossolúveis segundo as normas da AWPA para a substituição de peças intensamente deterioradas e inspeções periódicas dos componentes de madeira da torre, para a detecção e avaliação da extensão da deterioração biológica. A aspersão periódica com fungicida no madeiramento da torre é questionada em razão da lixiviação ser bastante intensa nestes equipamentos. 
Resumindo, no Brasil não existem normas que regulamentem a utilização de madeiras em torres de resfriamento de água e carecem estudos sistemáticos para avaliação do comportamento das espécies de madeira, dos produtos preservantes e dos métodos de tratamento utilizados. Portanto, a escolha das espécies de madeira e a adoção de algumas formas de controle dos fungos apodrecedores em torres de resfriamento foram empíricas. 


\section{MATERIAL E MÉTODOS}

3.1 Localização e características da torre de resfriamento de água estudada

O presente trabalho foi conduzido em uma torre de resfriamento denominada EF-901, da unidade industrial Petroquímica União S.A., localizada no município de Santo André - Estado de São Paulo.

A torre de resfriamento EF-901 foi construída em 1972, com madeira de Tabebuia sp. - ipê. Possui circulação forçada, tiragem induzida e dupla distribuição. Suas dimensões são: $15,0 \mathrm{~m}$ de altura, $21,0 \mathrm{~m}$ de largura e 115,0 m de comprimento, sendo constituída por 11 células com 10,5 m de comprimento cada (Figura 2). O sistema de resfriamento tem um volume de água de $3.800 \mathrm{~m}^{3}$, com uma vazão de recirculação de $16.000 \mathrm{~m}^{3} / \mathrm{h}$, sendo, a perda de água por respingos estimada em $24 \mathrm{~m}^{3} / \mathrm{h}$. A água de suprimento da unidade industrial tem uma temperatura média de $29^{\circ} \mathrm{C}$, enquanto que a água de retorno da unidade industrial para a torre de resfriamento tem, em média, $44,2^{\circ} \mathrm{C}$. 

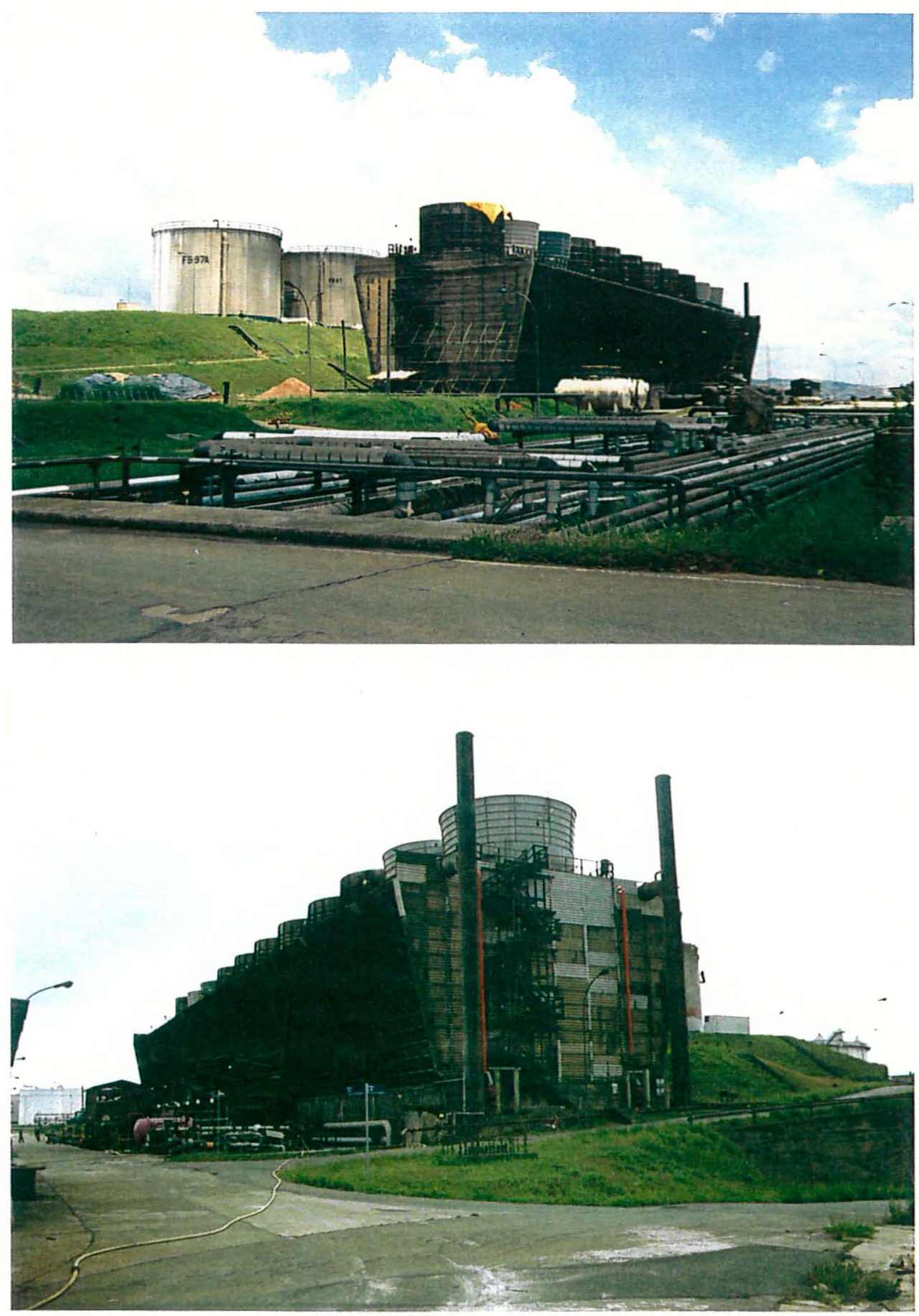

Figura 2, - Torre de resfriamento EF-901 da Petroquímica União S.A. situada no município de Santo André - Estado de São Paulo. 
A água de "make-up" - água de reposição do sistema de resfriamento - é fornecida pela SABESP. Esta água é tratada para atender aos parâmetros físicos e químicos de $\mathrm{pH}$ entre 7,0 e 8,5; alcalinidade total maior que 30 ppm; dureza (cálcio) entre 100 e 300 ppm; turbidez menor que 30 ppm; e concentração de cloreto $\left(\mathrm{Cl}^{-}\right)$menor que 400 ppm.

De acordo com os registros de manutenção da torre, foram realizados 8 tratamentos em seu madeiramento (1975 - 76 - 77 - 79 - 80 - 89 91 - 95), por aspersão de produtos preservantes à base de pentaclorofenol, pentaclorofenato de sódio ou creosoto. A adição de biocida na água é feita de forma rotineira para o controle de bactérias e algas no sistema de resfriamento, não sendo utilizados fungicidas para controle de fungos apodrecedores nas peças de madeira da torre.

O presente estudo foi realizado com as peças de madeira do eliminador de respingos e do enchimento - lado oeste - da célula GB-978 da torre de resfriamento de água.

\subsection{Coleta das amostras de madeira}

Para verificação da ocorrência de podridão mole na torre de resfriamento de água, identificação da madeira utilizada e isolamento de fungos, foram coletadas, aleatoriamente, amostras de madeira do eliminador de respingos e do enchimento.

A célula foi dividida em 6 níveis de altura (Figura 1, pág.11). Dos $1^{\circ}, 3^{\circ}$ e $5^{\circ}$ níveis do eliminador de respingos foram retiradas 12 ripas de madeira, com dimensão de $120 \times 7 \times 1 \mathrm{~cm}$, sendo 4 ripas por nível. A 
coleta de ripas do enchimento, com dimensão de $120 \times 4 \times 1 \mathrm{~cm}$, foi feita na região próxima ao eliminador de respingos, devido à dificuldade de acesso às ripas no interior da célula. Esta coleta também foi feita nos $1^{\circ}, 3^{\circ}$ e $5^{\circ}$ níveis de altura, sendo retiradas 4 ripas por nível, totalizando 12 ripas.

\subsection{Identificação da madeira}

Para a identificação e confirmação da espécie de madeira utilizada na construção da torre foi feita no Laboratório de Anatomia e Identificação de Madeira do Instituto de Pesquisas Tecnológicas do Estado de São Paulo - IPT, por meio de análise macro e microscópica das amostras coletadas (IPT, 1997).

Para a análise macroscópica, as amostras de madeira tiveram suas superfícies polidas com uma faca afiada e orientadas nos planos transversal e longitudinal tangencial em relação à direção de orientação da grã da madeira.

Para a análise microscópica, foram preparadas lâminas histológicas. Os cortes das madeiras foram obtidos em micrótomo de deslize utilizando-se navalhas "tipo C" e conservados entre duas lâminas de vidro, evitando-se o enrolamento. O seguinte procedimento foi utilizado para a montagem das lâminas: (i) coloração dos cortes finos da madeira (15-20 $\mu \mathrm{m}$ de espessura), com safranina aquosa a $1 \%$ e picroanilina aquosa a 1\%; (ii) desidratação em série etílica (50, 70, 90 e 100\%); (iii) lavagem em acetato de butila; (iv) posicionamento dos cortes nas lâminas com auxílio de pinça e de pincel; e (v) colocação do bálsamo-do-canadá e da lamínula. 
Os corantes safranina e picroanilina foram utilizados para evidenciar a presença de hifas e esporos de fungos na madeira.

\subsection{Avaliação da ocorrência de podridão mole na madeira}

A avaliação da ocorrência de podridão mole no madeiramento da célula GB-978, foi realizada por meio da análise macro e microscópica das amostras de madeira coletadas. Durante a coleta das amostras, foram feitas observações sobre o estado geral de sanidade biológica das peças de madeira que compõem o eliminador de respingos e o enchimento.

No exame das madeiras na torre e na análise macroscópica das amostras de madeira coletadas, foram observadas alterações na cor e no aspecto da madeira (desfibramento e amolecimento da superfície). Estas análises foram feitas com o auxílio de um estilete pontiagudo.

Para a análise microscópica as lâminas histológicas das amostras de madeira (item 3.3) foram examinadas em microscópio óptico comum sob luz difusa e polarizada. A luz polarizada foi utilizada para destacar as cavidades formadas pelas hifas dos fungos de podridão mole na parede das células da madeira.

As análises macro e microscópicas da estrutura anatômica das amostras de madeira afetadas pelos fungos causadores de podridão mole foram realizadas juntamente com a análise de madeira "sadia" com a finalidade de comparar as alterações causadas por esses fungos. 


\subsection{Isolamento e identificação de fungos}

No momento da coleta, as amostras de madeira foram envoltas com papel alumínio, transportadas para o Laboratório de Micologia do IPT e armazenadas em um refrigerador a $5^{\circ} \mathrm{C}$, para a realização das análises laboratoriais.

\subsubsection{Isolamento dos fungos}

$O$ isolamento dos fungos foi realizado na face inferior das amostras; esta face considerada em relação a sua posição inicial na torre de resfriamento de água. As ripas foram seccionadas transversalmente em 2 partes, e de cada uma foi escolhida, para o isolamento dos fungos, uma região com apodrecimento superficial. Nesta região, a porção superficial da madeira foi retirada, com auxílio de um pequeno formão flambado, para evitar o isolamento de fungos que não estariam colonizando a madeira. A seguir, foram retirados 2 fragmentos de madeira com uma goiva desinfetada em álcool $70 \mathrm{Gl}, \mathrm{e}$, posteriormente, flambada. Cada fragmento foi flambado e transferido para uma placa de Petri, em condiçōes assépticas, contendo um dos seguintes meios de cultura:

(i) Malte-ágar (MA) - meio de cultura não seletivo, composto de 
$30 \mathrm{~g}$ de extrato de malte, $15 \mathrm{~g}$ de ágar-ágar em 1 litro de água deionizada (Lepage et al., 1980a);

(ii) Celulose-ágar (CA) - meio de cultura para o isolamento de fungos que utilizam a celulose como fonte de carbono, composto de $0,5 \mathrm{~g}$ de nitrato de amônia, $1 \mathrm{~g}$ de fosfato de potássio monobásico, $0,01 \mathrm{~g}$ de sulfato de magnésio, 6,0 g de celulose (papel de filtro quantitativo Whatmann $n^{\circ} 41$ ) e $15 \mathrm{~g}$ de ágar-ágar em 1 litro de água deionizada (Line \& Cruickshank, 1979).

As placas de Petri foram incubadas a $28^{\circ} \mathrm{C}$ e $70 \%$ de umidade relativa. Diariamente estas placas foram verificadas quanto ao crescimento de microrganismos - fungos e bactérias - proveniente dos fragmentos de madeira. Os fungos filamentosos que cresceram foram transferidos para tubos de ensaio com meio de cultura MA inclinado, e incubados para crescimento das culturas. As bactérias foram apenas quantificadas

As culturas puras dos fungos isolados foram mantidas a $5{ }^{\circ} \mathrm{C}$ para posterior identificação taxonômica. A cada 3 meses estas culturas foram transferidas para novos tubos de ensaio com meio de cultura recém preparado (MA) para manutenção da viabilidade dos fungos.

\subsubsection{Identificação dos fungos isolados}

A identificação dos fungos isolados foi feita no Instituto de Botânica do Estado de São Paulo, Seção de Micologia. Esta identificação foi realizada por meio da observação das características morfológicas de cada 
fungo, em comparação com as descritas por Barnett \& Hunter (1987), Barron (1972), Domsch et al. (1980), Ellis (1971 e 1976), Gams (1971), Nelson et al. (1983) e Rifai (1969).

Para a identificação utilizou-se a técnica de microcultivo, onde um pequeno bloco de meio de cultura MA foi colocado sobre uma lâmina de vidro esterilizada, inoculado com esporos do fungo e coberto com uma lamínula de vidro. Este conjunto foi transferido para uma placa de Petri contendo papel de filtro umedecido com água esterilizada e incubado a $28^{\circ} \mathrm{C}$ e $70 \%$ de umidade relativa por cerca de 14 dias. Após este período, retirou-se o meio de cultura da lâmina e foram montadas, com a lâmina de vidro e com a lamínula, 2 lâminas para análises microscópicas.

Essas lâminas foram observadas a fresco e/ou coradas com azul de algodão. As lâminas coradas foram lutadas com esmalte de unha para conservação do material.

\subsection{Avaliação da capacidade de degradação dos fungos isolados}

A avaliação da capacidade de degradação dos fungos isolados foi realizada por meio de um ensaio acelerado, em laboratório, com madeiras consideradas de baixa resistência natural ao ataque de fungos. Esse ensaio permitiu analisar a perda de massa (\%) causada por esses fungos e confirmar o ataque de podridão mole nestas madeiras. 


\subsubsection{Ensaio acelerado de podridão mole}

O ensaio foi realizado de acordo com adaptação do método proposto por Duncan (1965) que consistiu na inoculação de corpos-de-prova de madeira com esporos dos fungos, previamente colocados em placas de Petri com meio de cultura composto de $6 \mathrm{~g}$ de nitrato de amônia, $4 \mathrm{~g}$ de fosfato de potássio monobásico, $5 \mathrm{~g}$ de fosfato de potássio dibásico, $4 \mathrm{~g}$ de sulfato de magnésio, $2,5 \mathrm{~g}$ de glicose, $0,5 \mathrm{~g}$ de extrato de levedura e $15 \mathrm{~g}$ de ágar-ágar em 1 litro de água deionizada.

Para comparação da capacidade de degradação dos fungos de podridão mole isolados foi utilizado no ensaio uma espécie referência, o fungo Chaetomium globosum da American Type Culture Collection - ATCC $\mathrm{n}^{\circ}$ 6205. Esta cepa foi isolada de fibras de algodão estocadas, sendo recomendada para avaliação da resistência de diversos materiais ao ataque de fungos (ATCC, 1970). O C. globosum foi também recomendado por Duncan (1965) e Bravery (1975) para ensaios de madeiras e de fungicidas para madeiras, realizados com culturas puras de fungos de podridão mole.

Dois tubos de ensaio de cada fungo isolado e do fungo referência, com crescimento micelial e frutificação intensos, foram utilizados para obtenção das suspensões de esporos. Esta suspensão foi feita adicionando-se água esterilizada, com 0,05\% de tergitol (agente surfactante), aos tubos de ensaio e esfregando-se a superfície da colônia do fungo com uma alça de platina. 
Cada placa de Petri foi inoculada com $0,5 \mathrm{ml}$ da suspensão de esporos e incubadas por cerca de 48 horas a $32^{\circ} \mathrm{C}$ e $90 \%$ de umidade relativa para crescimento micelial dos fungos.

Corpos-de-prova de Eucalyptus grandis e de Pinus elliottii nas dimensões de $10 \times 10 \times 2 \mathrm{~mm}$ (com a menor dimensão paralela aos raios da madeira), foram secos em estufa a $105^{\circ} \mathrm{C}$ por 24 horas e pesados em uma balança com aproximação de $0,0001 \mathrm{~g}$, para obtenção de sua massa seca inicial $\left(M_{\mathrm{si}}\right)$.

Seis réplicas de cada madeira foram utilizadas para cada fungo. A definição deste número de réplicas foi baseada na recomendação feita pela norma ASTM-D-2017 (1981) e pelo método de ensaio IPT n 1157-D5 (Lepage et al., 1980b).

Após pesagem, os corpos-de-prova foram flambados, colocados nas placas de Petri inoculadas com os fungos e o conjunto incubado novamente a $32^{\circ} \mathrm{C}$ e $90 \%$ de umidade relativa por 7 semanas.

Ao final deste período, os corpos-de-prova foram lavados cuidadosamente em água corrente, secos em estufa a $105^{\circ} \mathrm{C}$ por 24 horas e obtidas as suas massas secas finais $\left(\mathbf{M}_{\mathrm{sf}}\right)$.

A variável resposta do ensaio foi a perda de massa, expressa em porcentagem, calculada conforme fórmula (1):

$$
P M=\frac{M_{s i}-M_{s f}}{M_{s i}} \times 100
$$


onde: $\quad$ PM - perda de massa (\%);

$M_{\mathbf{s i}}$ - massa seca inicial $(\mathrm{g})$;

$M_{s f}$ - massa seca final $(\mathrm{g})$.

Controles estéreis também foram utilizados para assegurar que os resultados de perda de massa obtidos, fossem apenas devidos ao ataque dos fungos. Para tanto, 6 corpos-de-prova de $E$. grandis e 6 de $P$. elliottii foram colocados em placas de Petri com meio de cultura, porém sem inoculação de fungo. As perdas de massa (\%) dos corpos-de-prova inoculados com os fungos foram corrigidas com a média de perda de massa (\%) dos controles estéreis.

\subsubsection{Confirmação do ataque de podridão mole nas madeiras}

A confirmação da capacidade dos fungos isolados causarem podridão mole nas madeiras foi feita por meio da análise microscópica dos corpos-de-prova de Eucalyptus grandis e Pinus elliottii, que apresentaram as maiores perdas percentuais de massa no ensaio acelerado (item 3.6.1). Para a análise microscópica foram preparadas lâminas histológicas, contendo cortes do plano transversal das madeiras, conforme método descrito no item 3.3. Nestes cortes buscou-se evidências do ataque de fungos de podridão mole do tipo 1, caracterizado pela presença de cavidades na parede das células do xilema. 


\subsubsection{Análise estatística}

Os resultados de perda de massa, expressos em porcentagem, dos fungos que causaram podridão mole nos corpos-de-prova de $E$. grandis e/ou $P$. elliottii foram analisados estatisticamente, utilizando-se $\circ$ aplicativo Statistica (Statsoftt, Inc., 1995).

A análise estatística foi realizada adotando-se o nível de significância $(\alpha)$ de $5 \%$. Optou-se pela análise de variância paramétrica fatorial em um experimento totalmente aleatório com 2 fatores: espécie de madeira, com dois niveis ( $E$. grandis, $P$. elliottii); e espécie de fungo com 27 niveis (26 fungos isolados; fungo referência $C$. globosum). Seis observações foram feitas por tratamento.

Para atender à premissa de homogeneidade de variância entre os tratamentos, os valores de perda de massa (\%) foram transformados. Esses valores foram acrescidos de 1,86 e, posteriormente, elevados à potência de 0,573 .

O teste de comparação múltipla de médias de Tukey - " Tukey honest significant difference test" - foi utilizado para comparação das médias dos tratamentos. 


\section{RESULTADOS E DISCUSSÃO}

\subsection{Identificação da madeira}

O resultado da análise da estrutura anatômica macro e microscópica das amostras de madeira do eliminador de respingos e do enchimento da torre de resfriamento de água confirmou tratar-se de Tabebuia sp. da família Bignoniaceae.

Esta madeira pertence ao grupo de espécies que reúne madeiras pesadas, duras, de coloração pardo-acastanhada e vasos obstruídos por "lapachol" ou ipeína (Mainieri, 1958; Mainieri \& Chimelo, 1989 e Record \& Hess, 1943)

Este grupo de madeiras é bem representado no Brasil e numerosas espécies foram descritas (Record \& Hess, 1943). Segundo Mainieri (1958), sua ocorrência é generalizada - desde a Amazônia até o Rio Grande do Sul - recebendo nomes populares típicos: pau-d'arco ou pau-de-arco da Amazônia até o sul do Estado da Bahia; ipê, ipê-pardo, ipê-amarelo e ipê-una dos Estados de Minas Gerais até o do Rio Grande do Sul; e piuna ou piuva no sul do Mato Grosso e Goiás. 
As amostras de madeira coletadas eram de cerne que possui uma coloração castanho-escura, textura fina, grã irregular a revessa e cheiro e gosto imperceptíveis. São classificadas como altamente duráveis, sendo muito a extremamente duras e pesadas, com densidade entre 0,95 e 1,25 $\mathrm{g} / \mathrm{cm}^{3}$. Portanto, utilizadas como dormentes, cruzetas de poste, carrocerias de caminhões, vagões de trem, pontes e em sistemas construtivos de casas cercas, colunas, esquadrias, lambris e assoalhos (Mainieri \& Chimelo, 1989 e Record \& Hess, 1943).

Em estudos de laboratório e de campo, o cerne da madeira de ipê demonstrou alta resistência natural à deterioração causada por fungos apodrecedores e impermeável à soluções preservantes de madeira (Brito Neto et al., 1984; Cavalcante, 1983; Fosco Mucci et al., 1992; Gomes \& Melo, 1991; Lepage, 1983 e Mainieri \& Chimelo, 1989).

Estas características atendem às especificadas por Savory (1954) que sugeriu, para construção de torres de resfriamento de água, a utilização de madeiras de folhosas de alta durabilidade natural, corroborado por Kotchetkoff (1967) que recomendou o uso de cerne de madeira de ipê para peças com função estrutural devido à sua alta durabilidade natural.

Desta forma, a alta resistência mecânica e durabilidade natural da madeira de Tabebuia spp. ao ataque de fungos apodrecedores foram as características que justificaram, no passado, sua utilização em torres de resfriamento de água. 


\subsection{Avaliação da ocorrência de podridão mole na madeira}

As análises macro e microscópicas das amostras de madeira de Tabebuia sp., coletadas do eliminador de respingos e do enchimento da célula, demonstraram a presença de fungos de podridão mole. Os resultados dessas análises são apresentados na Tabela 2 para cada local da torre, nível de altura de coleta e amostras.

A podridão mole em torres de resfriamento de água, conhecida também como ataque superficial, tem sido objeto de investigações em vários países. Sua ocorrência foi observada em madeiras de coníferas e de folhosas utilizadas, principalmente, nos eliminadores de respingos (região de neblina) e nos enchimentos (região de respingos).

Nas madeiras de coníferas, este tipo de apodrecimento foi detectado por Brown (1964) em madeira de Sequoia sp. utilizadas na região de respingos de torres; Townsend (1964) no enchimento de uma torre construída com madeira dessa espécie sem tratamento preservante, após 4 anos de operação; Puckorius (1984 e 1985) nas madeiras de Sequoia sp. e Pseudotsuga sp., com e sem tratamento preservante, dos enchimentos e peças estruturais de torres; Neves et al. (1989) em madeira de Sequoia sp. creosotada e de Araucaria angustifolia tratada com CCB e; Singh et al. (1992) em madeira de Pinus radiata, tratada com CCA, do enchimento de uma torre de resfriamento. 
Tabela 2. Análises macro e microscópicas das amostras de madeira de Tabebuia sp. do eliminador de respingos e do enchimento para detecção da podridão mole.

\begin{tabular}{|c|c|c|c|c|}
\hline \multirow{2}{*}{$\begin{array}{c}\text { Local da } \\
\text { coleta }\end{array}$} & \multirow{2}{*}{$\begin{array}{c}\text { Nivel de } \\
\text { Altura }\end{array}$} & \multirow{2}{*}{ Amostra } & \multicolumn{2}{|c|}{ Ocorrência de podridão mole ${ }^{4}$} \\
\hline & & & Macroscopia & Microscopia \\
\hline & $1^{0}$ & $\begin{array}{l}A \\
B \\
C \\
D\end{array}$ & $\begin{array}{l}+ \\
+ \\
+ \\
+\end{array}$ & $\begin{array}{l}+ \\
+ \\
+ \\
+\end{array}$ \\
\hline $\begin{array}{l}\text { eliminador } \\
\text { de } \\
\text { respingos }\end{array}$ & $3^{\circ}$ & $\begin{array}{l}E \\
F \\
G \\
H\end{array}$ & $\begin{array}{l}+ \\
+ \\
+ \\
+\end{array}$ & $\begin{array}{l}+ \\
+ \\
+ \\
+\end{array}$ \\
\hline & $5^{\circ}$ & $\begin{array}{l}\mathrm{I} \\
\mathrm{J} \\
\mathrm{K} \\
\mathrm{L}\end{array}$ & $\begin{array}{l}+ \\
- \\
-\end{array}$ & $\begin{array}{l}+ \\
+ \\
+ \\
+\end{array}$ \\
\hline & $1^{0}$ & $\begin{array}{l}M \\
N \\
O \\
P\end{array}$ & $\begin{array}{l}+ \\
+ \\
+ \\
+\end{array}$ & $\begin{array}{l}+ \\
+ \\
+ \\
+\end{array}$ \\
\hline enchimento & $3^{\circ}$ & $\begin{array}{l}Q \\
R \\
S \\
T\end{array}$ & $\begin{array}{l}+ \\
+ \\
+ \\
+\end{array}$ & $\begin{array}{l}+ \\
+ \\
+ \\
+\end{array}$ \\
\hline & $5^{0}$ & $\begin{array}{l}\mathrm{U} \\
\mathrm{V} \\
\mathrm{X} \\
\mathrm{Z}\end{array}$ & $\begin{array}{l}- \\
- \\
-\end{array}$ & $\begin{array}{l}+ \\
+ \\
- \\
-\end{array}$ \\
\hline
\end{tabular}

1 - amostra de madeira de Tabebuia sp. com $(+)$ e sem $(-)$ podridão mole 
Com relação às madeiras de folhosas utilizadas em torres de resfriamento, Aspidosperma polyneuron (peroba-rosa) e Cedrela sp. (cedro) apresentaram baixa resistência natural ao apodrecimento por fungos, sendo que em 3 anos de operação as peças foram totalmente atacadas (Kotchetkoff, 1967). Podridão mole também foi citada por Cavalcante (1985) em madeira de manilkara sp. (maçaranduba) utilizada nos eliminadores de respingos e enchimentos de torres.

Em torres de madeira de Tabebuia sp., Kotchetkoff (1967) detectou podridão mole nos eliminadores de respingos e enchimentos de uma torre após 4 anos de funcionamento, concluindo que as peças intensamente apodrecidas tinham sido confeccionadas com madeira de alburno e as de cerne mostraram elevada resistência natural. Cavalcante (1985) cita a podridão mole como a principal causa de deterioração da madeira de Tabebuia spp. dos enchimentos e eliminadores de respingos de torres. Posteriormente, Neves et al. (1989) descreveram a presença de podridão mole em madeira de Tabebuia $\mathrm{sp}$. dos eliminadores de respingos e enchimentos de uma torre em operação a 10 anos; em outra torre, com 5 anos em operação, não foi observada deterioração biológica, mas após 7 anos de operação, a análise microscópica de amostras de madeira de Tabebuia sp. detectou um "estágio inicial" de podridão mole.

De modo geral, as observações feitas por Cavalcante (1985), Kotchetkoff (1967) e Neves et al. (1989) têm indicado a alta durabilidade natural da madeira de Tabebuia sp. em torres de resfriamento de água com relação ao ataque de fungos de podridão mole. 


\subsubsection{Análise macroscópica}

A análise macroscópica das amostras de madeira de Tabebuia sp. do eliminador de respingos e do enchimento (Tabela 2, pág. 48), coletadas nos $1^{\circ}$ e $3^{\circ}$ níveis de altura da célula da torre, apresentaram ataque característico de podridão mole. Esse apodrecimento era evidente nas faces inferiores das amostras, considerando sua posição na torre; nas faces superiores a madeira, aparentemente sadia, apresentou deposição de substâncias oriundas da água de resfriamento (Figura 3).

No $5^{\circ}$ nível de altura do eliminador de respingos e do enchimento da torre, as amostras não apresentaram sinais de ataque de fungos de podridão mole (Tabela 2). Essas peças, no entanto, estavam esbranquiçadas, com amolecimento superficial e com aparência fibrosa em ambas as faces. Este tipo de alteração da madeira é conhecido como ataque químico (Figuras 4). Somente 1 amostra de madeira do $5^{\circ}$ nivel (amostra I) apresentou apodrecimento causado por fungos de podridão mole, restrito à sua face inferior. 

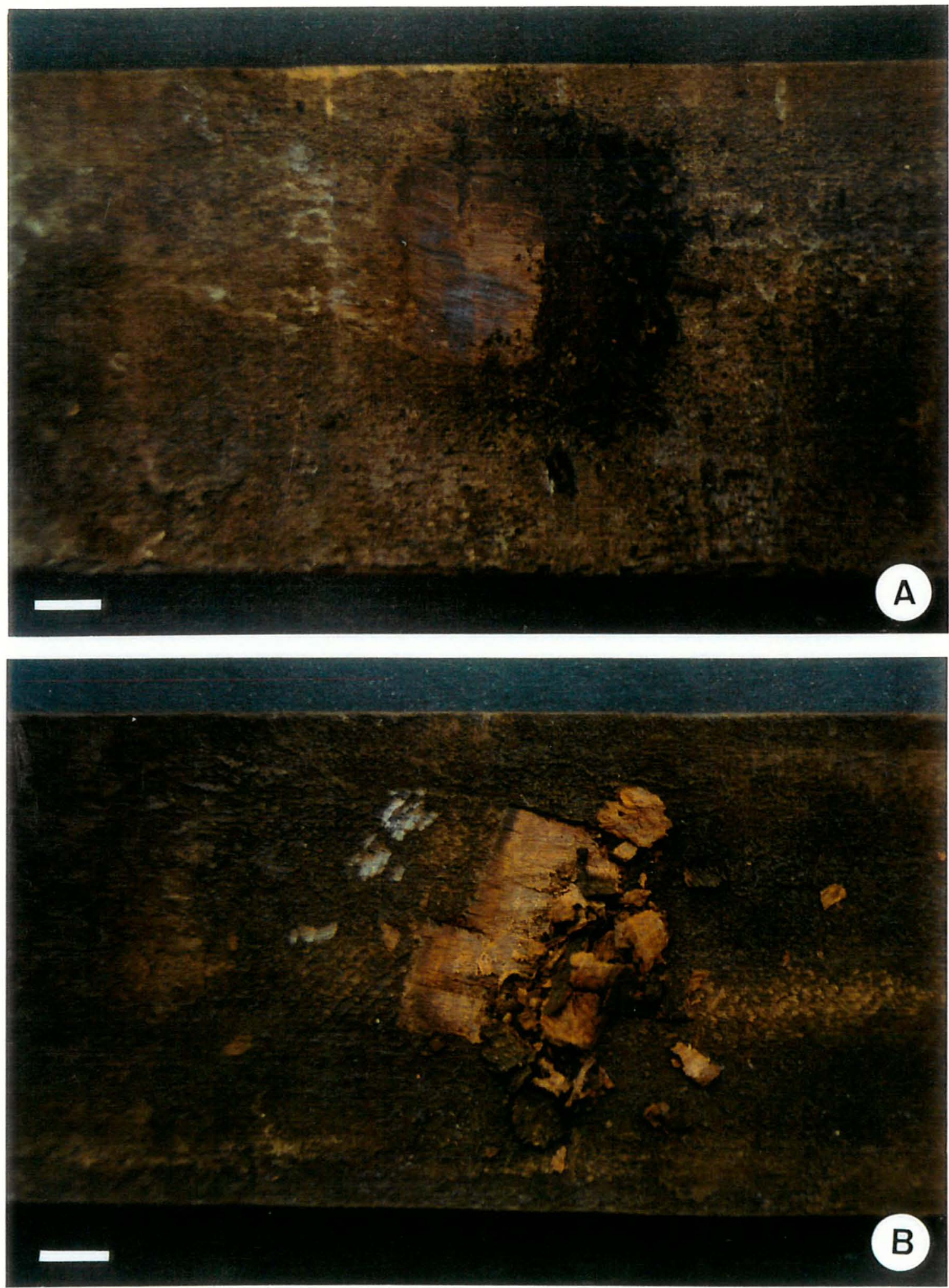

Figura 3 - Aspecto macroscópico de uma amostra de madeira de Tabebuia sp do eliminador de respingos com podridão mole; (A) face superior $e$ (B) inferior (escala $=1 \mathrm{~cm})$. 

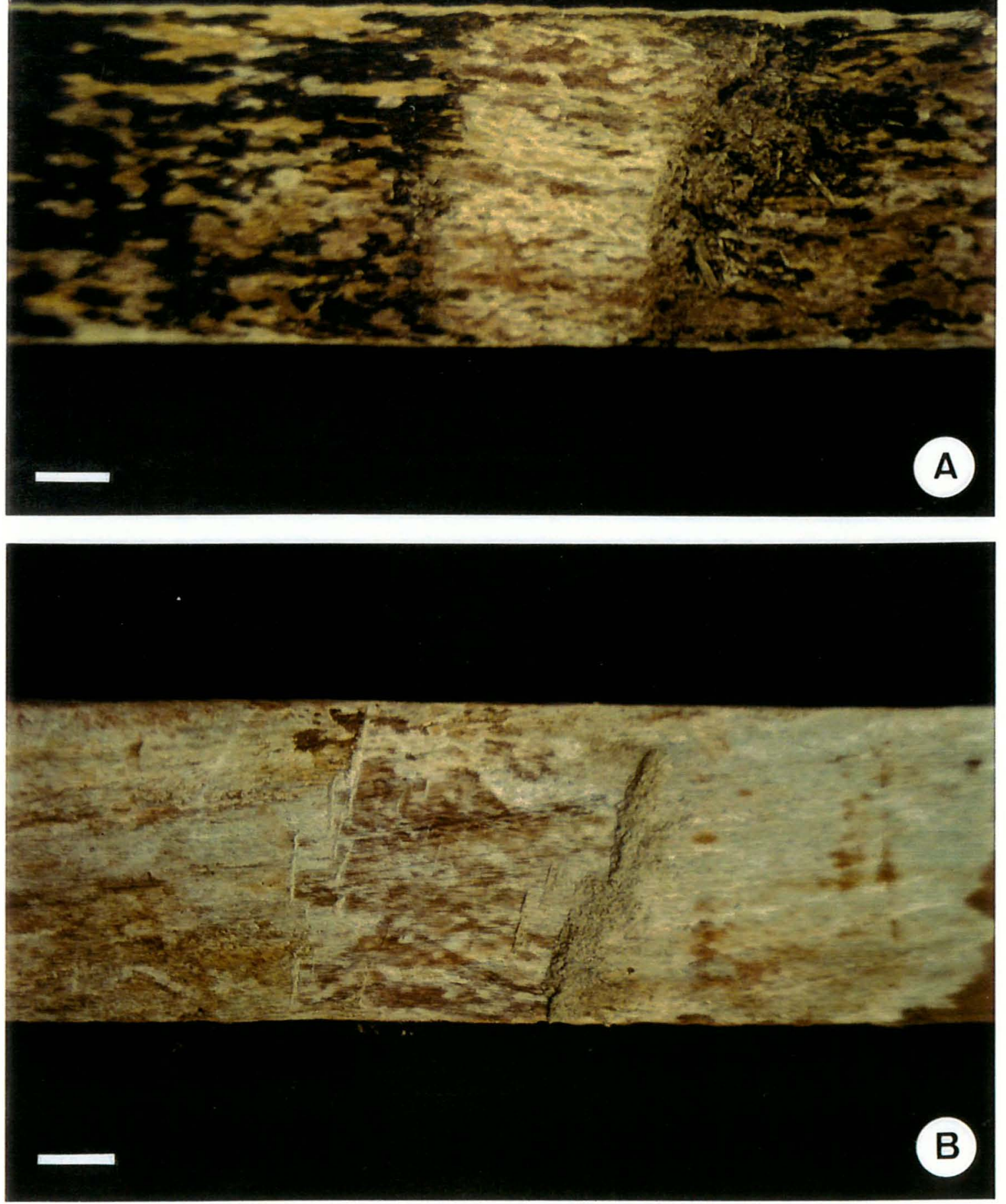

Figura 4 - Aspecto macroscópico de uma amostra de madeira de Tabebuia sp do enchimento com ataque químico. (A) face superior e (B) inferior; $($ escala $=1 \mathrm{~cm})$. 
As observações de ataque mais intenso de fungos de podridão mole, nas amostras de madeira do eliminador de respingos e do enchimento, nos níveis inferiores da torre, foram comprovadas durante a coleta das amostras. Distinguiram-se na torre, com facilidade, 2 regiōes: sendo a primeira nos $1^{\circ}, 2^{\circ}, 3^{\circ}$ e $4^{\circ}$ níveis, com a madeira escurecida e apodrecida e; a segunda, nos $5^{\circ}$ e $6^{\circ}$ níveis, com a madeira esbranquiçada e amolecida, característica de ataque químico. Essas observações foram corroboradas com as de Neves et al. (1989), que em inspeção no eliminador de respingos de uma torre construída com madeira de Tabebuia sp., observou uma maior ocorrência de apodrecimento da madeira nos níveis inferiores da torre.

As amostras de madeira de Tabebuia sp. úmidas e atacadas por fungos de podridão mole, apresentaram-se escurecidas e com amolecimento das camadas superficiais, facilmente removíveis com o uso de um estilete. Nas camadas mais interiores, a madeira não apresentou sinais de podridão mole, confirmando tratar-se de apodrecimento superficial, com progressão para o interior da peça. As amostras de madeira intensamente atacadas, quando secas, apresentaram na sua superfície, fissuras paralelas e perpendiculares em relação às fibras da madeira (Figura 5). Em torres de resfriamento de água, este padrão de ataque foi também descrito por Savory (1954), Duncan (1960) e Neves et al. (1989), para madeiras de coníferas (Pinus spp., Sequoia spp., Pseudotsuga sp., Picea spp. e Thuja spp.) e de folhosas (Dipterocarpus sp. e Tabebuia sp.). 

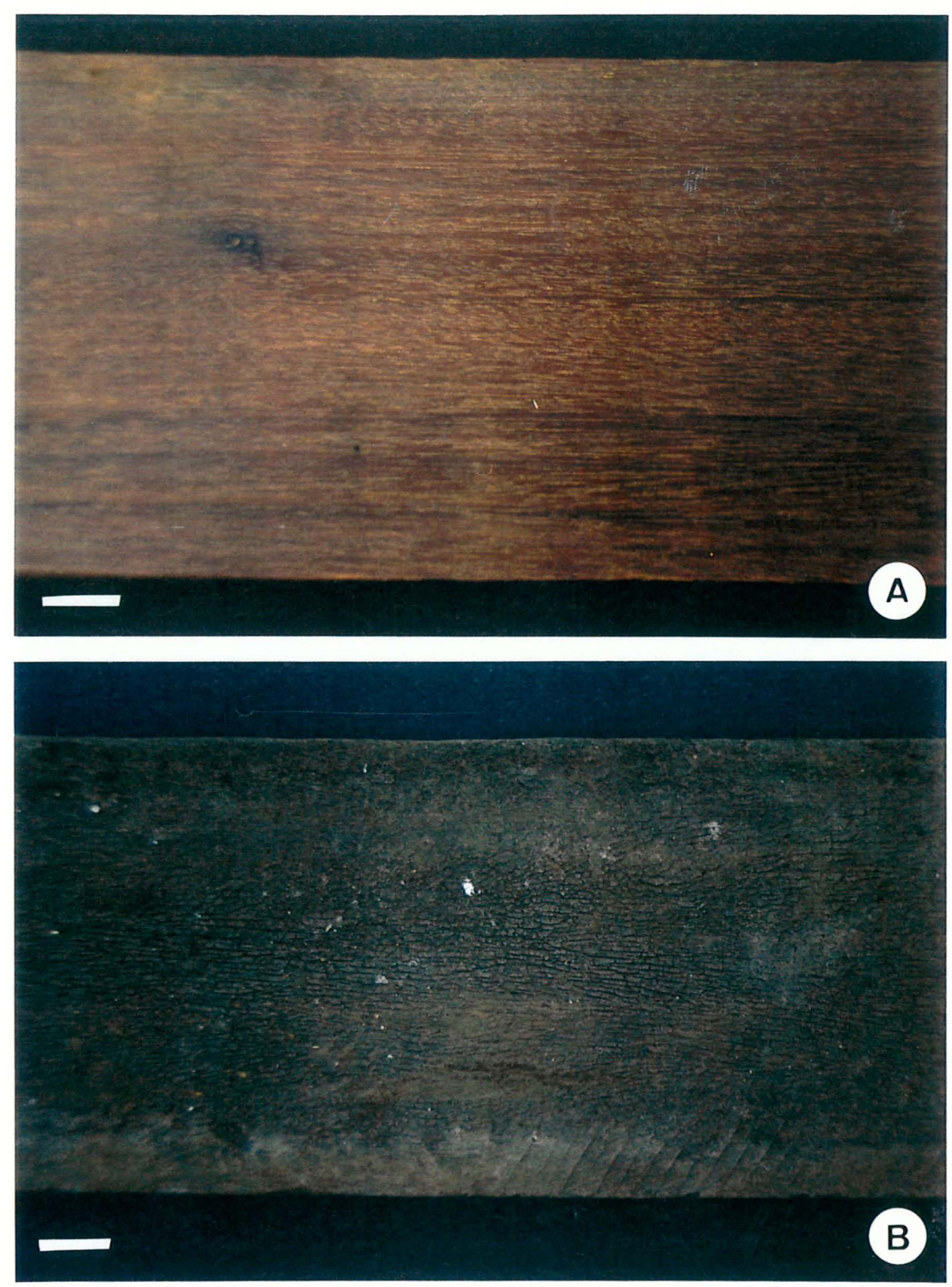

Figura 5 - Amostras de madeira de Tabebuia sp do eliminador de respingos. (A) madeira sadia e (B) com ataque de fungos de podridão mole $($ escala $=1 \mathrm{~cm})$ 
A profundidade do ataque das peças de madeira, segundo Oliveira et al. (1986), pode variar em função das condições de sua exposição. Enquanto que em torres de resfriamento a camada apodrecida pode apresentar apenas alguns milímetros de espessura, em postes de eucalipto pode ultrapassar a $2 \mathrm{~cm}$. A podridão mole foi descrita por Savory (1954) como um processo superficial, com os fungos afetando as camadas mais internas da madeira quando esta não é continuamente submersa em água. Por outro lado, Eaton (1972) relacionou o grau de apodrecimento da madeira, medido pela profundidade de ataque, e o número de corpos-defrutificação dos fungos em sua superfície, sendo que, quanto maior o seu número mais intenso o apodrecimento.

Os estudos do ataque químico de madeiras do CTI (1959 e 1963), principalmente dos enchimentos das torres, mostraram que os agentes alcalinos, como carbonatos e bicarbonatos, removem a lignina da madeira expondo as microfibrilas de celulose que podem ser carreadas pela ação da água. Este efeito pode ser aumentado pelas altas concentrações de oxidantes na água da torre, como os cloretos, bromatos e alguns algicidas que reagem com os extrativos e a lignina da madeira formando compostos mais solúveis em água.

Para controle do ataque químico da madeira de torres recomenda-se a utilização da água de resfriamento com pH na faixa entre 6 e 7, de agentes oxidantes em concentrações abaixo de 1 ppm e de utilização de algicidas não oxidantes. Como o processo de deslignificação e de remoção de extrativos das madeiras facilitam o ataque de fungos de podridão mole, o controle da qualidade da água reduz a taxa de apodrecimento da madeira (CTI, 
1959 e 1963).

Analisando os registros históricos da Petroquímica União S.A., referentes aos parâmetros químicos da água de resfriamento da torre EF-901, observamos que os valores de ph entre 7,0 e 8,5 e a alta concentração de cloretos encontrada (> $100 \mathrm{ppm}$ ), corroboram o fato de ter sido encontrado ataque químico e biológico nas madeiras deste equipamento.

A madeira de Tabebuia sp. pode atingir vida útil superior a 15 anos, desde que seja realizado o controle químico e microbiológico da água de resfriamento (Neves et al., 1989). Esta afirmação corrobora as observações feitas na torre de resfriamento EF-901 que está em operação há mais de 23 anos e cujas peças não estruturais de madeira (eliminador de respingos e enchimento) apresentaram somente sua superfície apodrecida.

\subsubsection{Análise microscópica}

A análise microscópica das amostras de madeira de Tabebuia sp. confirmou o ataque de fungos de podridão mole (Tabela 2, pág. 48), nas faces inferiores das amostras apodrecidas, e nas faces superiores, aparentemente sadias sob análise macroscópica.

Nas amostras de madeira $\mathrm{J}, \mathrm{Ke} \mathrm{L}$ do eliminador de respingos e $\mathrm{U}$ e $\mathrm{V}$ do enchimento do $5^{\circ}$ nível de altura da torre, consideradas sadias sob análise macroscópica, foi também constatado o ataque de fungos de podridão mole sob microscopia sendo, no entanto, incipiente e observado em poucas células da madeira. Nas amostras de madeira $\mathrm{X}$ e $\mathrm{Z}$ do enchimento não foram observadas estruturas típicas de fungos (hifas ou esporos) e sinais de ataque 
no nível microscópico.

O exame dos cortes histológicos transversais da madeira de Tabebuia sp., afetada por fungos de podridão mole, sob microscópio, mostrou 3 regiões distintas (Figura 6):

i) superficial (S) com todas as células do xilema (lenho) severamente afetadas por fungos de podridão mole (Figura 7);

ii) intermediária (I) com células intactas e atacadas por fungos de podridão mole, sendo observadas hifas e/ou esporos de fungos (Figura 8);

iii) interna (IN) com as células do xilema com as paredes intactas e sem a presença de hifas e/ou esporos (Figura 9).

O padrão de ataque observado para os fungos de podridão mole em madeira de Tabebuia sp. foi descrito por Savory (1954) ao verificar que este tipo de apodrecimento inicia-se na superfície da madeira, podendo progredir para o seu interior.

Em análise da secção transversal da região superficial (S) e intermediária (I) da madeira afetada pelos fungos de podridão mole (Figuras $7 \mathrm{e}$ 8) verificou-se a presença de hifas e esporos no lume das células dos vasos (Figura 10), raios e parênquima axial (Figura 11). Em maior ampliação, notouse as hifas no lume das fibras e sua passagem fibra-a-fibra feita através das pontoações (Figura 12). Estas observações corroboram os resultados obtidos por Eaton \& Hale (1993) e Levy \& Stevens (1966) que descreveram a colonização inicial do xilema de folhosas, por fungos de podridão mole, a partir das células dos raios, seguida pela penetração passiva das hifas através das pontoações das fibras $e$, podendo ocorrer também pelos vasos, sendo o parênquima axial uma rota preferencial de colonização da madeira. 
Figuras 6 a 9 -Secções transversais de amostras de madeira de Tabebuia sp., sob microscopia, com alterações na sua estrutura celular causadas por fungos de podridão mole.

Figura 6 - Vista geral da secção transversal do xilema, mostrando as regiões superficial (S), intermediária (I) e interna (IN), com diferentes intensidades de alterações causadas pelos fungos de podridão mole (escala $=200 \mu \mathrm{m})$

Figura 7 - Detalhe da secção transversal do xilema na região superficial (S) da amostra, mostrando as células severamente afetadas e degradadas pelos fungos de podridão mole (escala $=20 \mu \mathrm{m}$ ).

Figura 8 - Detalhe da seç̧ão transversal do xilema na região intermediária (I) da amostra, mostrando fibras com as paredes intactas (A) e atacadas por fungos de podridão mole $(B)-$ escala $=20 \mu \mathrm{m}$.

Figura 9-Detalhe da secção transversal do xilema na região interna (IN) da amostra, mostrando células com paredes sem ataque de fungos de podridão mole (escala $=20 \mu \mathrm{m}$ ). 


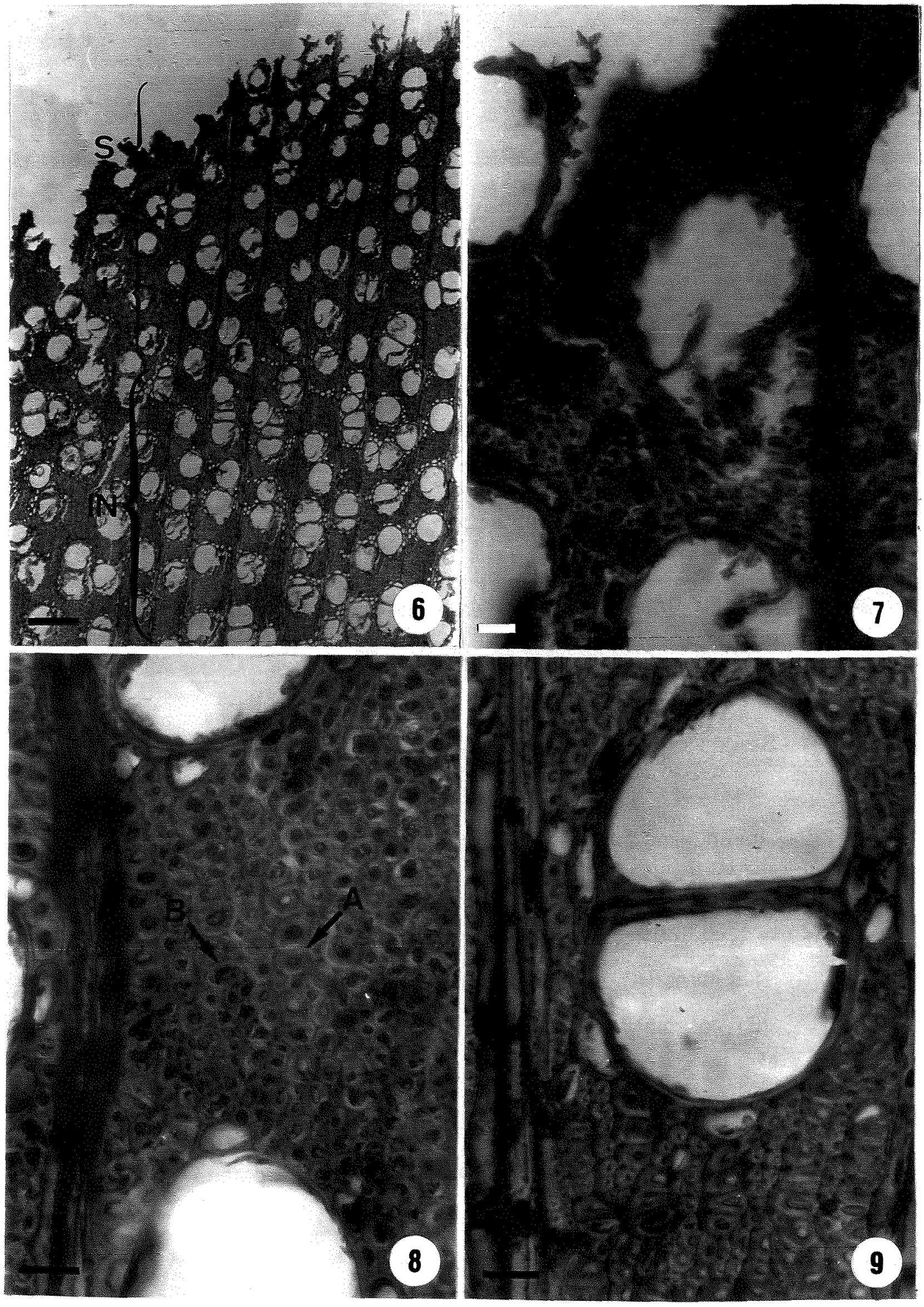


Figuras 10 a 13 - Secçōes transversais e longitudinal de amostras de madeira de Tabebuia sp., sob microscopia, mostrando as fases de colonização e ataque à parede das células por fungos de podridão mole.

Figura 10 - Secção transversal do xilema mostrando hifas pigmentadas e septadas no lume do vaso (escala $=10 \mu \mathrm{m}$ ).

Figura 11 - Secção longitudinal radial do xilema mostrando hifas pigmentadas e septadas no lume das células do parênquima radial $(A)$ e do parênquima axial $(B)-$ escala $=30 \mu \mathrm{m}$.

Figura 12 - Secção transversal do xilema mostrando hifas dos fungos no lume das fibras (A) e a passagem fibra-a-fibra através das pontoações (B) - escala $=5 \mu \mathrm{m}$.

Figura 13 - Secção transversal do xilema mostrando a presença de cavidades formadas por fungos de podridão mole, na parede das fibras (escala $=5 \mu \mathrm{m})$. 


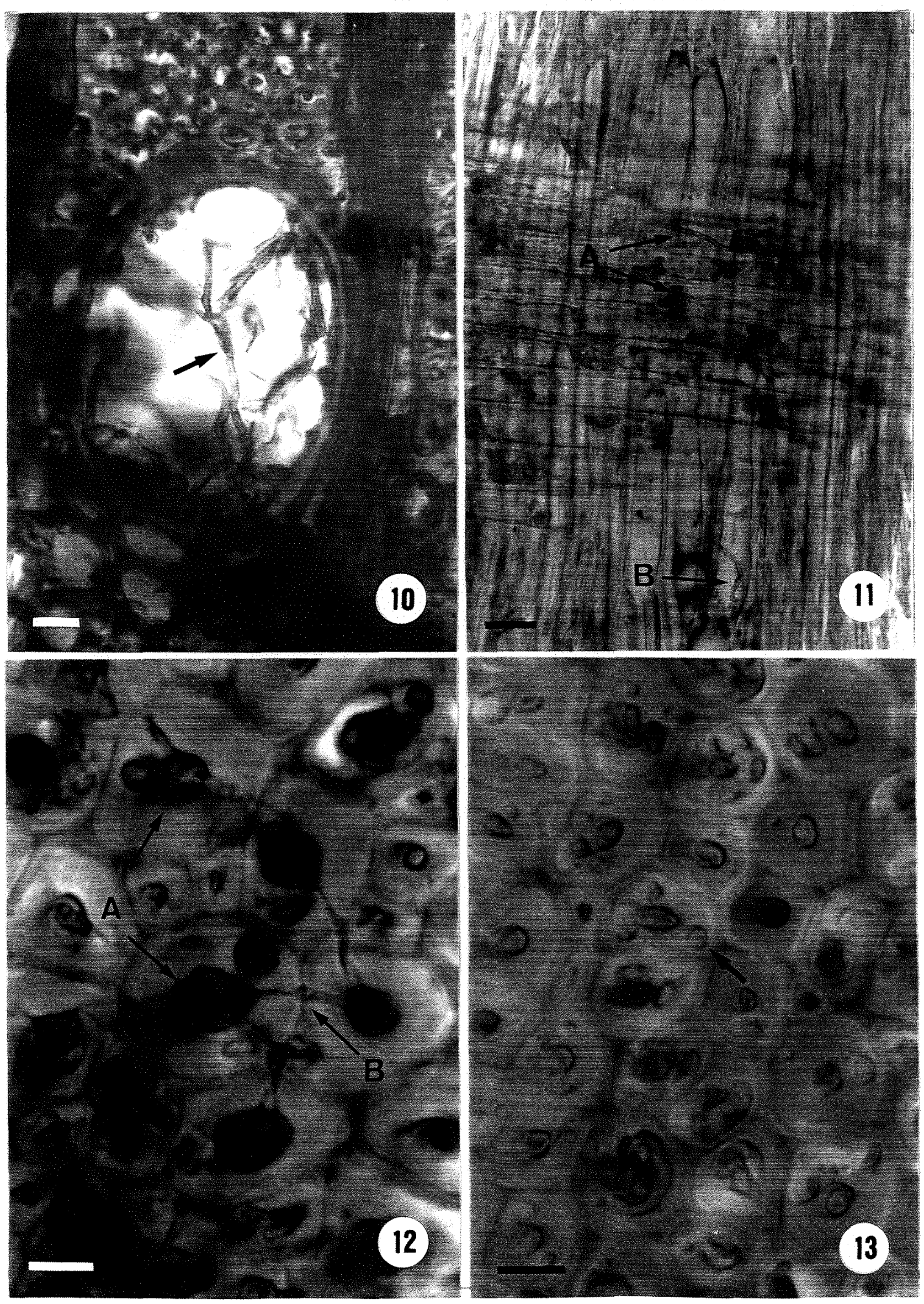


Nas secções transversais da madeira de Tabebuia sp. afetada pelos fungos observou-se, com nitidez, 0 ataque de podridão mole tipo 1 confirmado pela presença de cavidades na parede secundária das fibras (Figura 12 e 13), sendo que hifas pigmentadas, septadas e espessas foram observadas dentro dessas cavidades. As células mais intensamente atacadas (região superficial) apresentavam a parede celular completamente destruída (Figura 7 , pág. 57). A lamela média do xilema pode ser eventualmente degradada, conforme observou Singh et al. (1992) em madeira de Pinus radiata tratada com CCA.

A formação das cavidades está relacionada com o crescimento da hifa no interior da parede celular, e é explicada pela difusão limitada das enzimas secretadas para a degradação, principalmente, da celulose (forma cristalina e amorfa) e das hemiceluloses. De maneira geral, os fungos de podridão mole produzem enzimas hidrolíticas (endo e exoglucanases, xilanases, mananases, galactanases e $\beta$-glicosidases) e enzimas oxidativas (celobiose oxidase, glicose oxidase e celobiose dehidrogenase) que transformam os polissacarídeos em substâncias de fácil assimilação para o fungo, como a glicose e a frutose. O processo de degradação da lignina ainda é parcialmente entendido, mas foi demonstrado que a taxa de degradação da celulose é dependente da taxa de modificação da lignina, uma vez que a lignina dificultaria o acesso das enzimas ao substrato (Eaton \& Hale, 1993; Eriksson \& Wood, 1985 e Oliveira et. al., 1986). 
Estes fungos de podridão mole provocaram a formação de cavidades nas paredes das fibras, não sendo observadas cavidades nas paredes dos vasos, das células dos raios e do parênquima axial (Figura 14). Savory (1954) também observou ataque mais evidente nas paredes das fibras e em uma extensão menor, o ataque na parede das células dos raios.

As paredes das fibras afetadas pelos fungos apresentaram, nos cortes histológicos longitudinais tangenciais, cavidades com diferentes dimensão e formas, sendo alongadas, cilíndricas, com as pontas cônicas e com forma rombóide (Figura 15) e outras curtas, bicônicas e com forma de diamante (Figuras 16). As extremidades cônicas das cavidades apresentavam-se interligadas, formando cadeias em espiral dentro da parede celular das fibras. Estas cadeias faziam um ângulo com o eixo principal das fibras (Figura 17). Com respeito à formação dessas cavidades, Bayley \& Vestal, citados por Savory (1954), mostraram que as hifas do fungo crescem no interior da parede celular das fibras, acompanhando a orientação helicoidal das microfibrilas de celulose.

O padrão das cavidades é influenciado pela espécie de fungo, espécie de madeira e, também, por fatores como temperatura e umidade (Oliveira et al., 1986). 
Figuras 14 a 17 - Secções transversal e longitudinais tangenciais de amostras de madeira de Tabebuia sp., sob microscopia, mostrando as cavidades formadas na parede celular das fibras por fungos de podridão mole.

Figura 14 - Secção transversal do xilema mostrando o ataque das hifas dos fungos na parede das fibras $(A)$ em relação às paredes intactas dos vasos (B), das células dos raios (C) e das células do parênquima axial (D) intactas (escala $=30 \mu \mathrm{m}$ ).

Figura 15 -Secção longitudinal tangencial do xilema, sob luz polarizada, mostrando cavidades alongadas, cilíndricas, com as pontas cônicas e com formato rombóide na parede celular das fibras (escala $=10 \mu \mathrm{m})$.

Figura 16 - Secção longitudinal tangencial do xilema, sob luz polarizada, mostrando cavidades curtas, bicônicas com forma de diamante na parede celular das fibras (escala $=10 \mu \mathrm{m})$.

Figura 17 -Secção longitudinal tangencial do xilema, sob luz polarizada, mostrando a interligação das cavidades na parede secundária e o ângulo formado com o eixo principal das fibras (escala $=20 \mu \mathrm{m}$ ). 


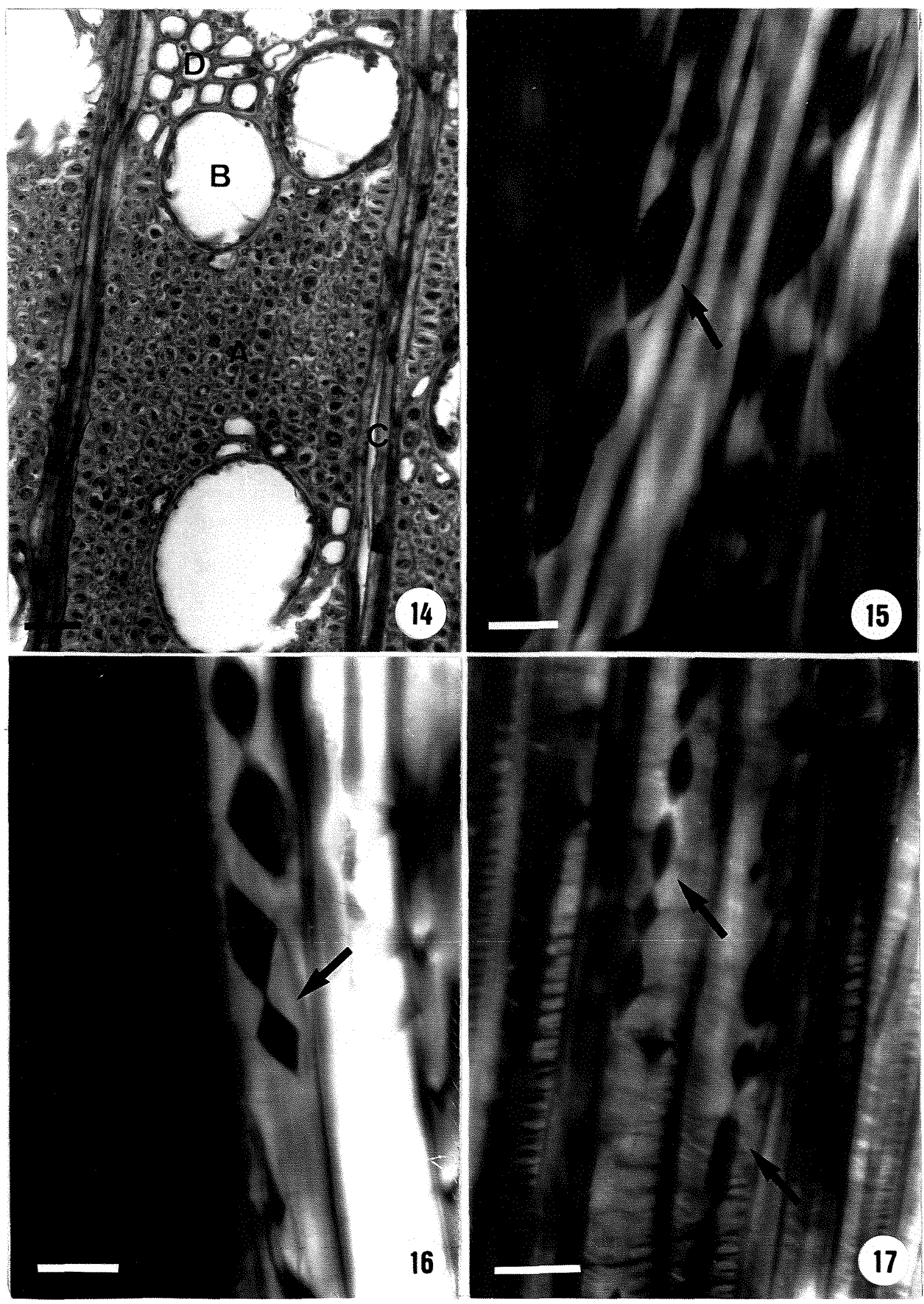


Courtois, citado por Eaton \& Hale (1993), descreveu 14 formas de ataque de podridão mole nas células da madeira, identificando diversos estágios de formação de cavidades e de ataque das camadas da parede celular, sendo que, os fungos de podridão mole mais agressivos foram capazes de provocar maior variedade de padrões de ataque. Verificou-se, também, que a morfologia das cavidades na parede das células, produzidas por fungos marinhos, apresentavam variações entre diferentes espécies de fungos e entre linhagens de uma mesma espécie (Mouzouras, 1989).

Os resultados do presente trabalho mostraram, por meio das análises macro e microscópicas das amostras de madeira de Tabebuia sp., a existência de ataque generalizado de fungos de podridão mole nas madeiras do eliminador de respingos e do enchimento da torre. Um diagnóstico adequado da ocorrência de podridão mole no madeiramento de uma torre de resfriamento de água pode auxiliar na adoção de medidas preventivas e curativas para controle da deterioração biológica.

\subsection{Isolamento e identificação dos fungos}

O plaqueamento dos fragmentos de madeira de Tabebuia sp., em meio de cultura, propiciou o isolamento de inúmeras espécies de fungos, cujas freqüências relativas de ocorrência (\%), são apresentadas na Tabela 3. Os resultados obtidos para os fungos isolados foram ilustrados na Figura 18. 
Tabela 3. Espécies de fungos isolados das amostras de madeira de Tabebuia sp., da torre de resfriamento de água, e suas freqüencias relativas de ocorrência (\%).

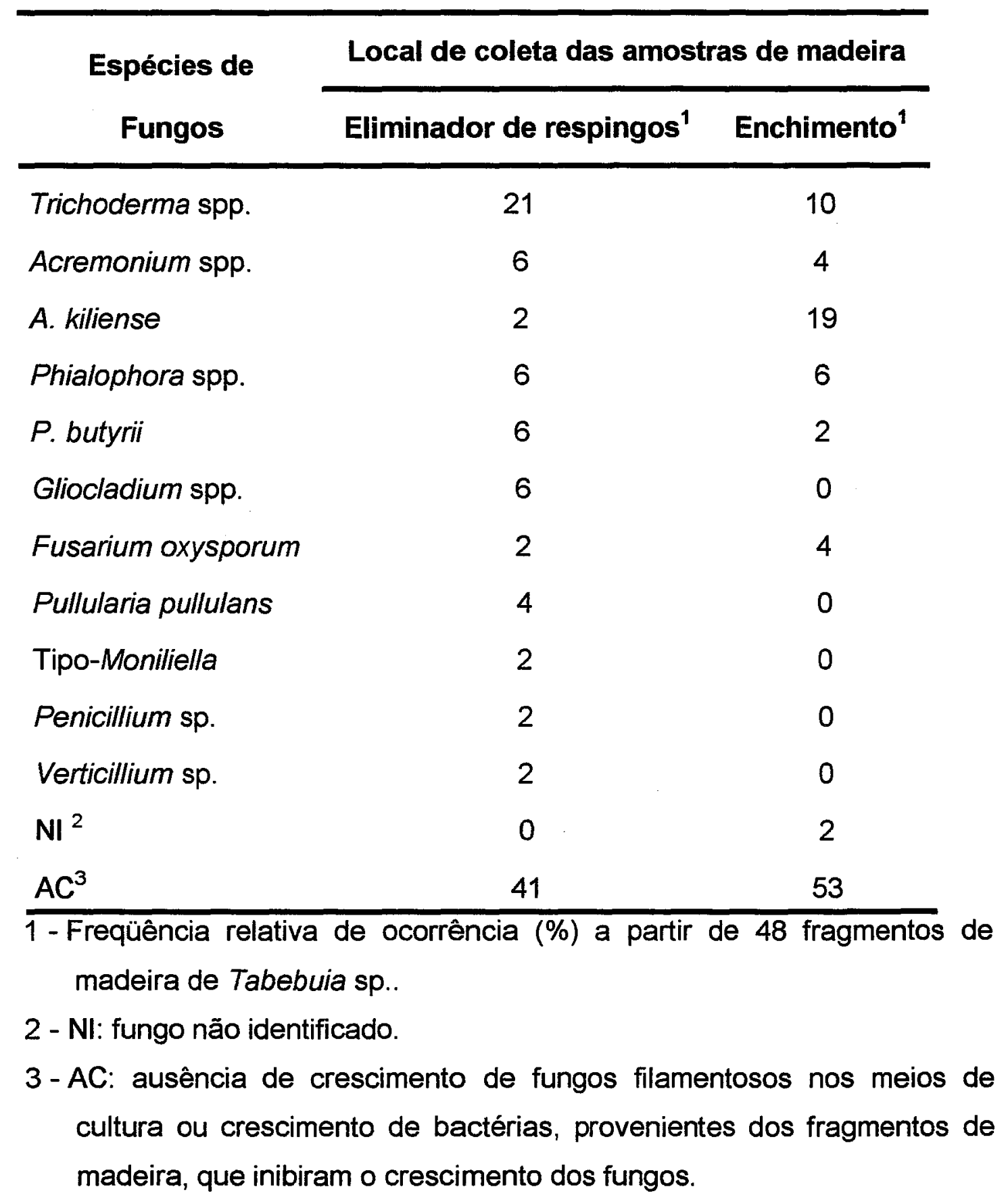




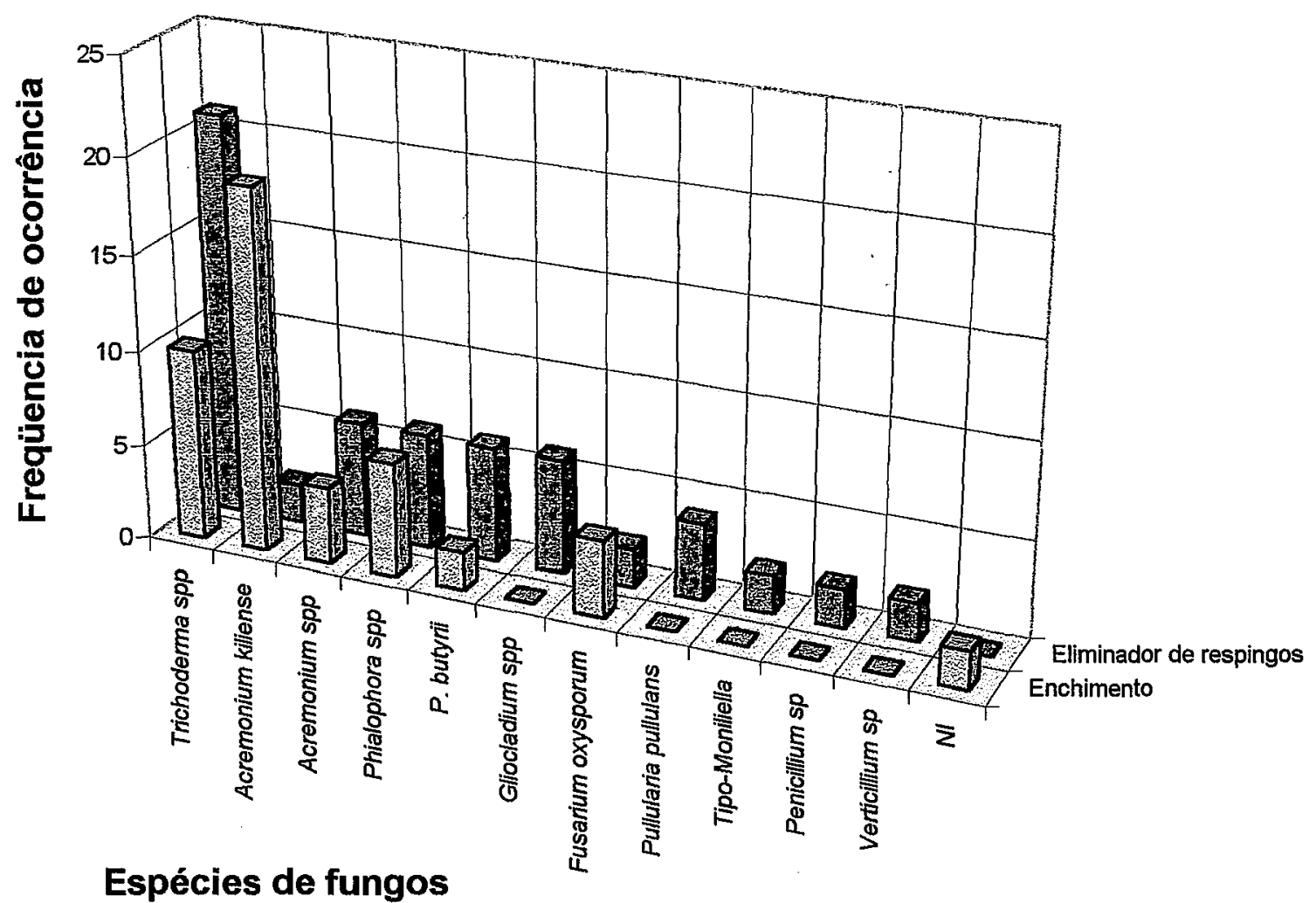

Figura 18 -Espécies de fungos isolados das amostras de madeira de Tabebuia sp. da torre de resfriamento de água, e suas freqüencias relativas de ocorrência (\%). 
Da madeira afetada da torre de resfriamento foram isolados e identificados espécies de fungos imperfeitos (Subdivisão Deuteromycotina), confirmando as observações feitas por Natarajan \& Udaiyan (1978), de que o uso de água doce em torres de resfriamento induziria a predominância desse grupo de fungos.

Um total de 51 fungos, pertencentes a 9 gêneros - Acremonium, Fusarium, Gliocladium, "Tipo-Moniliella", Penicillium, Phialophora, Pullularia, Trichoderma e Verticillium - foram isolados. As espécies pertencentes aos gêneros Acremonium, Trichoderma e Phialophora foram as mais freqüentes na madeira da torre, com 31, 31 e 20\%, respectivamente. Estes fungos ocorreram na madeira do eliminador de respingos e do enchimento, sendo que no enchimento, os mais freqüentes foram os fungos do gênero Acremonium $(23 \%)$, enquanto que no eliminador de respingos os fungos do gênero Trichoderma (21\%).

Uma maior variedade de espécies de fungos foi observada na madeira do eliminador de respingos: Gliocladium spp., Penicillium sp., Pullularia pullulans, Tipo-Moniliella e Verticillium sp. foram encontradas apenas neste local; Fusarium oxysporum foi isolado na madeira do eliminador de respingos e do enchimento. Entretanto, todas essas espécies de fungos ocorreram na torre em freqüência igual ou inferior a $6 \%$.

A comparação das espécies de fungos isolados da madeira da torre de resfriamento com os levantamentos realizados em torres de outros países (Tabela 1, pág. 14), permitiu concluir que todos os gêneros observados foram citados na literatura. 
Savory (1954) observou que Fusarium spp., Penicillium spp. e Trichoderma spp. eram freqüentes em madeira de Pinus sp., Picea sp. e Dipterocarpus sp. com podridão mole; e Phialophora spp. e Pullularia spp. mais raros.

Cephalosporium sp. (=Acremonium sp.), Fusarium sp. e Phialophora sp. foram observados em corpos-de-prova de madeira de Fagus sylvatica e Pinus sylvestris instalados em 2 torres na Inglaterra (Eaton \& Jones, 1971a,b e Eaton \& Irvine, 1972). O Fusarium sp. foi considerado colonizador primário, por ter sido observado logo após à instalação dos corpos-de-prova; Cephalosporium sp. foi observado somente após 6 semanas de exposição da madeira na torre, sendo classificado como um colonizador secundário; e Phialophora sp. foi considerado não freqüente. Sugere-se que os colonizadores primários seriam estimulados a frutificar pela disponibilidade de nutrientes solúveis na superfície da madeira e pela relativa ausência de organismos competidores; podendo persistir se possuírem capacidade de degradar a celulose ou desaparecer se existirem competição com outros fungos com maior capacidade de degradar a celulose. Os colonizadores secundários aparecem quando a podridão mole já se desenvolveu na madeira, podendo competir com os primários (Eaton \& Jones, 1971a).

Cephalosporium spp. e Fusarium spp.. foram freqüentes na madeira de $F$. sylvatica na região de respingos (enchimento) de 16 torres de resfriamento; apenas Fusarium spp. foi observado com alta freqüência na madeira de $P$. sylvestris; Penicillium, Phialophora, Trichoderma e Verticillium foram pouco freqüentes (Eaton, 1972). 
Espécies do gênero Phialophora ( $P$. richardsiae, $P$. melinii, $P$. bubaki e Phialophora sp.) foram isoladas com maior freqüencia da madeira de Sequoia sempervirens, utilizada no enchimento de uma torre nos E.U.A., sendo que Pullularia pullulans foi considerada não freqüente (Morrel \& Smith, 1988).

Espécies dos gêneros Fusarium (F. oxysporum e F. solani), Penicillium ( $P$. rubrum), Trichoderma ( $T$. piluliferum, $T$. pseudokoningii e $T$. viride) e Gliocladium (G. penicilloides) foram isoladas por Natarajan \& Udaiyan (1978) de madeira de Pinus longifolia e $P$. roxburghii, tratadas com o produto preservante CCA, e de $P$. patula e Fagus rhamnifolia, sem tratamento preservante, utilizadas no enchimento de uma torre de resfriamento na Índia.

Acremonium sp., Trichoderma harzianum, Penicillium stofoniferum e fungos do gênero Gliocladium (G. penicillioides e G. putredinis) eram dominantes em madeira de $P$. roxburghii tratada com CCA, utilizadas no enchimento de duas torres de resfriamento, enquanto que fungos do gênero Phialophora ( $P$. phaeopora e $P$. richardsiae) eram comuns (Udaiyan \& Manian, 1990).

Os gêneros Fusarium, Gliocladium, Penicillium, Tipo-Moniliella, Trichoderma e Acremonium foram isolados de corpos-de-prova de $P$. patula e $F$. rhamnifolia, instalados na região de respingos, sendo que $F$. solani, $G$. penicillioides, G. virens, $P$. stoloniferum foram isolados regularmente (Udaiyan \& Manian, 1991).

A maior freqüência dos fungos dos gêneros Acremonium e Trichoderma, na torre de resfriamento EF-901, foi convalidada pelos estudos realizados por Eaton (1972), Savory (1954) e Udaiyan \& Manian (1991). No caso de Acremonium spp., Eaton \& Jones (1971a) e Udaiyan \& Manian (1991) 
classificaram algumas espécies como colonizadoras secundárias por terem sido observadas posteriormente ao desenvolvimento da podridão mole na madeira.

Fungos do gênero Phialophora foram somente observados em maior freqüência por Morrel \& Smith (1988), em madeira de Sequoia sempervirens com alta resistência natural ao ataque de fungos apodrecedores, sendo que espécies desse gênero tiveram ocorrência esporádica em outras torres (Eaton, 1972; Eaton \& Irvine, 1972 e Savory, 1954).

Fusarium spp., Gliocladium spp. e Penicillium spp. foram citados por Eaton (1972), Savory (1954) e Udaiyan \& Manian (1991) como freqüentes em torres de resfriamento; entretanto, ocorreram em baixa freqüência no presente estudo. Segundo Udaiyan \& Manian (1991), espécies desses gêneros seriam consideradas colonizadoras primárias em madeiras recém expostas nas torres, quando ainda não ocorreu ataque de fungos de podridão mole.

Fungos Tipo-Moniliella foram observados por Udaiyan \& Manian (1990 e 1991) sendo considerados como colonizadores secundários e de ocorrência não significativa. $E$ os fungos do gênero Verticillium (V. candelabrum) foram citados por Eaton (1972) em apenas uma torre de resfriamento de água.

$\mathrm{Na}$ literatura consultada, não foram encontradas citações dos fungos Acremonium kiliense e Phialophora butyrii em madeiras de torres de resfriamento de água. $O A$. kiliense foi o mais freqüente na madeira das amostras do enchimento (19\%), em relação à madeira do eliminador de respingos $(2 \%)$, demonstrando melhor adaptação à condições mais agressivas de exposição. 
As diferenças das espécies de fungos isoladas e suas freqüencias relativas no eliminador de respingos e no enchimento, podem ser explicadas pelas condições de exposição das madeiras dentro da torre. Enquanto que no enchimento (região de respingos) as madeiras estão em contato com a água aquecida e forma-se um filme d'água na sua superfície, diminuindo a disponibilidade de oxigênio para os microrganismos, no eliminador de respingos (região de neblina) o ambiente saturado de vapor de água, com maior disponibilidade de oxigênio para os microrganismos, favoreceria o seu crescimento.

Segundo Eaton \& Jones (1971b) as diferenças de temperatura e dos constituintes da água podem influenciar no crescimento e no padrão de colonização dos microrganismos na madeira da torre de resfriamento. A ocorrência de espécies de microrganismos pode ser determinada pelas condições ambientais e outras particularidades de instalação da torre, sendo que a procedência da água pode definir a micota conforme demonstraram Eaton (1972) e Eaton \& Irvine (1972) ao verificar que a madeira de torres de resfriamento que utilizaram água salgada, foi colonizada por fungos aquáticos marinhos.

Udaiyan \& Manian (1990 e 1991), mostraram que os fatores químicos e físicos, como a temperatura e concentração de efluentes, procedência da água de "make up" e as condições de operação das torres têm um profundo efeito na composição da micota na madeira. 
A madeira de Tabebuia sp., de alta durabilidade natural ao ataque de fungos apodrecedores, pode ter influenciado na infecção, desenvolvimento e freqüência das espécies de fungos na torre de resfriamento EF-901. Em madeira de Ocotea rodiaei, também considerada de alta durabilidade natural, foi observado menor número de espécies de fungos na madeira em comparação com as madeiras de $F$. sylvatica e $P$. sylvestris, demonstrando a influência pela espécie de madeira utilizada (Eaton \& Jones, 1971)

Bactérias foram observadas nas amostras de madeira de Tabebuia sp., sendo mais freqüentes nos fragmentos de madeira do eliminador de respingos $(40 \%)$ do que nos fragmentos do enchimento $(15 \%)$ da torre de resfriamento de água.

Butcher (1972), encontrou uma forte associação positiva entre bactérias e fungos de podridão mole na colonização da madeira de Betula spp. em contato com o solo, o que pode representar uma ação sinergética entre estes grupos de microrganismos.

Segundo Singh et al. (1992), a importância da degradação da madeira por bactérias, em torres de resfriamento, foi reconhecida por vários autores desde a década de 60 . Em estudo com madeira de Pinus radiata tratada com CCA, observou-se o ataque de bactérias formadoras de túneis e que causam erosão na parede celular, sendo demonstrada que a ação conjunta de bactérias e fungos de podridão mole causaram a deterioração da madeira na torre. 
A deterioração causada por bactérias deve ser melhor investigada para um controle mais efetivo da deterioração da madeira em torres de resfriamento, onde são mais freqüentes os estudos com fungos causadores de podridão mole.

\subsection{Avaliação da capacidade de degradação dos fungos isolados}

A Tabela 4 apresenta as médias de perda de massa dos corpos-de-prova de Eucalyptus grandis e de Pinus elliottii submetidos à ação dos fungos isolados e do fungo referência Chaetomium globosum. Os valores são expressos em porcentagem, sendo relacionados seus respectivos desvios padrão. Na tabela também são apresentados os resultados da análise da estrutura anatômica da madeira dos corpos-de-prova, inoculados com esses fungos, para a observação de cavidades nas paredes das células e confirmação do ataque de podridão mole. Os resultados da perda de massa (\%) são apresentados em detalhes nas Tabelas 5 e 6 do Apêndice 1 . 
0
0
0
0
0
0
0
8
8
8
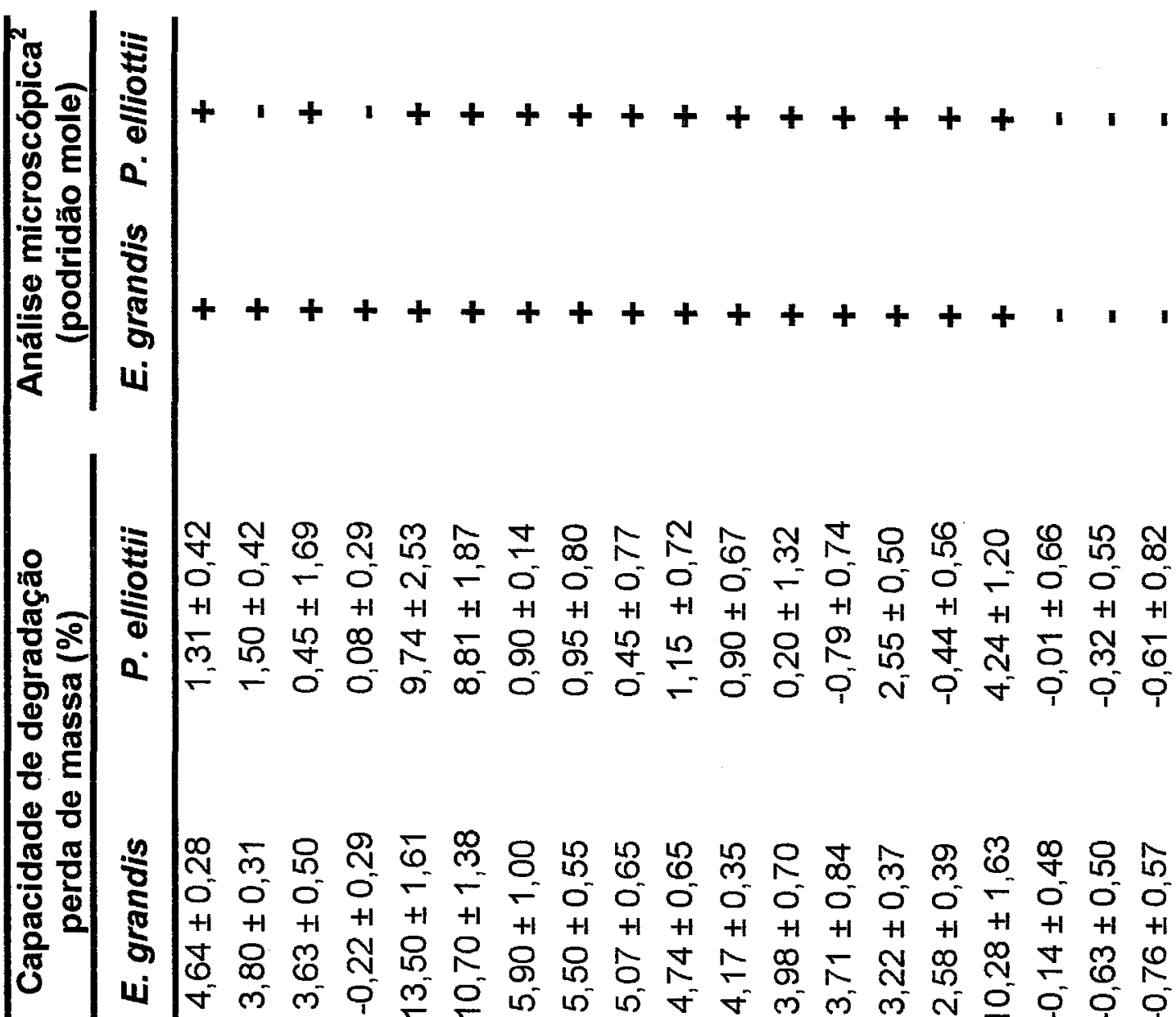

.

山i

\%

(ั)

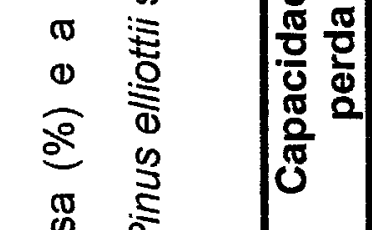

๓ $\cong$ m

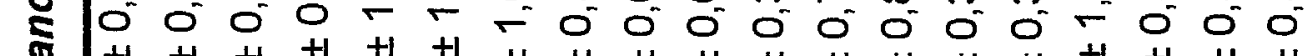

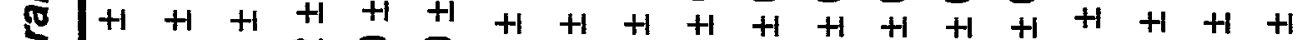

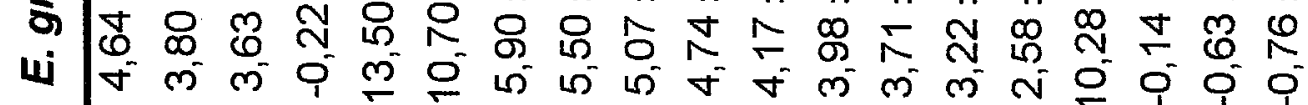

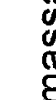

8

$\frac{8}{8}$

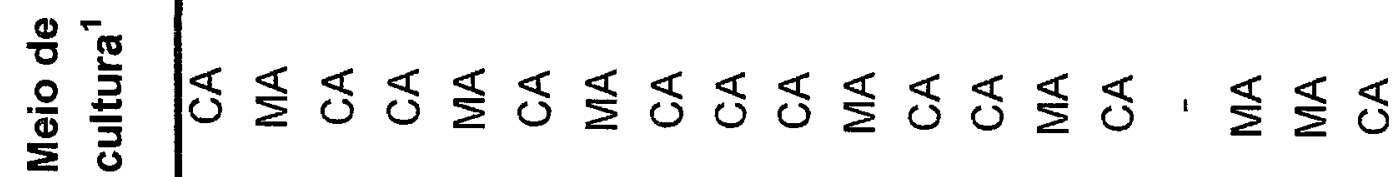

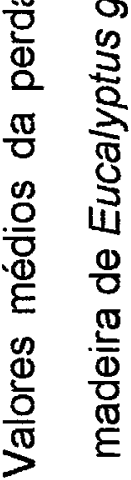

$\forall$

$\frac{\mathbb{d}}{\mathbb{D}}$

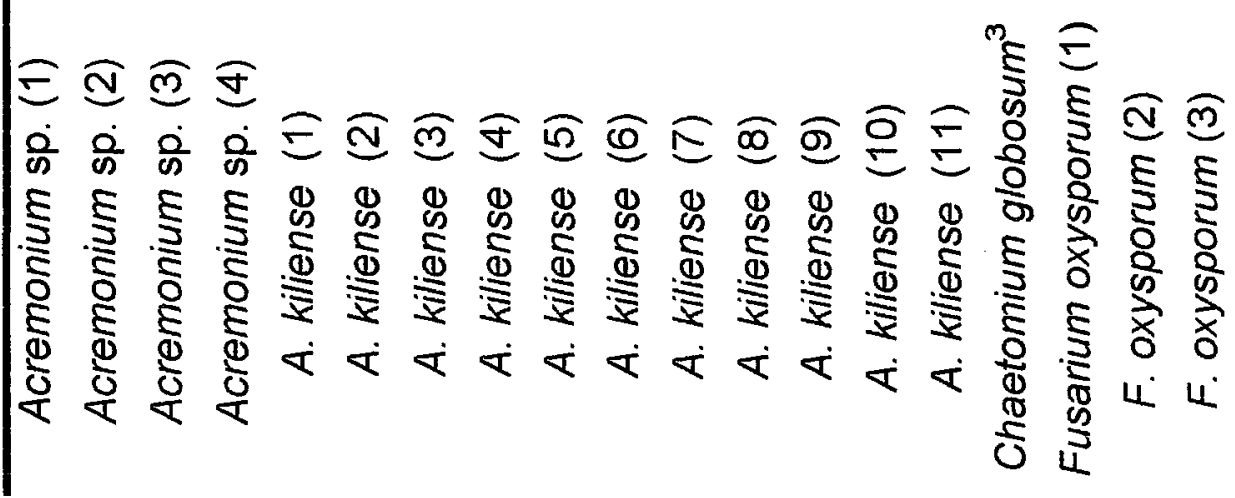




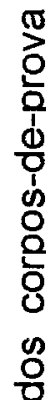

(

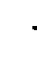

.

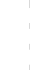

है

$\frac{1}{0}$

중

ष्ठ

要

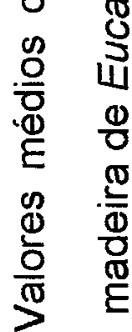

密

两

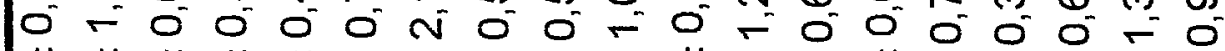

$\begin{array}{lllllllllllllllllll}+1 & +1 & +1 & +1 & +1 & +1 & +1 & +1 & +1 & +1 & +1 & +1 & +1 & +1 & +1 & +1 & +1 & +1 & +1\end{array}$

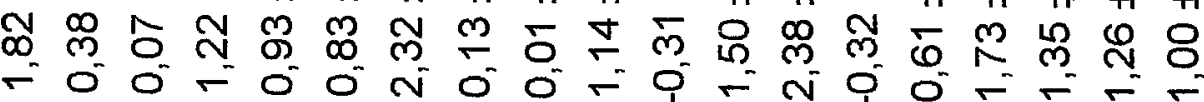

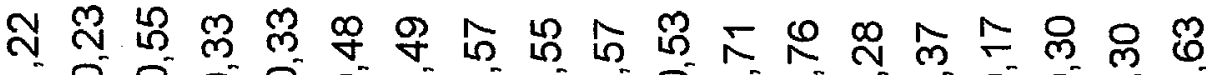

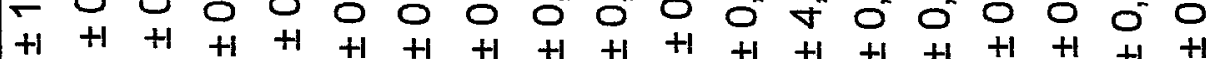
采

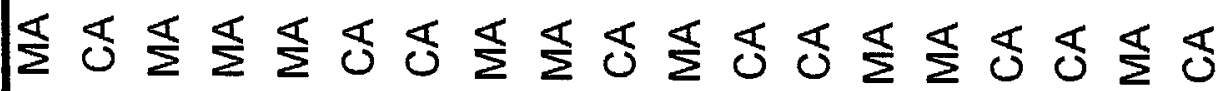

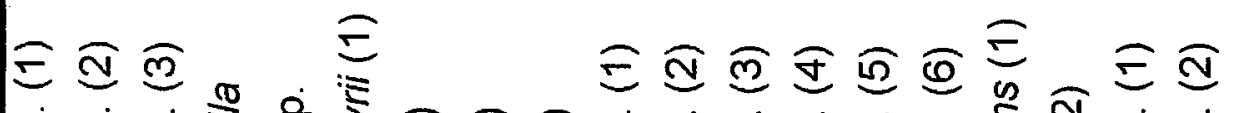

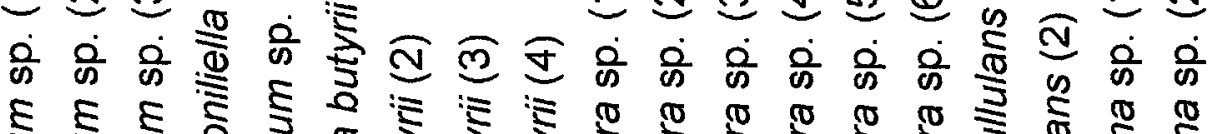

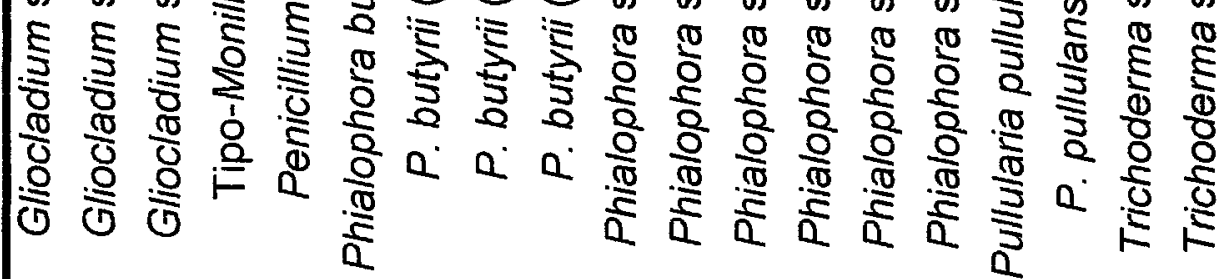




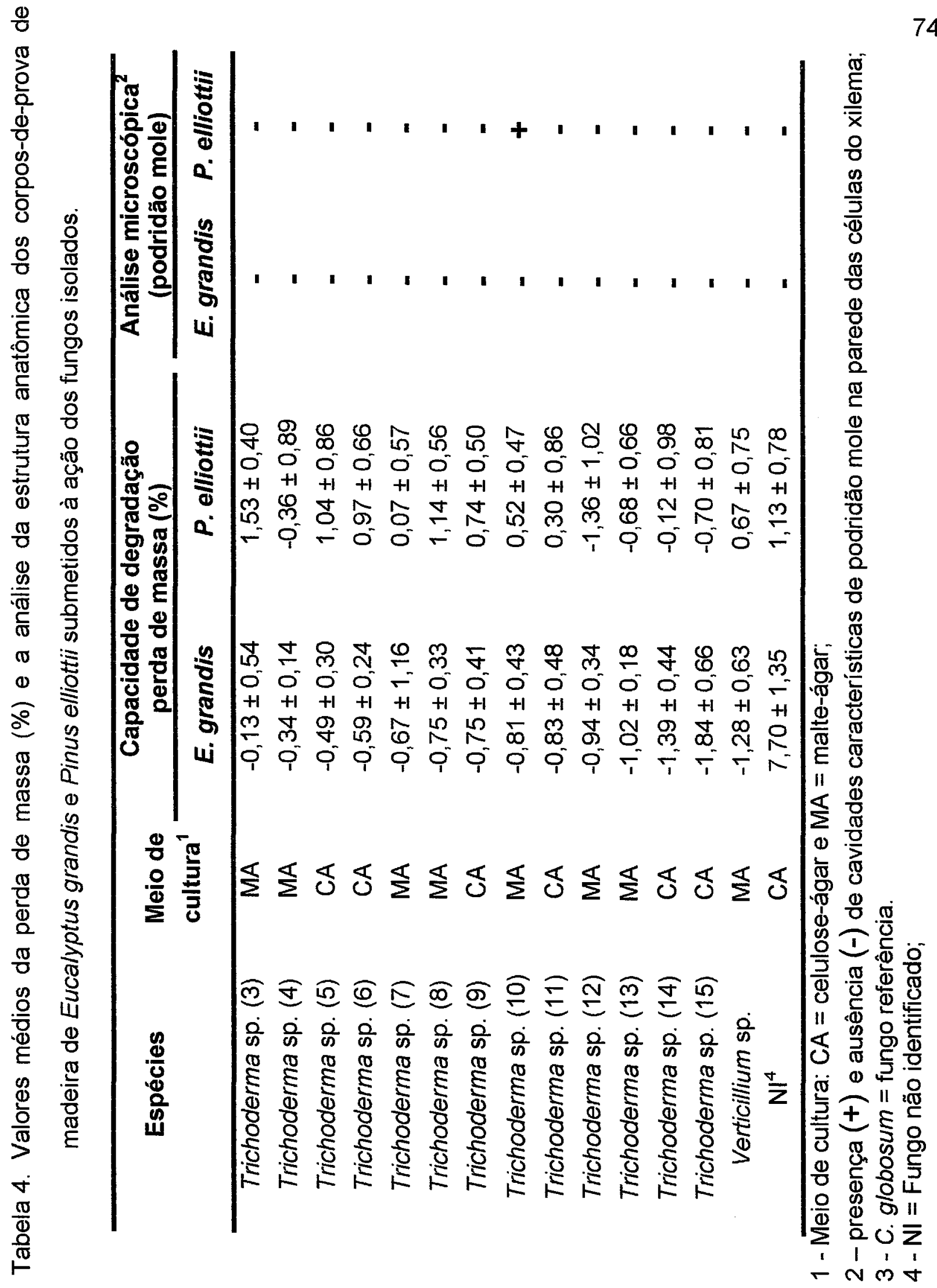




\subsubsection{Confirmação do ataque dos fungos de podridão mole}

Os resultados do presente trabalho referentes aos fungos isolados e à formação de cavidades típicas de podridão mole nas paredes das células das madeiras de Eucalyptus grandis e Pinus elliottii, comparados com os da literatura, permitiram os seguintes comentários:

a) Dos 52 fungos isolados das amostras de madeira de Tabebuia sp., apenas 26 causaram podridão mole nas madeiras de $E$. grandis e/ou $P$. elliottii.

b) Os isolados Fusarium oxysporum, Tipo-Moniliella, Penicillium sp., Pullularia pullulans e Verticillium sp. não causaram podridão mole nas madeiras ensaiadas:

b.1) Duncan \& Eslyn (1966), Eaton \& Jones (1971a) e Nilsson (1973) observaram a formação de cavidades por Fusarium spp. e Fusarium solani, entretanto, não foram encontradas informações sobre a capacidade do fungo Fusarium oxysporum, isolado no presente trabalho, produzir cavidades típicas de podridão mole nas madeiras;

b.2) Duncan \& Eslyn (1966) classificaram algumas cepas de Penicillium sp. como fungos de podridão mole; a formação de cavidades na parede celular foi observada nos fungos $P$. rubrum e $P$. tardum (Knox, 1977 e 
Morrel \& Smith, 1988); entretanto, Nilsson (1973) e Line \& Cruickshank (1979) não observaram a formação de cavidades em Penicillium spp.;

b.3) Butcher (1968), Nilsson (1973) e Morrel \& Smith (1988) não observaram cavidades produzidas por Pullularia pullulans e Nilsson (1973) afirma que apesar de ser um importante fungo manchador, causador de mancha azul, não é capaz de degradar a madeira;

b.4) segundo Nilsson (1973), as espécies Verticillium falcatum, V. nigrescens. e $V$. psalliotae não possuem capacidade para a formação de cavidades típicas de podridão mole.

c) No gênero Gliocladium, apenas o isolado (1) causou podridão mole na madeira de E. grandis. Duncan \& Eslyn (1966) e Knox (1977) citaram o Gliocladium roseum como fungo de podridão mole, entretanto, não foi observada a formação de cavidades pelos fungos $G$. catenulatum, $G$. catenulatum e G. penicillioides (Butcher, 1968 e Nilsson, 1973).

d) No gênero Trichoderma, apenas o isolado (10) causou podridão mole na madeira de $P$. elliottii; sendo 0 ataque incipiente $e$ restringindo-se à formação de cavidades nas paredes de poucas células do lenho outonal. Liese \& Pechman, Courtois, Minell e Levy, citados por Nilsson (1973), observaram cepas de Trichoderma viride formando cavidades de podridão mole. Em contraste, Butcher (1968) não observou a formação de cavidades por Trichoderma viride e Nilsson (1973) não observou em $T$. 
polyporum e T. viride.

e) Os fungos dos gêneros Phialophora e Acremonium causaram podridão mole nas 2 espécies de madeira; apenas os isolados (2) e (4) de Acremonium sp. e os isolados (5) e (6) de Phialophora sp. não atacaram a madeira de $P$. elliottii; $\quad$ o isolado (2) de Phialophora sp. não causou podridão mole nas madeiras testadas. Duncan (1960), Duncan \& Eslyn (1966), Butcher (1968), Eaton \& Jones (1971a), knox (1977) e Nilsson (1973) observaram que fungos destes gêneros possuem uma considerável capacidade de produzir podridão mole em madeiras de folhosas e coniferas:

e.1) Nilsson (1973) confirmou que as espécies Acremonium atro-griseum, A. furcatum e Acremonium sp. produziram cavidades nas madeiras; apenas Cruickshank \& Line (1979) não observaram a formação de cavidades por Acremonium spp. em Eucalyptus obliqua, entretanto, o teste realizado em laboratório durou apenas 3 semanas;

e.2) Duncan \& Eslyn (1966) citam as espécies $P$. fastigiata, $P$. richardsiae e Phialophora sp. como fungos capazes de causarem podridão mole; Nilsson (1973) as espécies Phialophora sp., P. cyclaminis, P. fastigiata, $P$. hoffmannii, $P$. lignicola, $P$. luteo-viridis, $P$. mutabilis $e \quad P$. richardsiae; Cruickshank \& line (1979) a espécie P. mutabilis; e Morrel \& Smith (1988) as espécies $P$. melinii e $P$. richardsiae. 
f) O fungo não identificado (NI) não causou podridão mole nas madeiras ensaiadas, observando-se, entretanto, uma grande perda percentual de massa média para o $E$. grandis $(7,70 \pm 1,35 \%)$ em comparação com a maioria dos fungos isolados; a análise macro e microscópica realizada para sua identificação taxonômica (aspecto macroscópico da colônia e ausência de conídias ou ascosporos) forneceu informações de que esse fungo pertence à Subdivisão Basidiomycotina, embora não sendo encontradas estruturas típicas deste grupo de fungos, tais como, corpos-de-frutificação, grampos de conexão nas hifas, basídios e basidiósporos que confirmassem sua identificação como um basidiomiceto apodrecedor.

g) As cepas (2) de Gliocladium sp.; (2), (5), (6), (9), (11), (14) e (15) de Trichoderma sp.; (1) e (2) de Pullularia pullulans; e (3) de Fusarium oxysporum foram isoladas em meio celulose-ágar o que indicou alguma atividade celulolítica, entretanto, não causaram podridão mole nas madeiras de E. grandis e $P$. elliottii; Nilsson (1973) também observou fato semelhante em 12 culturas de fungos e sugeriu 2 hipóteses: (i) falta de algumas enzimas que participam do processo de degradação da parede celular, como as xilanases e mananases e; (ii) incapacidade de degradação das microfibrilas de celulose associadas à lignina, considerada uma substância incrustante da parede celular.

Os resultados obtidos neste estudo, comparados com os apresentados na literatura, demonstraram que nem todos os fungos isolados de madeiras com podridão mole (freqüentes ou não), são capazes de reproduzir os 
sintomas desse ataque nas células da madeira Entretanto, estudos ecológicos de deterioração de madeiras por fungos em torres de resfriamento indicaram sua importância no processo de deterioração das madeiras (Eaton, 1972; Eaton \& Jones, 1971a,b; e Udaiyan \& Manian, 1991). Já os fungos dos gêneros Acremonium e Phialophora foram isolados em maior freqüência e são comprovadamente causadores de podridão mole, constituindo-se em importantes agentes de deterioração da madeira em torres de resfriamento.

\subsubsection{Ensaio acelerado - fungos de podridão mole}

Os valores médios de perda de massa (\%) dos corpos-de-prova de $E$. grandis e $P$. elliottii submetidos aos 26 fungos que comprovadamente causaram podridão mole (Tabela 4, pág. 72) são apresentados na Figura 19.

A análise de variância dos resultados de perda de massa (\%), apresentada no Apêndice 2, mostrou que os fatores madeira e fungo e a interação madeira $x$ fungo foram significantes $(p=0,00)$. A significância da interação demonstrou que existe uma dependência entre as espécies de madeira e de fungos testadas, ou seja, o efeito das madeiras depende da espécie de fungo analisada e o efeito das espécies de fungos depende da madeira.

O teste de comparação múltipla de Tukey realizado para as médias da interação madeira $x$ fungo, apresentado no Apêndice 2 , resultou em: 
Trichoderma sp 10 Acremonium sp 4 P. butyrii 4 Gliocladium sp 1 P. butyrii 3 A. kiliense 11 Phialophora sp 6

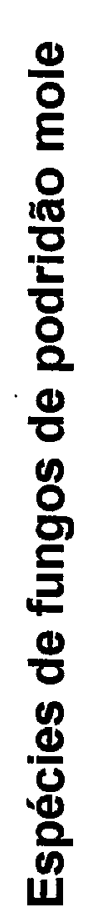

A. kiliense 10 Phialophora sp 5 Acremonium sp 3

A. kiliense 9 Acremonium sp 2 Phialophora sp 1 A. kiliense 8 A. kiliense 7 Acremonium sp 1 A. kiliense 6 Phialophora sp 3 A. kiliense 5 P. butyrii 2 Phialophora butyrii 1 A. kiliense 4 Phialophora sp 4 A. kiliense 3 Chaetomium globosum A. kiliense 2 Acremonium kiliense 1
80

圆 Pinus elliottii

圆 Eucalyptus grandis

Figura 19 - Valores médios da perda de massa (\%) de corpos-de-prova de madeira $E$. grandis e $P$. elliottii causada por fungos de podridão mole. 
a) os isolados (4) de Acremonium sp., (2) e (10) de Acremonium kiliense, (1) de Gliocladium sp., (3) e (4) de Phialophora butyrii e (10) de Trichoderma sp. não diferiram significativamente entre si, quando comparados seus desempenhos nas madeiras de $E$. grandis e de $P$. elliottii; para todos os outros fungos isolados, inclusive o fungo referência $C$. globosum, foi observada diferença significativa entre as madeiras testadas, sendo que o E. grandis apresentou maiores valores de perda de massa (\%) indicando sua maior susceptibilidade;

b) para a madeira de $E$. grandis, apenas os isolados (1) e (2) de A. kiliense não diferiram significativamente do fungo C. globosum; todos os outros fungos isolados diferiram do fungo referência e apresentaram menor capacidade de degradação da madeira;

c) para a madeira de $P$. elliottii, os isolados (1) e (2) de $A$. kiliense diferiram significativamente do C. globosum apresentando uma maior capacidade de degradação da madeira; os isolados (10) de A. kiliense, (4) de Phialophora sp. e (2) de $P$. butyrii não diferiram do $C$. globosum; entretanto, todos os demais fungos isolados diferiram do fungo referência e apresentaram uma menor capacidade de degradação da madeira; 
d) os isolados (1) e (2) de $A$. kiliense não diferiram significativamente entre si, para as madeiras de $E$. grandis e de $P$. elliottii, entretanto, diferiram de todos os outros fungos de podridão mole testados em ambas as madeiras, apresentando os maiores valores de perda de massa (\%).

Analisando os resultados obtidos, ilustrados pela Figura 19, nota-se que a madeira de $E$. grandis mostrou-se mais susceptível ao apodrecimento causado pelos fungos de podridão mole do que a de $P$. elliottii. Estes resultados coincidem com os estudos de Savory (1954), Duncan (1960), Courtois (1963), Eaton \& Jones (1971a) e Nilsson (1973) que, em condições laboratoriais, verificaram a menor resistência da madeira de folhosas em relação a de coníferas aos fungos de podridão mole.

Atualmente, a hipótese formulada por Butcher \& Nilsson (1982) é a mais aceita para explicar a susceptibilidade de madeiras ao ataque de fungos de podridão mole, e propõe que:

i) espécies de madeira com baixos teores de lignina são mais susceptíveis ao ataque de fungos de podridão mole porque as microfibrilas de celulose na parede celular estariam disponíveis para a degradação enzimática;

ii) espécies de madeira com altos teores de lignina têm uma maior resistência natural a fungos de podridão mole porque as microfibrilas de celulose estariam protegidas da atividade das enzimas pela incrustação de lignina na parede celular; 
iii) espécies de madeira que contêm ligninas ricas em grupos guaiacil (como a das coníferas) são mais resistentes à podridão mole do que as que contêm ligninas ricas em grupos siringil (como a das folhosas).

Segundo Nilsson (1982), as madeiras de coníferas possuem, normalmente, um maior teor de lignina do que a das folhosas. A lignina representaria, portanto, uma barreira física e, possivelmente química, à decomposição das microfibrilas de celulose. A hipótese da lignina se baseia na correlação negativa existente entre a susceptibilidade ao ataque de fungos de podridão mole e o teor de lignina da madeira.

Entretanto, para explicar a alta susceptibilidade à podridão mole de madeiras de folhosas ricas em lignina, Butcher \& Nilsson (1982) postularam que a natureza das ligninas (grupos guaiacil e siringil) seria responsável. Posteriormente, Daniel \& Nilsson (1987) demonstraram que a natureza da lignina na parede celular dos diferentes elementos anatômicos de Betula verrucosa interferiram na sua resistência natural à podridão mole: quanto mais rica a parede celular dos elementos anatômicos em lignina do grupo guaiacil maior sua resistência e quanto mais rica em grupo siringil menor a resistência aos fungos de podridão mole.

Savory (1954), ao estudar o ataque de C. globosum em madeira de Fagus sp., observou que as cavidades de podridão mole ocorriam preferencialmente na camada $S_{2}$ da parede secundária em detrimento da camada $S_{1}$ que seria mais lignificada, sugerindo que, inicialmente, o ataque do 
fungo foi inversamente proporcional à quantidade de lignina na parede celular. Por outro lado, Courtois (1963) e Morrel \& Zabel (1987) demonstraram que a deslignificação parcial de madeiras alterou o grau e a natureza dos danos produzidos por fungos de podridão mole, confirmando que as ligninas possuem um papel importante na resistência à deterioração da madeira.

Quanto às espécies de fungos de podridão mole, pode-se afirmar que os isolados (1) e (2) de A. kiliense possuem potencial para serem utilizados em ensaios laboratoriais com culturas puras na avaliação da resistência natural de madeiras de coniferas e de folhosas, sendo comparáveis com o fungo referência $C$. globosum e demais fungos isolados. $O$ fungo $C$. globosum foi considerado por Duncan (1965) como a espécie mais agressiva em ensaios com madeiras de folhosas e Bravery (1975) afirmou que este fungo têm sido aceito para os testes de madeira de folhosas, embora sua relevância prática seria incerta. Portanto, considera-se interessante aprofundar o nível taxonômico destas culturas - variedade, forma etc. - além de estudar mais detalhes da sua forma de ataque na madeira.

Os fungos de podridão mole que demonstraram uma pequena capacidade de degradação nas madeiras de $E$. grandis e $P$. elliotii podem ser sugeridos para estudos da resistência natural de madeiras, utilizando-se métodos que considerem a interação de diferentes espécies de fungos no processo de deterioração.

Com relação aos valores de perda de massa para os fungos de podridão mole, ocorreram variações na habilidade de degradação da madeira em isolados pertencentes a uma mesma espécie (Figura 19). Esta variabilidade também foi detectada por Knox (1977) em fungos de podridão 
mole isolados de solo. A existência de diferenças de comportamento entre linhagens de fungos de uma mesma espécie, devido à variações genéticas, é amplamente reconhecida pela microbiologia. 


\section{CONCLUSÕES}

Os resultados do presente estudo permitiram concluir que:

1) as condições ambientais da torre de resfriamento favoreceram o desenvolvimento de fungos na madeira de Tabebuia sp., sendo deteriorada por fungos de podridão mole, de forma generalizada, no eliminador de respingos e no enchimento da célula GB-978;

2) o ataque de fungos de podridão mole em madeira de Tabebuia sp. foi mais intenso nos níveis inferiores da torre, sendo detectado nos niveis superiores somente por meio da análise da estrutura anatômica microscópica da madeira;

3) sob microscopia, o ataque na madeira de Tabebuia sp. foi identificado como podridão mole tipo 1 , restringindo-se às células das fibras do lenho;

4) existem indicações de que a micota dentro de uma torre de resfriamento pode variar quanto à ocorrência de espécies e frequência de isolamento, de acordo com o local amostrado - região de neblina e de respingos; 
5) no isolamento, observou-se uma predominância dos fungos imperfeitos (Subdivisão Deuteromycotina), sendo mais freqüentes os dos gêneros Acremonium, Phialophora e Trichoderma;

6) dos fungos isolados da madeira de Tabebuia sp., nem todos causaram sintomas de podridão mole nas madeiras de Eucalyptus grandis e de Pinus elliottii, apesar de algumas espécies, como Trichoderma spp., serem reconhecidamente celulolíticas;

7) os fungos Acremonium sp., Acremonium kiliense, Phialophora sp. e Phialophora butyrii foram freqüentemente isolados da madeira de Tabebuia sp. e são comprovadamente causadores de podridão mole, constituindo-se em importantes organismos deterioradores na torre de resfriamento;

8) a madeira de E. grandis, em comparação com a de $P$. elliottii, é mais susceptivel ao ataque dos fungos de podridão mole isolados, corroborando resultados de pesquisas que comprovaram a susceptibilidade das madeiras de folhosas aos fungos de podridão mole em relação as de coníferas. 


\section{REFERÊNCIAS BIBLIOGRÁFICAS}

AMERICAN SOCIETY OF TESTING MATERIALS - ASTM. Accelerated laboratory test of natural decay resistance of woods. ASTM-D-2017, 1981.

AMERICAN TYPE CULTURE COLLECTION - ATCC. Catalogue of strains. $9^{a}$ ed. Rockville, Maryland, 1970. 243p.

AMERICAN WOOD PRESERVER'S ASSOCIATION - AWPA. Lumber, timber, bridge, ties and mine ties - preservatives treatment by pressure processes: AWPA C2 (96).

AMERICAN WOOD PRESERVER'S ASSOCIATION - AWPA. Lumber, timber and plywood for cooling towers-preservative treatment by pressure processes: AWPA C 30 (96).

AMERICAN WOOD PRESERVER'S ASSOCIATION - AWPA. Standard for coal tar creosote for land and fresh water and marine (coastal water use): AWPA P1/P13 (96).

BARNETT, H.L.; HUNTER, B.B. Illustrated genera of imperfect fungi. $4^{\text {a }}$ ed. Minneapolis: Burgess, 1987. 241p.

BARRON, G.L. The genera of Hyphomycetes from soil. 1a ed. Baltimore: Robert E. Kriegér Publishing Company, 1972. 364p.

BRAVERY, A. F. Microbiological assay of chemicals for the protection of wood. Building Research Establishment Current Paper 92/75. Garston, England: BRE. 1975. 13p. 
BRITO NETO, O.; FREITAS, A.R.; CAVALCANTE, M.S.; OLIVEIRA, I.A. Madeiras amazônicas para a produção de dormentes. Boletim ABPM, São Paulo, n. 12, março 1984.

BROWN, W. C. Fungus control in cooling towers. In: ANNUAL MEETING, 1964. Proceedings. New Orleans, Louisiana: COOLING TOWER INSTITUTE -CTI, 1964. (N TP64-06).

BUTCHER, J.A. The ecology of fungi infecting untreated sapwood of Pinus radiata. Canadian Journal of Botany, Canada, v. 46, p.1577-1589, 1968.

BUTCHER, J.A. Analysis of the fungal population in wood. In: WALTER, A.H. e HUECK-VAN DER PLAS, E.H. (ed). Biodeterioration of materials. London: Applied Science, 1972. v. 2, p.319-325.

BUTCHER, J.A.; NILSSON, T. Influence of variable lignin content amongst hardwood on soft-rot susceptibility and performance of CCA preservatives. In: ANNUAL MEETING, 13, 1982. Proceedings. Stockholm: The International Research Group on Wood Preservation - IRG, 1982. (IRGMP/1151).

CAVALCANTE, M.S. Dados sobre a durabilidade de 182 madeiras. Boletim ABPM, São Paulo, n. 2, set. 1983.

CAVALCANTE, M.S. Biodeterioration problems affecting wood in Brazil. In: INTERNATIONAL UNION OF FORESTRY RESEARCH ORGANIZATIONS - IUFRO - DIVISION 5 - SUBJECT GROUP 5.5 .03 WOOD PROTECTION, 1985. Guarujá, São Paulo. 23p. 
COOLING TOWER INSTITUTE-CTI. Report on the study of wood maintenance for water-cooling towers. CTI Bulletin WMS-104. U.S.A: CTI, 1959. 16p.

COOLING TOWER INSTITUTE - CTI. Wood maintenance for water-cooling towers. CTI Bulletin WMS-104. U.S.A.: CTI, 1963. 13p.

COURTOIS, V.H. Beitrag zur frage holzabbauender Ascomyceten und Fungi Imperfecti. Holzforschung, Berlin, v. 17, n. 6, p.176-183, 1963./resumo/

DANIEL, G.; NILSSON, T. Comparative studies on the distribution of lignin and CCA elements in birch using electron microscopic x-ray microanalysis. In: ANNUAL MEETING, 18, 1987. Proceedings. Stockholm: The International Research Group on Wood Preservation - IRG, 1987. (IRGNP/1328).

DOMSCH, K.H.; GAMS, W.; ANDERSON, T.H. Compendium of soil fungi. London: Academic Press, 1980. v. 1 e 2.

DREW PRODUTOS QUÍMICOS. Princípios de tratamento de águas industriais. São Paulo: Drew Produtos Químicos S.A., 1979. 331p.

DUNCAN, C.G. Soft rot in wood, and toxicity studies on causal fungi. In: $56^{\circ}$ ANNUAL MEETING OF THE AMERICAN WOOD PRESERVER'S ASSOCIATION, 1960. Proceedings. New York, NY: AWPA, 1960. v. 56, p.27-35.

DUNCAN, C.G. Determining resistance to soft-rot fungi. Research Paper FPL 48. Madison, Wisconsin: Forest Products Laboratory Forest Service - U.S. Department of Agriculture - USDA, 12p., 1965. 
DUNCAN, C. G.; ESLYN, W.E. Wood-decaying Ascomycetes and Fungi Imperfecti. Mycologia, v. 58, p.642-45, 1966.

EATON, R.A. Fungi growing on wood in water cooling towers. International Biodeterioration Bulletin, Birmingham, v. 8, n. 2, p. 39-48, 1972.

EATON, R.A.; HALE, M.D.C. Wood: decay, pests and protection. London : Chapman \& Hall, 1993 546p.

EATON, R.A.; IRVINE, J. Decay of untreated wood by cooling tower fungi. In: WALTER, A.H. e HUECK-VAN DER PLAS, E.H. (ed). Biodeterioration of materials. London: Applied Science, 1972. v. 2, p.192-200.

EATON, R.A.; JONES, E.B.G. The biodeterioration of timber in water cooling towers. I. Fungal ecology and the decay of wood at Connahs Quay and Ince. Material und Organismem, Berlin, V. 6, n.1, p.51-80, 1971a.

EATON, R.A.; JONES, E.B.G. The biodeterioration of timber in water cooling towers. II. Fungi growing on wood in different positions in a water cooling system. Material und Organismem, Berlin, V. 6, n. 2, p.81-92, $1971 \mathrm{~b}$.

ELLIS, M.B. Dematiaceous hyphomycetes. Kew, Surrey, England: CAB International Mycological Institute, 1971 608p.

ELLIS, M.B. More dematiaceous hyphomycetes. Kew, Surrey, England:

CAB - International Mycological Institute, 1976 507p. 
ERIKSSON, K.E.; WOOD, T.M. Biodegradation of cellulose. In: HIGUCHI, T (ed). Biosynthesis and biodegradation of wood components, 1a. ed. London: Academic Press INC., 1985. p.469-98.

FOSCO MUCCI, E.S.; LOPEZ, G.A.C.; MONTAGNA, R.G. Durabilidade natural de madeiras em contato com o solo IV. In: CONGRESSO NACIONAL SOBRE ESSÊNCIAS NATIVAS, 2., 1992, São Paulo. Anais. São Paulo: Instituto Florestal 1992.

GAMS, W. Cephalosporium-artige schimmelpilze (Hyphomycetes). Stuttgart: G. Fischer, 1971. 262p.

GOMES , J.I.; MELO, C.F.M. Durabilidade de madeiras amazônicas em contato com o solo. Boletim ABPM, São Paulo, n. 69, jan. 1991.

HUTTON, D.P.E. Preservative treatment of cooling tower lumber a state-of-the art report. In: ANNUAL MEETING, 1978. Proceedings. Houston, Texas: COOLING TOWER INSTITUTE -CTI, 1978. (No TP78-10).

INSTITUTO BRASILEIRO DE PETRÓLEO - IBP. Inspeção em equipamentos: inspeção em torres de resfriamento. Guia No. 10. Brasil, 1973. 16p.

INSTITUTO DE PESQUISAS TECNOLÓGICAS DO ESTADO DE SÃO PAULO - IPT. Identificação botânica de madeiras: Procedimento interno DPFLAIM-01, 1997.

KNOX, M.D.E. Occurrence and decay abilities of soft rot fungi from New Zealand soils. Material und Organismen, Berlin, v. 12, n. 1, p. 17-24, 1977. 
KOTCHETKOFF, P.A. Torres de resfriamento-uma ocorrência de apodrecimento em unidade construída com madeiras brasileiras. In: IV SEMINÁRIO - UTILIZADADES, INSTITUTO BRASILEIRO DO PETRÓLEO -IBP, 1967. Anais. p.7-14.

LEPAGE, E.S. Comparação da resistência natural de madeira através de ensaio de campo e de laboratório. Boletim ABPM, São Paulo, n. 6, nov. 1983.

LEPAGE, E.S.; LELIS, A.T.; MILANO, S. et al. Isolamento de fungos de madeira apodrecida. In: Métodos de ensaios e análises em preservação de madeiras. São Paulo: IPT. Publicação IPT no 1157, parte D8, 1980a.

LEPAGE, E.S.; LELIS, A.T.; MILANO, S. et al. Ensaio acelerado de laboratório para determinação da eficiência de preservativos contra fungos de podridão mole. In: Métodos de ensaios e análises em preservação de madeiras. São Paulo: IPT. Publicação IPT n 1157, parte D5, 1980b.

LEVY, M.P. Soft rot. In: $74^{\circ}$ ANNUAL MEETING OF THE AMERICAN WOOD PRESERVER'S ASSOCIATION, 1978. Proceedings. New York, NY: AWPA, 1978. v. 74, p.145-164.

LEVY J.F.; STEVENS M.G. The initiation of attack by soft rot fungi in wood. J. Institute of Wood Science, v. 16, p.49-55, 1966.

LINE, M.A.; CRUICKSHANK, R.H. Soft-rot fungi from cooper-chrome-arsenic treated hardwood transmission poles in Tasmania. International Biodeterioration Bulletin, Birmingham, v. 15, n. 4, p.113-118, 1979. 
MAINIERI, C. Madeiras denominadas caixeta. Publicação IPT No. 572, São Paulo: Instituto de Pesquisas Tecnológicas do Estado de São Paulo S.A. IPT, 28p., 1958.

MAINIERI, C.; CHIMELO, J.P. Fichas de caracteristicas das madeiras brasileiras. São Paulo: Instituto de Pesquisas Tecnológicas do Estado de São Paulo S.A. - IPT, 419p., 1989.

MORREL,J.J.; SMITH, S.M. Fungi colonising redwood in cooling towers: identities and effects on wood properties. Wood and Fiber Science, USA, v. 20, n. 2, p. $243-49,1988$.

MORREL, J.J.; ZABEL, R.A. Partial delignification of wood: its effect on the action of soft rot fungi isolated from preservative-treated southern pines. Material und Organismen, Berlin, v. 22, n. 3, p.215-224, 1987.

MOUZOURAS, R. Soft rot decay of wood by marine microfungi. J. Institute of Wood Science, v. 11, n. 5, p.193-210, 1989.

NATARAJAN, K. e UDAIYAN, K. Cooling tower fungi in India. International Biodeterioratin Bulletin, Birmingham, v.14, n.3, p.85-87, 1978.

NELSON, P.E.; TOUSSON, T.A.; MARAJAS, W.F.O. Fusarium species. An illustrated manual for identification. The Pennsylvania State University Press, University Park and London, 1983. 193p. 
NEVES, F.C.M.; BRAZOLIN, S.; MONTEIRO, M.B.B. Inspeção dos internos de uma torre de resfriamento. In: I SEMINÁRIO LATINO-AMERICANO DE INSPEÇÃO DE EQUIPAMENTOS E XVII SEMINÁRIO BRASILEIRO DE INSPEÇÃO DE EQUIPAMENTOS, Rio de Janeiro: Instituto Brasileiro de Petróleo - IBP, 1989. 17p.

NILSSON, T. Studies on wood degradation and cellulolytic of microfungi. Studia Forestalia Suecica No. 104. Stockholm, Sweden: Royal College of Forestry, 41p., 1973.

NILSSON, T. Comments on soft rot attack in timbers treated with CCA preservatives: a document for discussion. In: ANNUAL MEETING, 13, 1982. Proceedings. Stockholm: The International Research Group on Wood Preservation - IRG, 1982. (IRGMP/1167).

NILSSON, T. Defining fungal decay types - final proposal. In: ANNUAL MEETING, 19, 1988, Madri, Spain. Proceedings. Stockholm: The International Research Group on Wood Preservation - IRG, 1988. (IRGMP/1355).

OLIVEIRA, A.M.F.; LELIS, A.T.; LEPAGE, E.S. et al. Agentes destruidores da madeira. In: LEPAGE, E.S. (coord.). Manual de preservação de madeiras. São Paulo: IPT, 1986. v. 1, p.101-130.

PRICE, E.A.S. Correlating laboratory and field tests on the behaviour of a wood preservative towards. Wood, United Kindom, v. 22, n. 5, p.193-6; 1957. 
PUCKORIUS, R.P. Cooling tower wood decay identification, current incidence and control methods. In: ANNUAL MEETING, 1984. Proceedings. Houston, Texas: COOLING TOWER INSTITUTE CTI, 1984. ( $\mathrm{N}^{\circ} \mathrm{TP84}-10$ ).

PUCKORIUS, R.P. Cooling tower wood decay preliminary survey results and conclusions. In: ANNUAL MEETING, 1985. Proceedings. New Orleans,

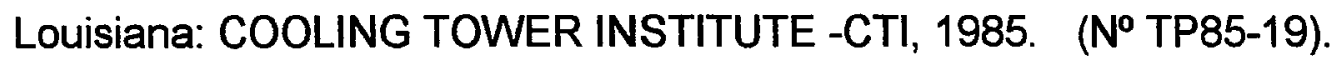

RECORD, S.J.; HESS, R.W. Timbers of the world. New Haven Yale University Press, 1943.

RIFAI, M.A. A revision of the genus Trichoderma. Mycological papers, $n$. 116, 56p., 1969.

SAVORY, J.G. Breakdown of timber by Ascomycetes and fungi imperfecti. Annual Applied Biology, v. 41, n. 2, p.336-47, 1954.

SINGH, A.P.; HEDLEY, D.R.; PAGE, C.S. et al. Microbial degradation of CCAtreated cooling tower timbers. IAWA Bulletin, New Zealand, v. 13, n. 2, p.215-231, 1992.

STATSOFTT INCORPORATION. Programa Statistica for windows: programa estatístico para análise de dados (software). Tulsa, OK: StatSoftt, Inc., 1995.

TOWSEND, R.F. A western utility's experience with treated wood. In: $60^{\circ}$ ANNUAL MEETING OF THE AMERICAN WOOD PRESERVER'S ASSOCIATION, 1964. Proceedings. San Francisco, California: AWPA, 1960. v. 60, p.13-19. 
UDAIYAN, K; MANIAN, S. Fungal deteriogens from preservative treated service timber packing in water cooling towers. International Biodeterioration \& Biodegradation, England, v. 27, p.275-279, 1990.

UDAIYAN, K; MANIAN, S. Fungi colonising wood in the cooling tower water system at the Madras Fertilizer Company, Madras, India. International Biodeterioration \& Biodegradation, England, v. 27, n. 4, p.351-371, 1991.

WILCOX, W.W. Degradation in relation to wood structure. In: NICHOLAS, D.D (ed.). Wood deterioration and its prevention by preservative treatments - Degradation and protection of wood, 1a. ed. Syracuse, New york: Syracuse University Press, 1973. v.1, p.107-148 


\section{APÊNDICE 1}

Tabelas dos resultados do ensaio acelerado de podridão mole

Valores de perda de massa (\%) dos corpo-de-prova de Eucalyptus grandis e Pinus elliottii submetidos aos 52 fungos isolados e ao fungo referência Chaetomium globosum. 


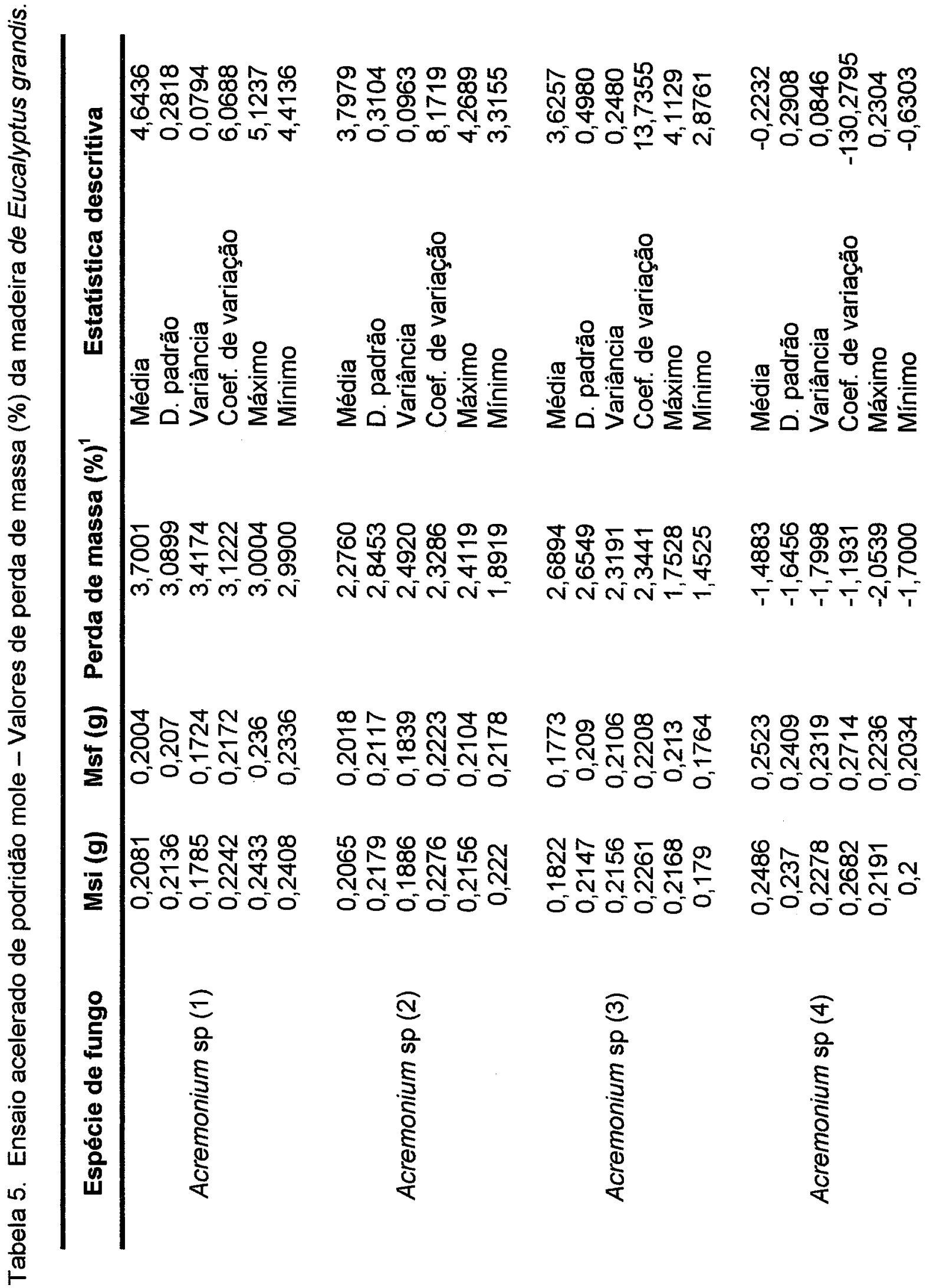




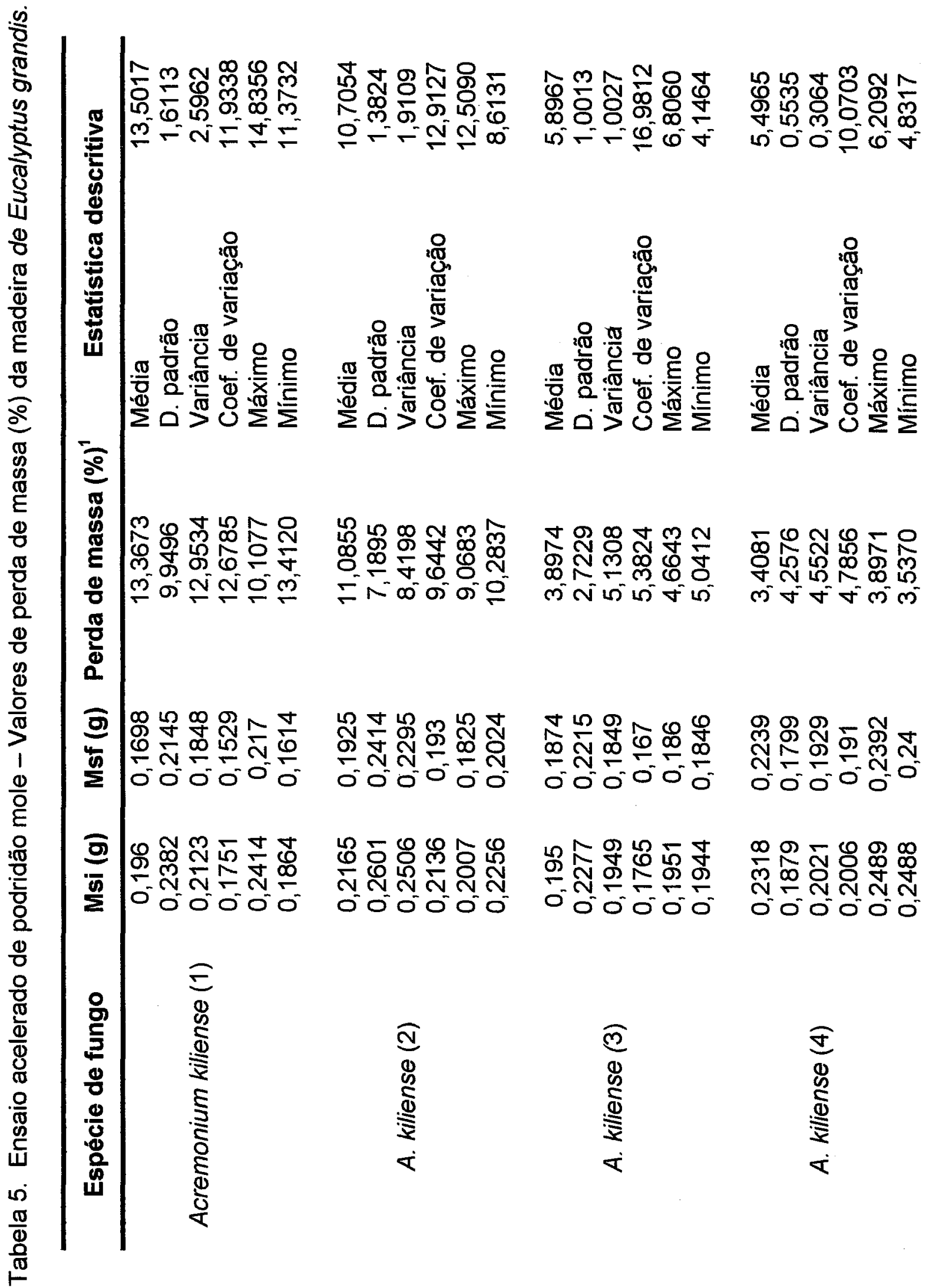




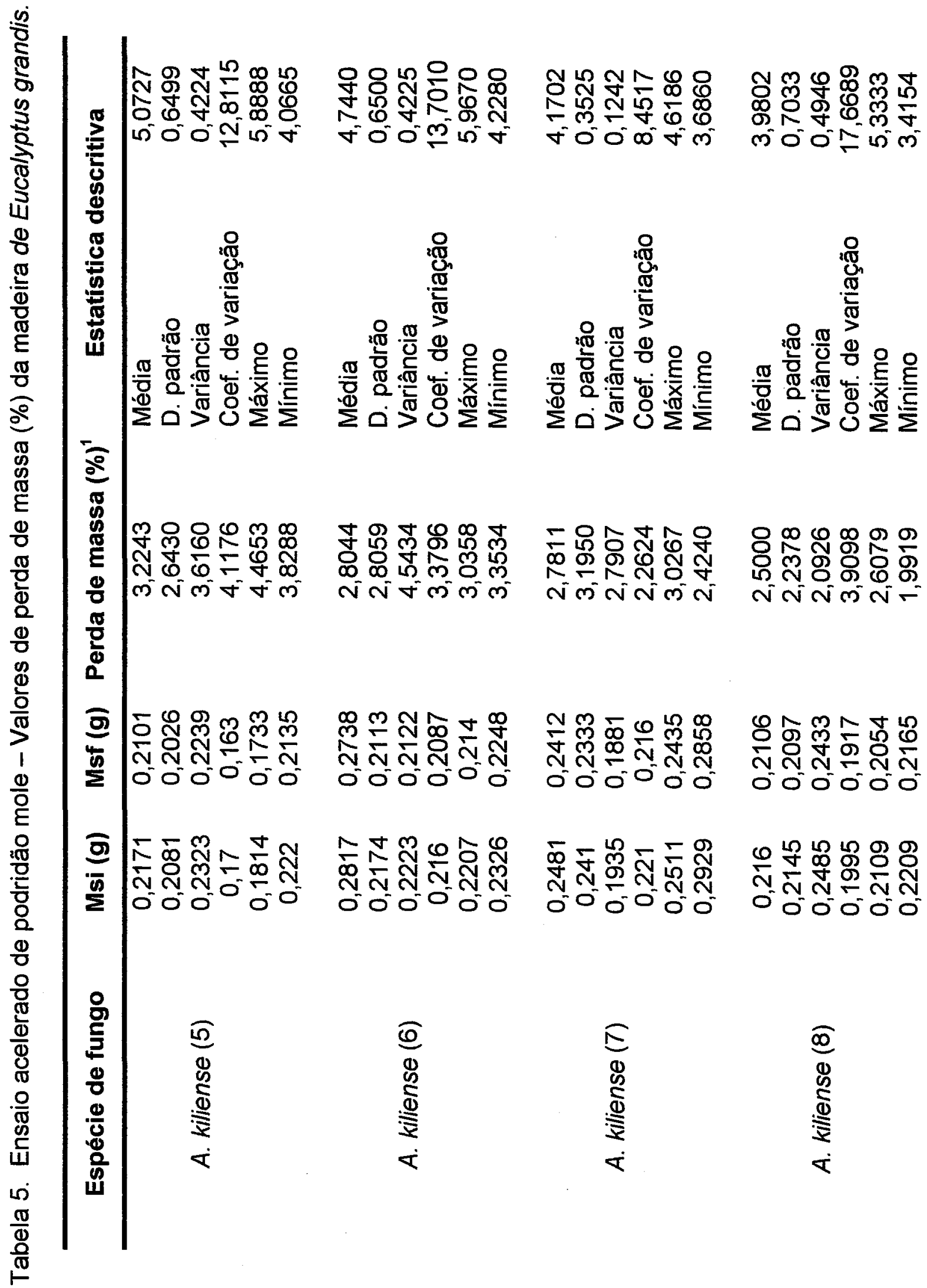




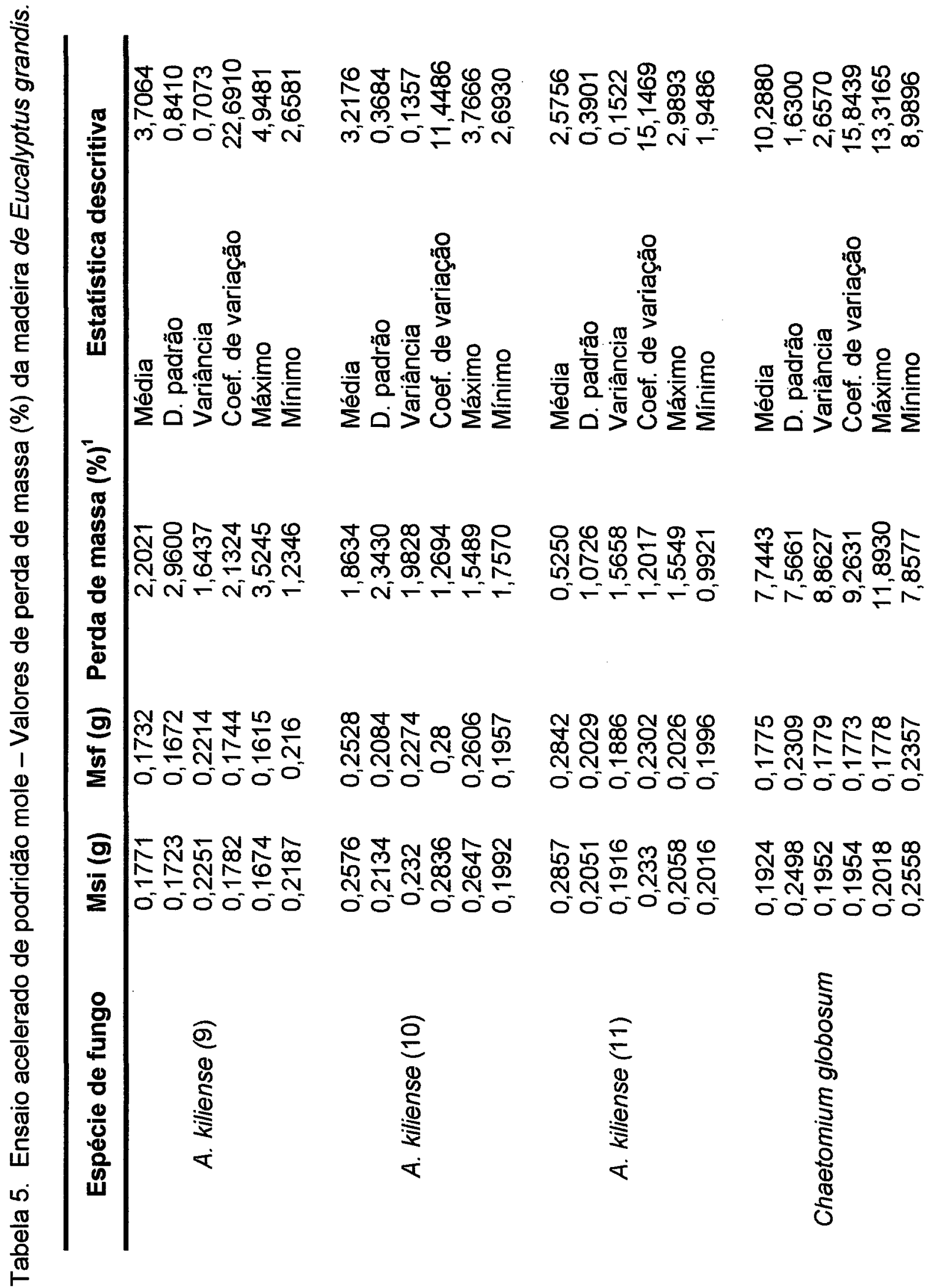




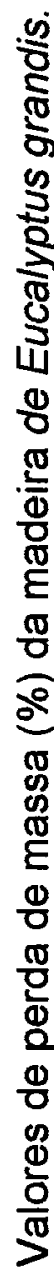

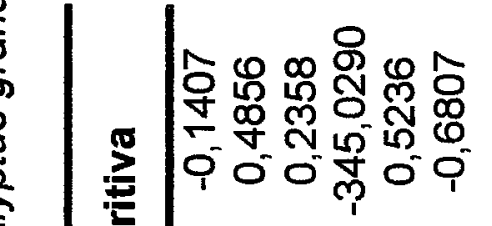

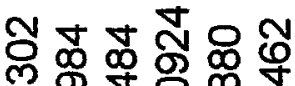

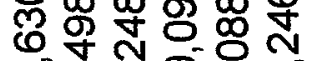

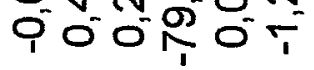

শิ

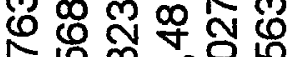

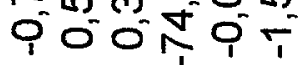

๘

ㅅํㅇํำ พิ

テ

$\frac{\pi}{0}$

a

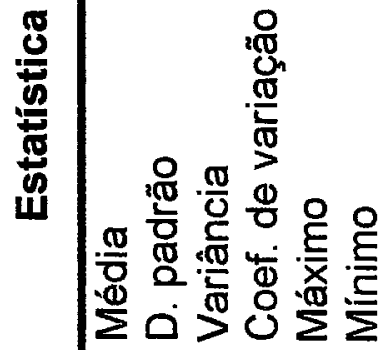

0

खृ

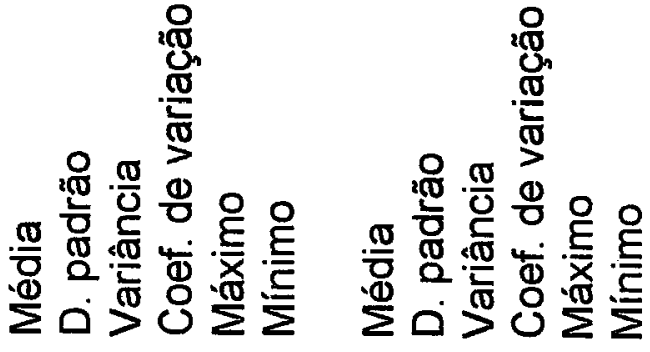

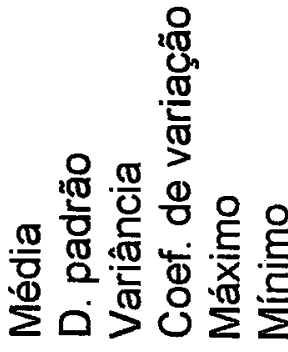

区ั

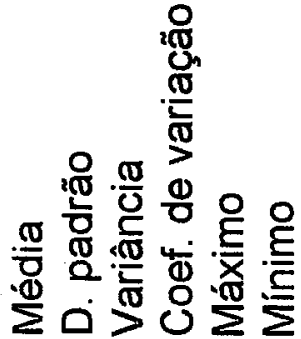

g.

$\frac{1}{0}$

号

욤

은

응

웅

8

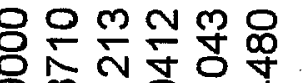
危

๙ัฒ ๙

ํํㅇํํํํำ

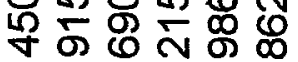

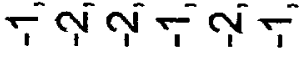

ז

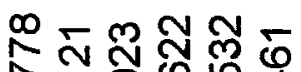

Nํำ

우 $\div, \div$,

Q

อี 균ำ 는

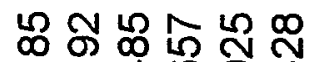

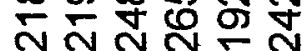

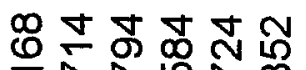

NNMn

サ용

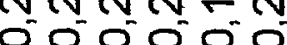

กิ

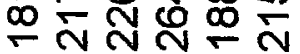

00000

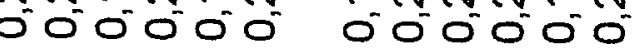

ஹ

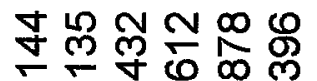

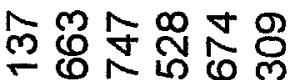

N $N$ N

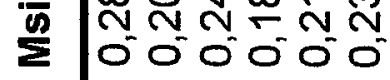

กำ

00000

$\infty$ ๘

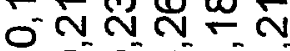

\%०000 00000

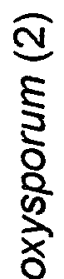

4
लำ

4

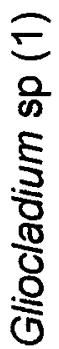




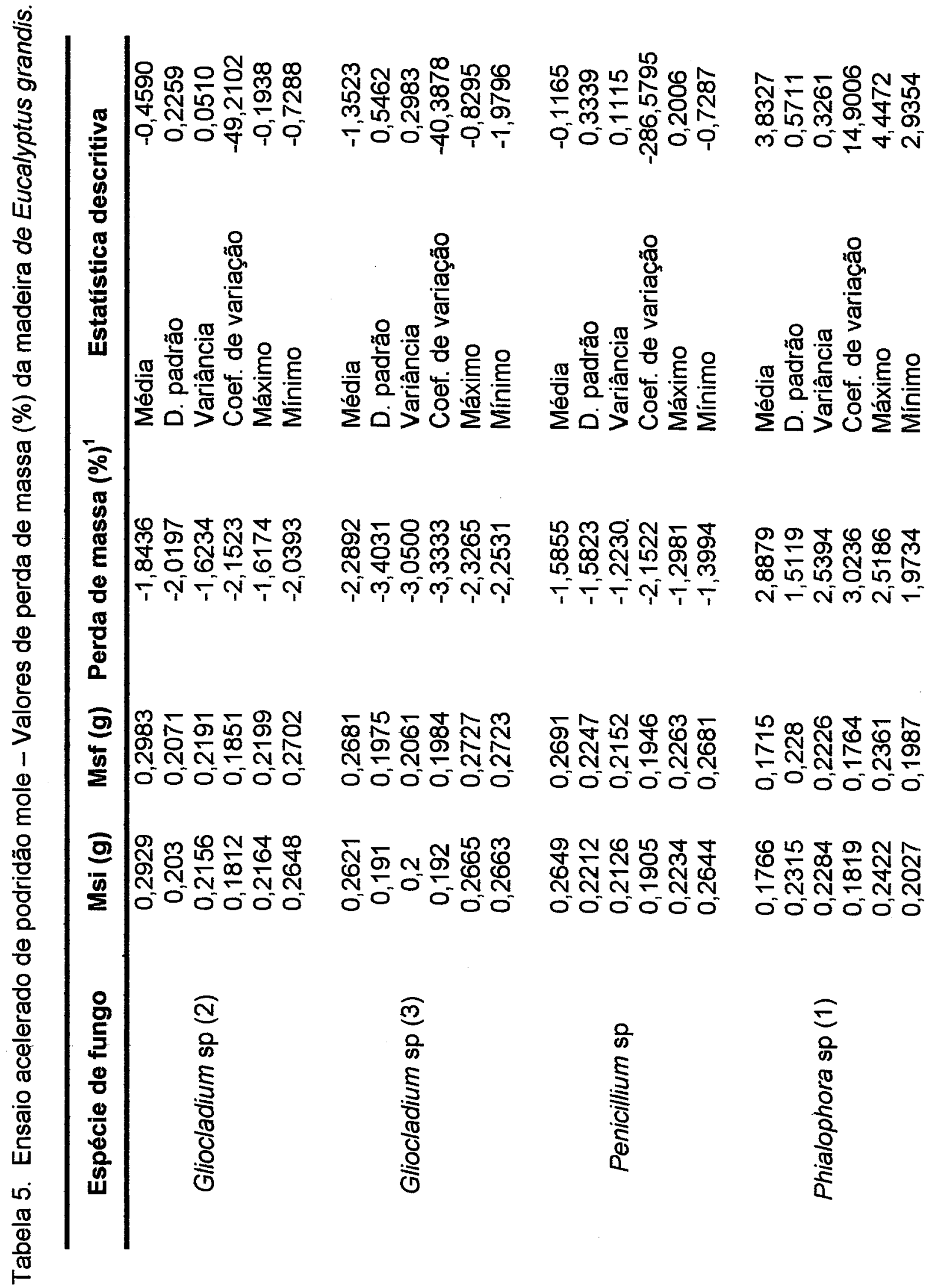




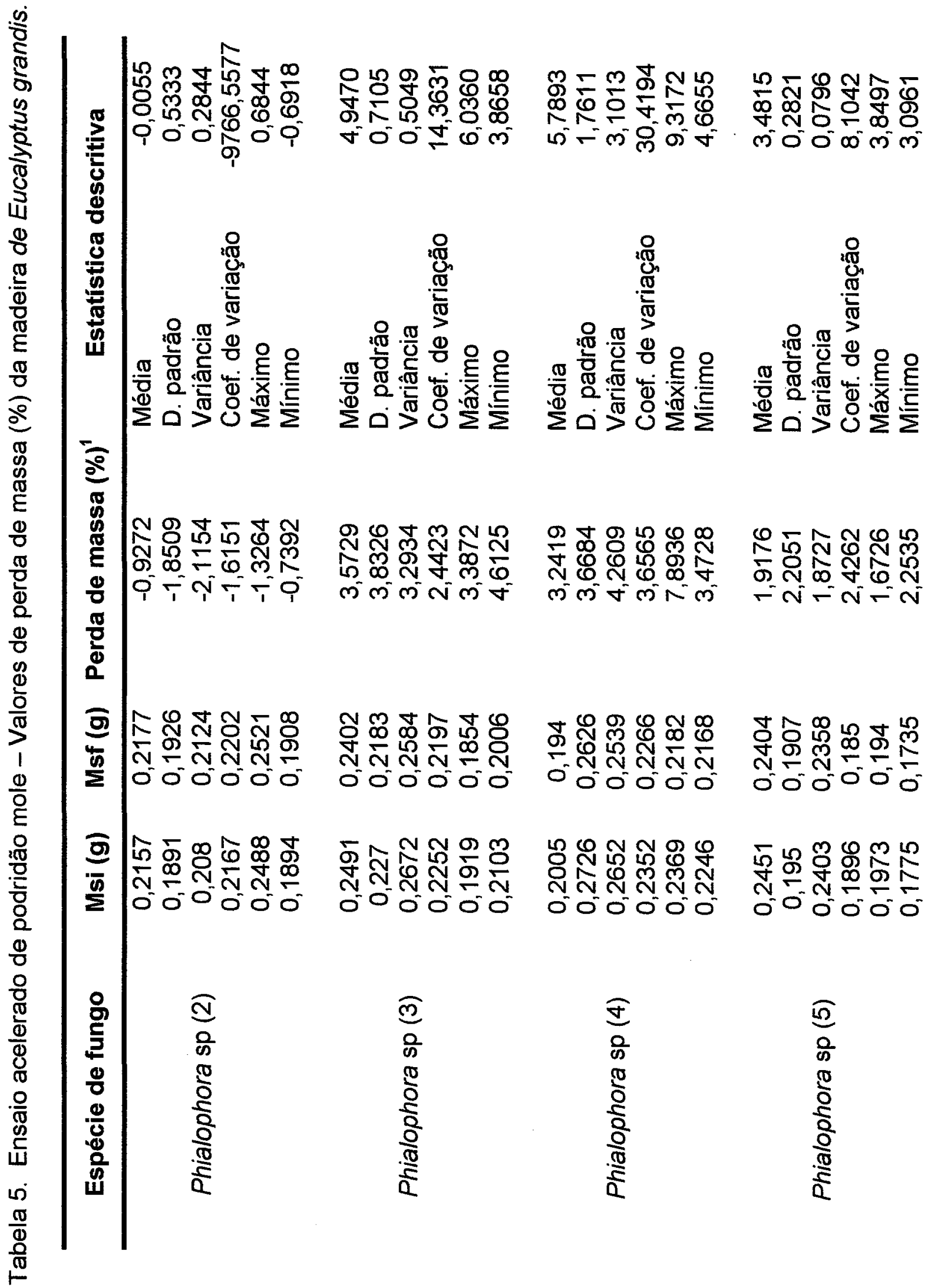




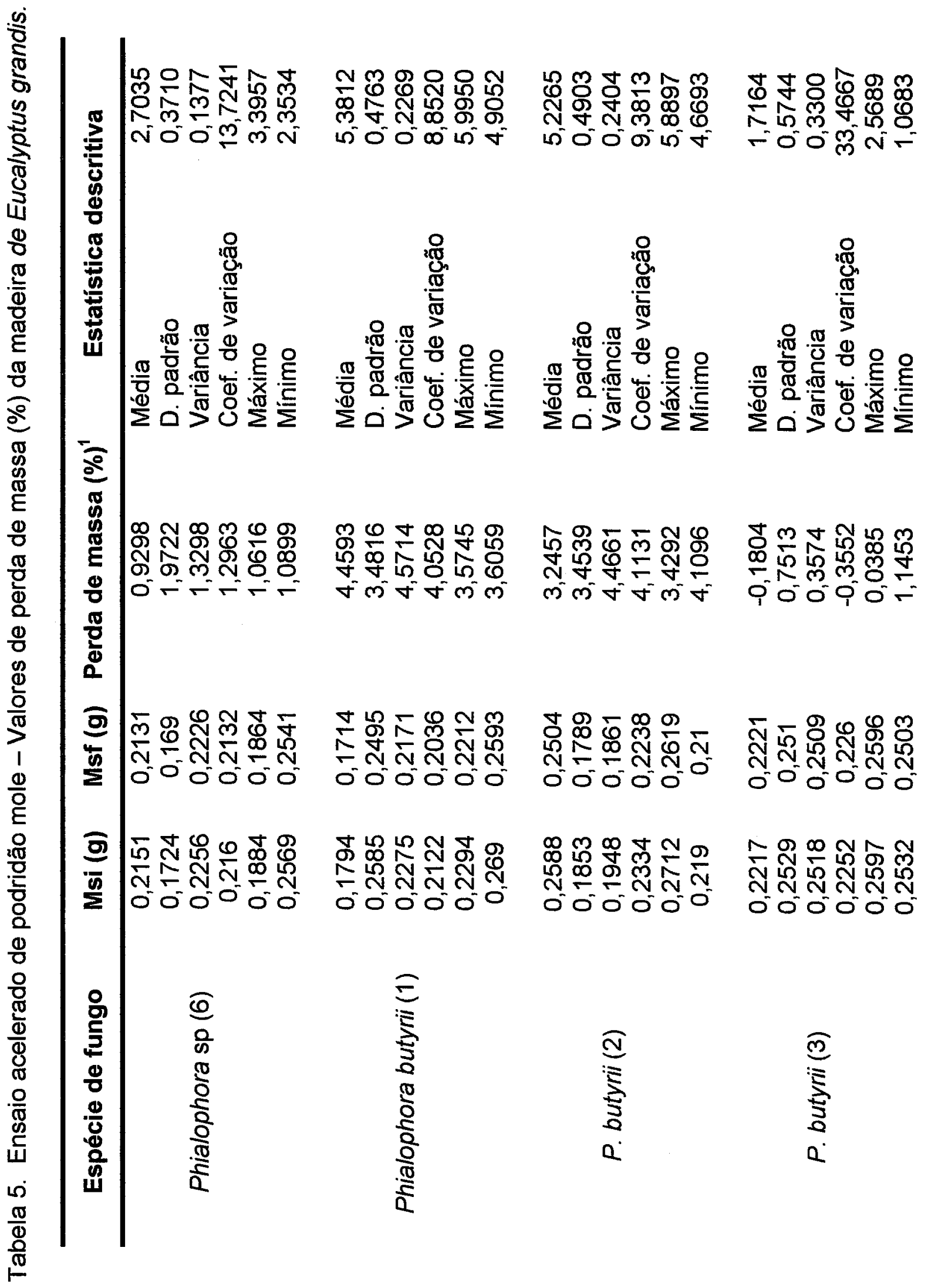




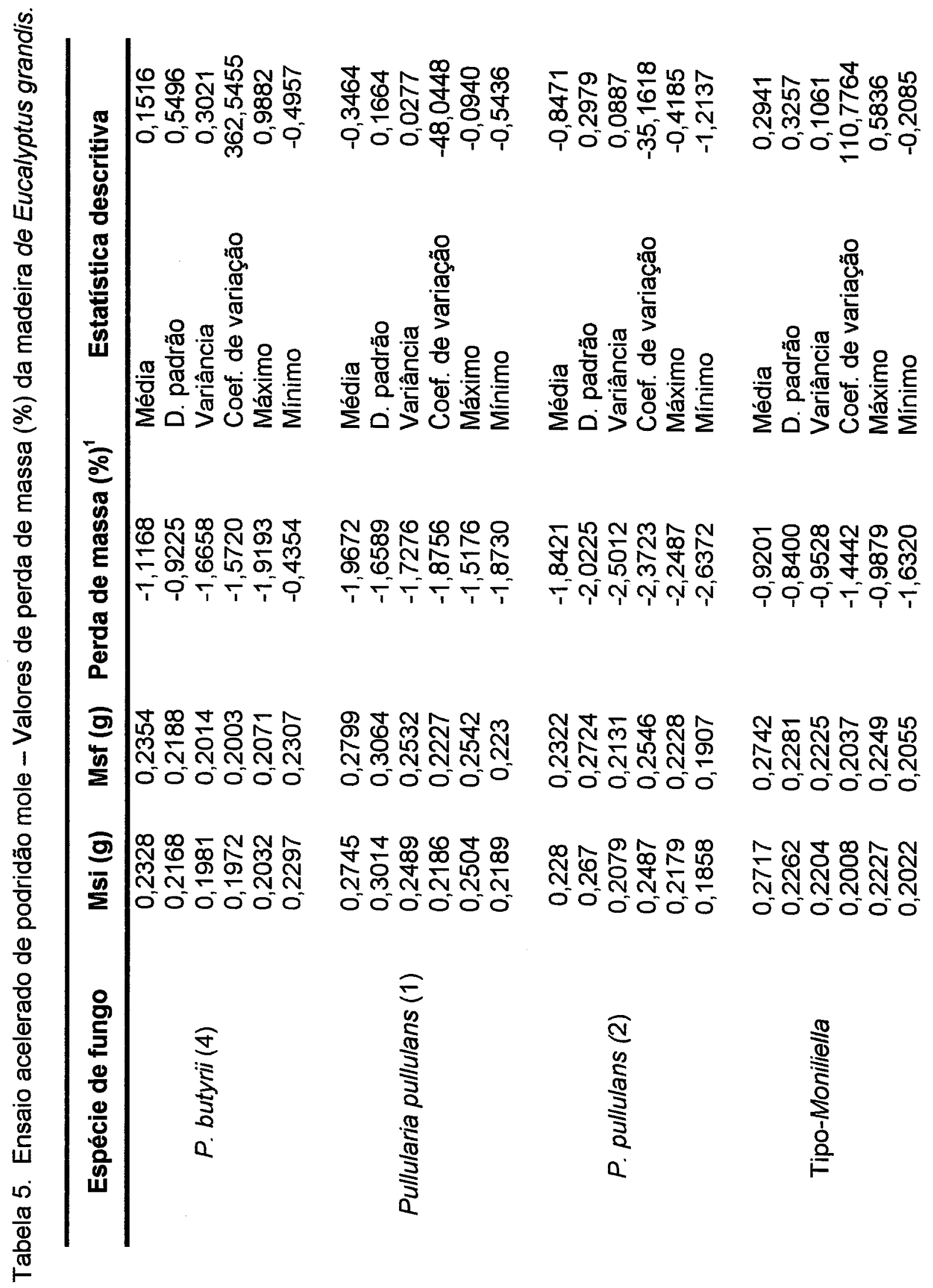




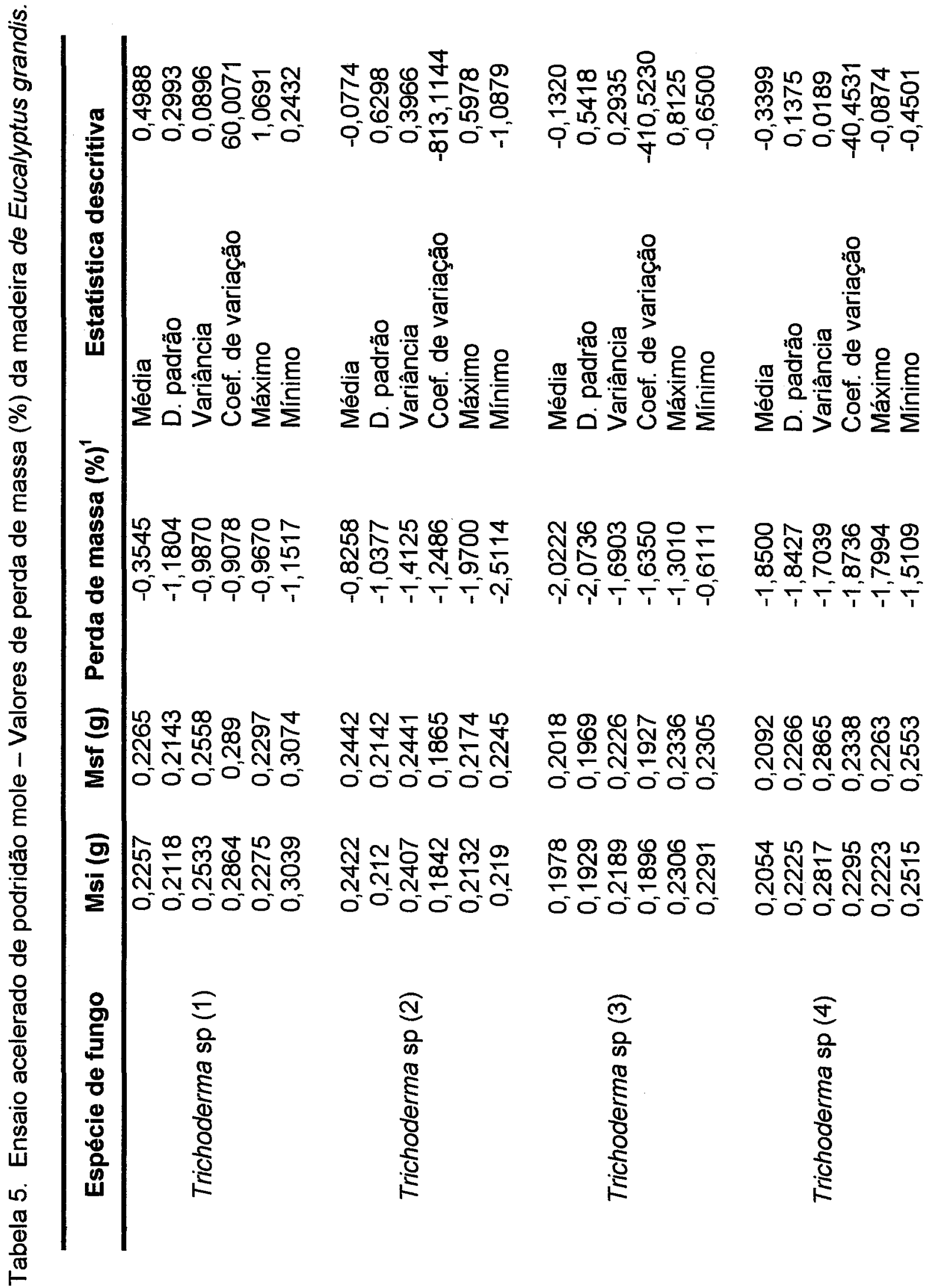


$\frac{5}{\frac{2}{0}}$

8

.

$\sqrt{0}$

要

ํ유유요 ติ חN N

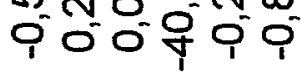

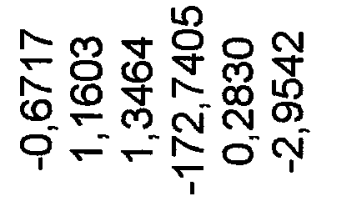

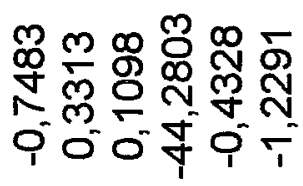

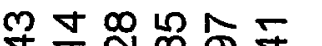

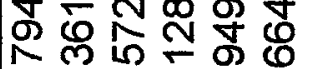

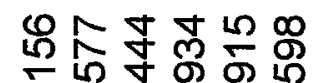
ले \&

๓๐용ำ

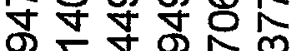

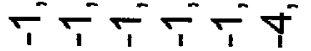

ฟัษ์

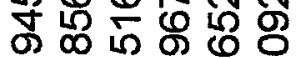

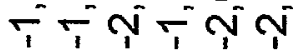

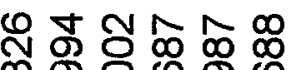
궁유 웡

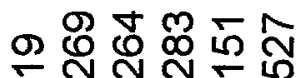
ธNNNNNㄴN

웅요용 8 ํํำ ํํำ 00000

뉴요 సิ융ำ 00000

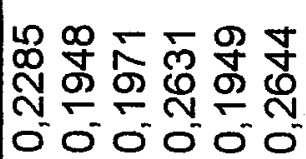

เกิ พิ้

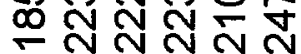

员舟穴守

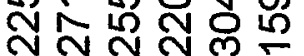
000000 ○0 0000

牙安品的

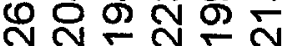
00000

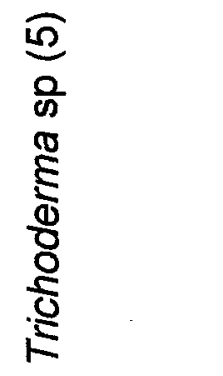

อ

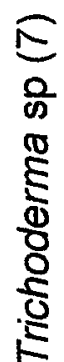

0
0
0
0
$\frac{0}{8}$
$\frac{8}{8}$
$\frac{0}{0}$
$\frac{1}{5}$ 


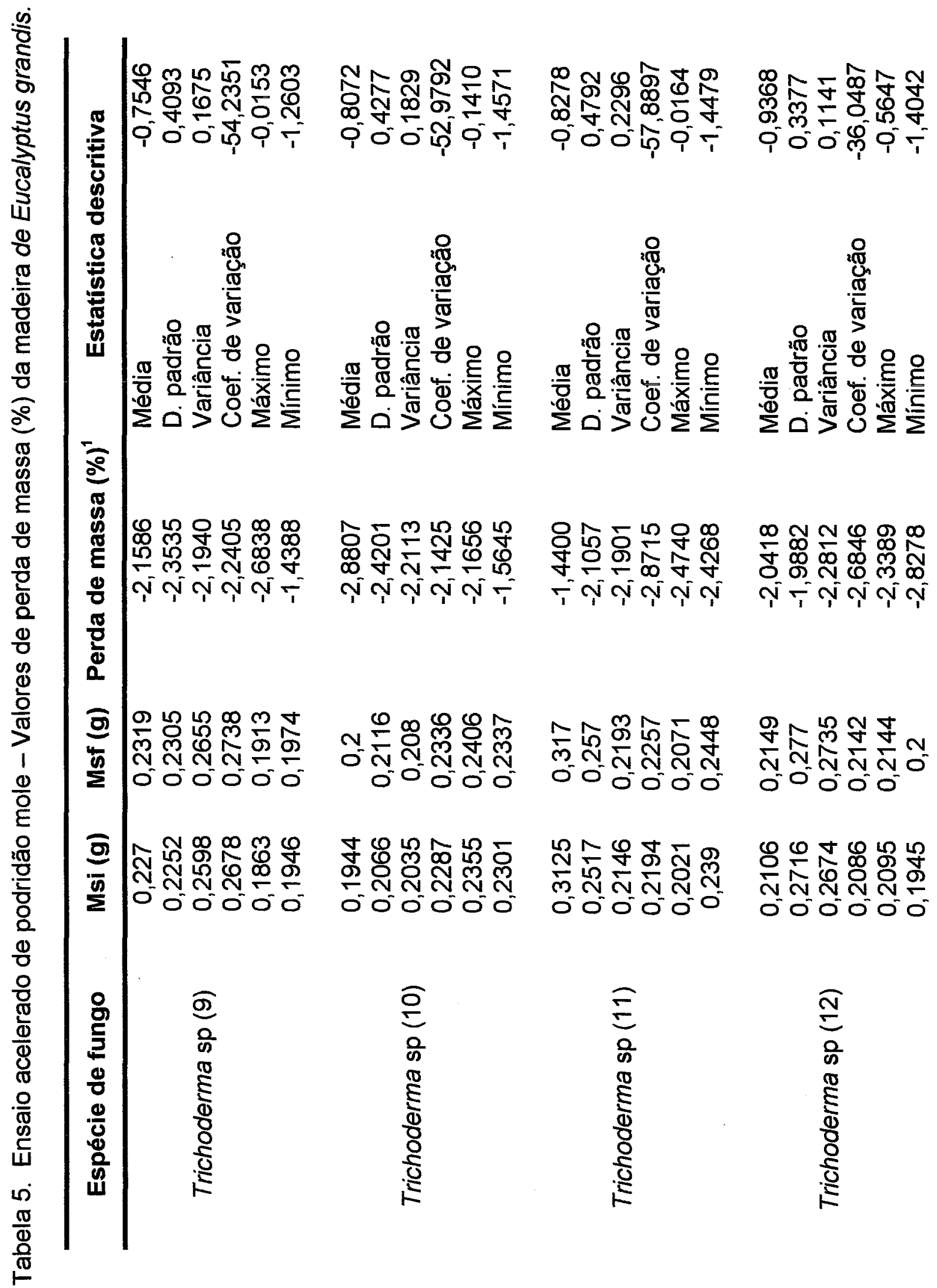




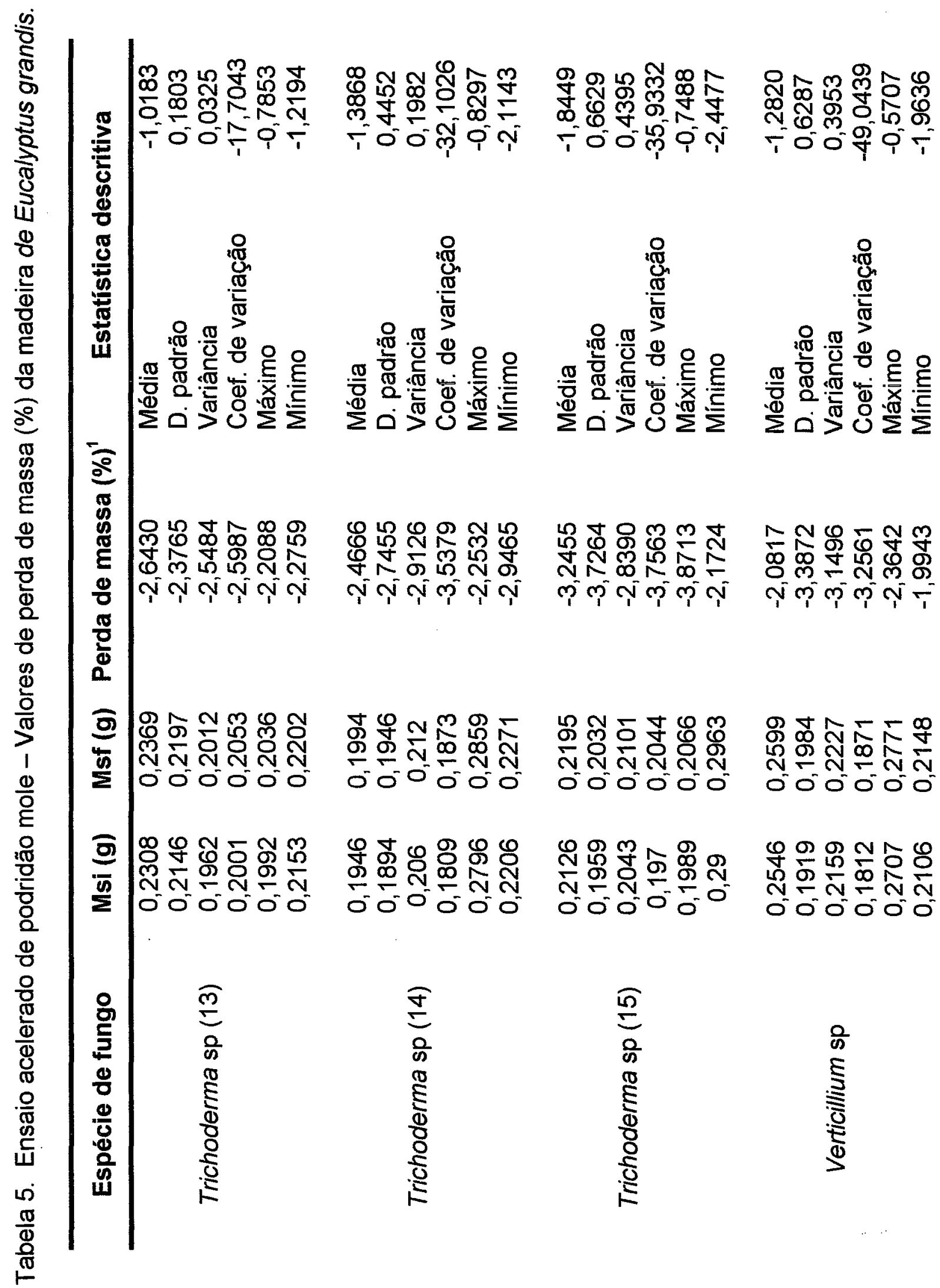




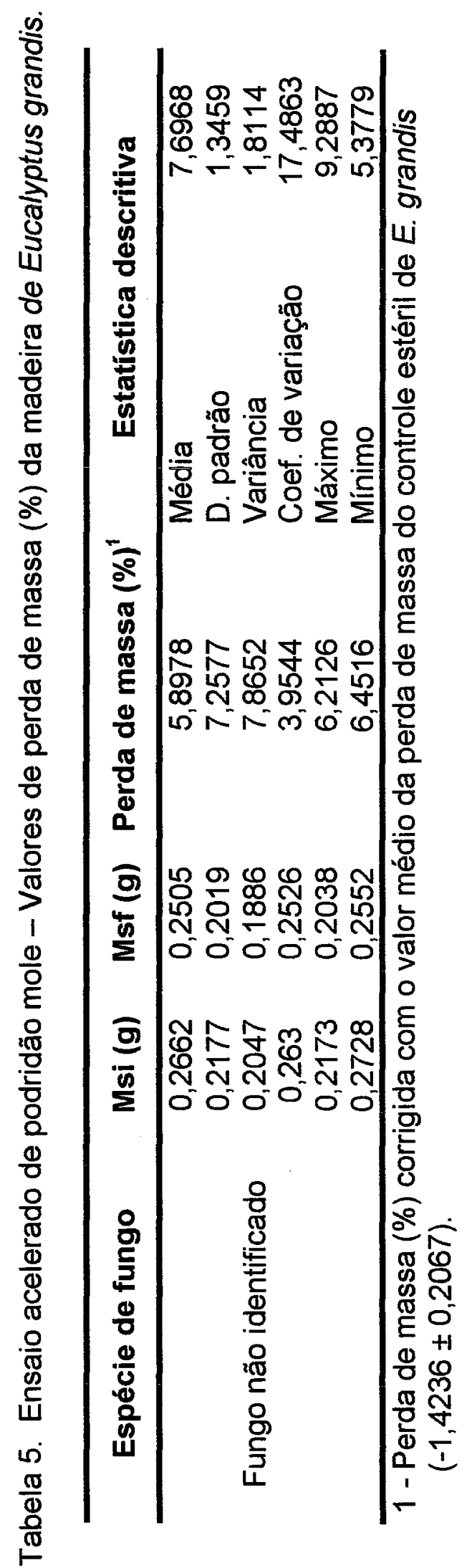




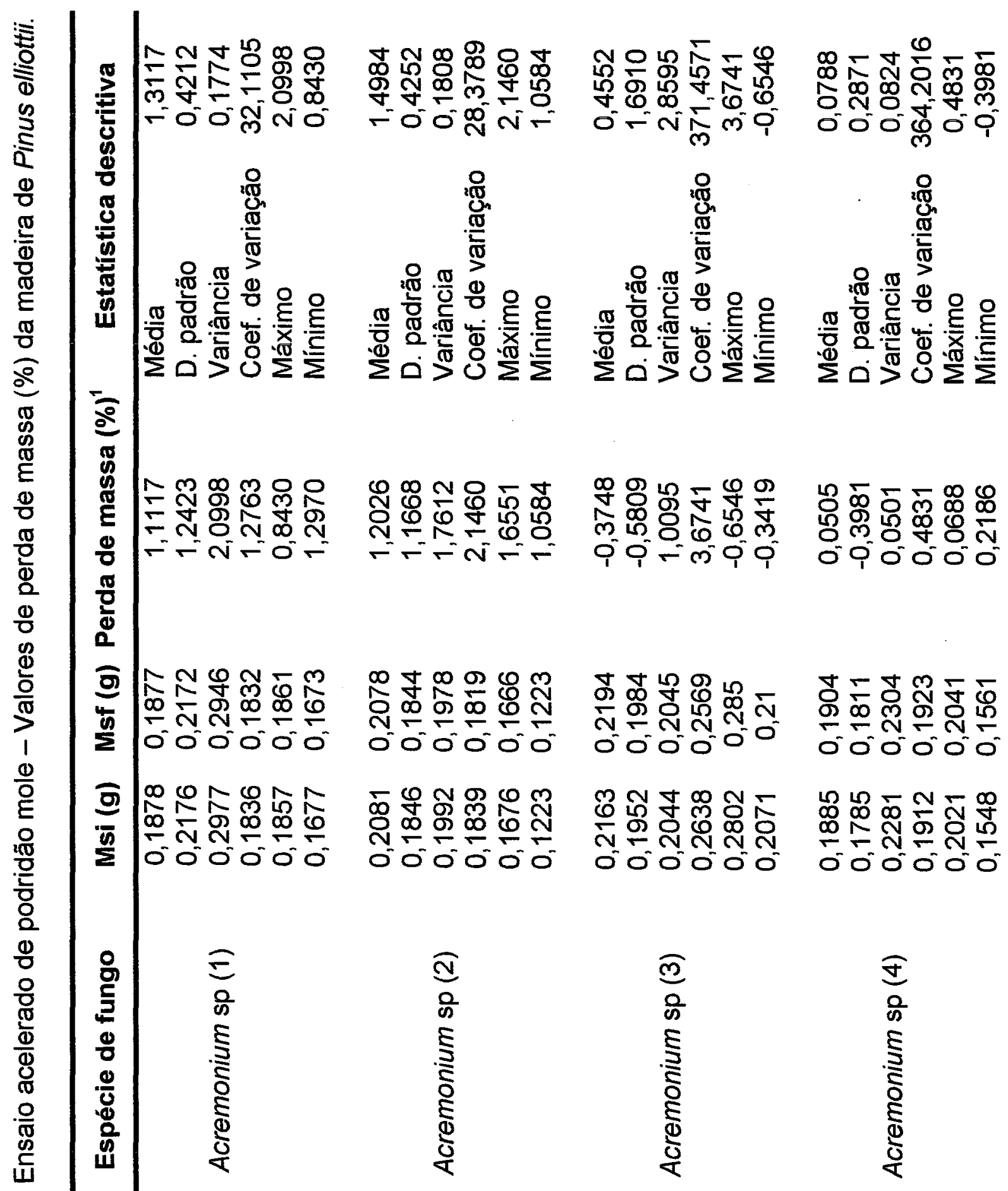




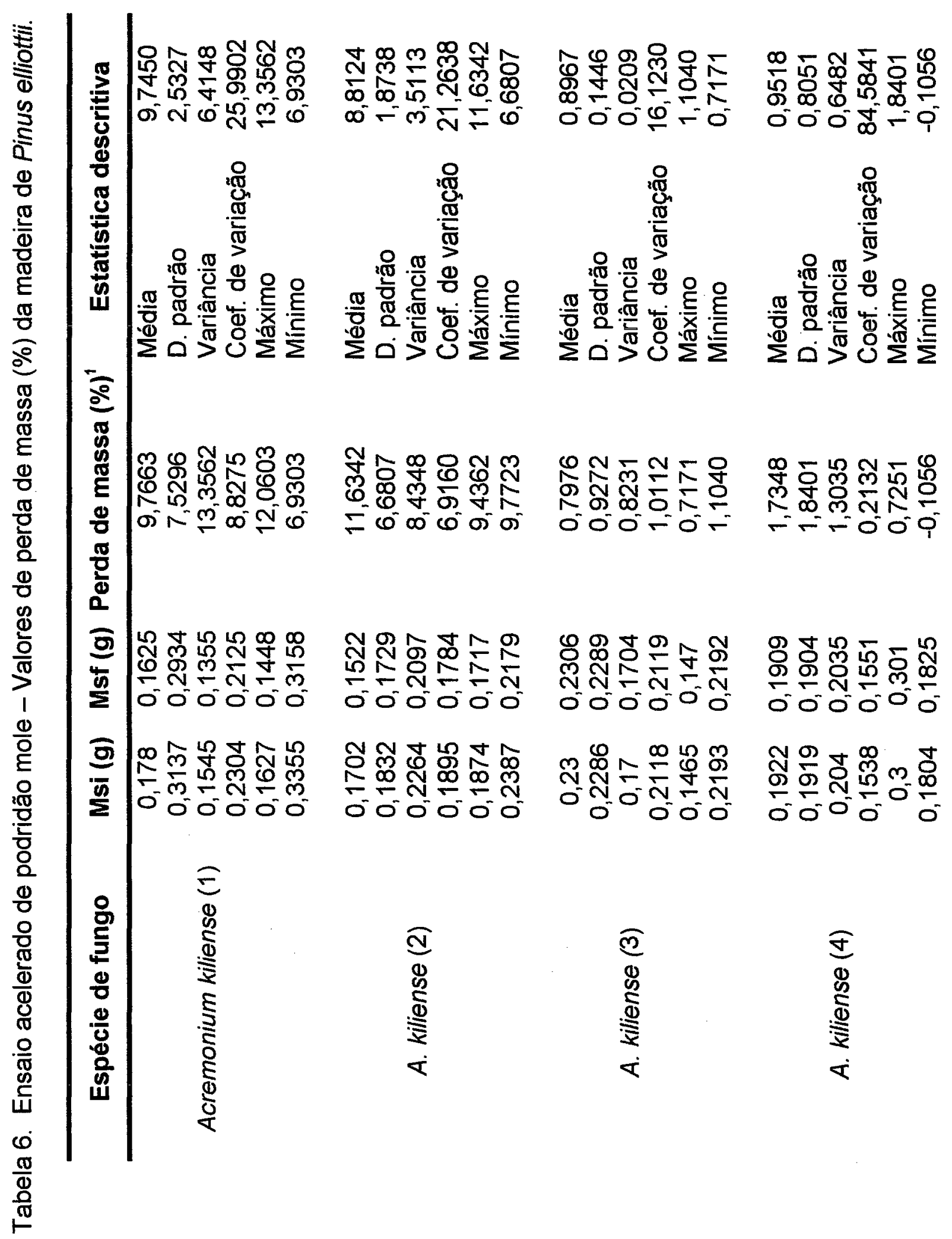




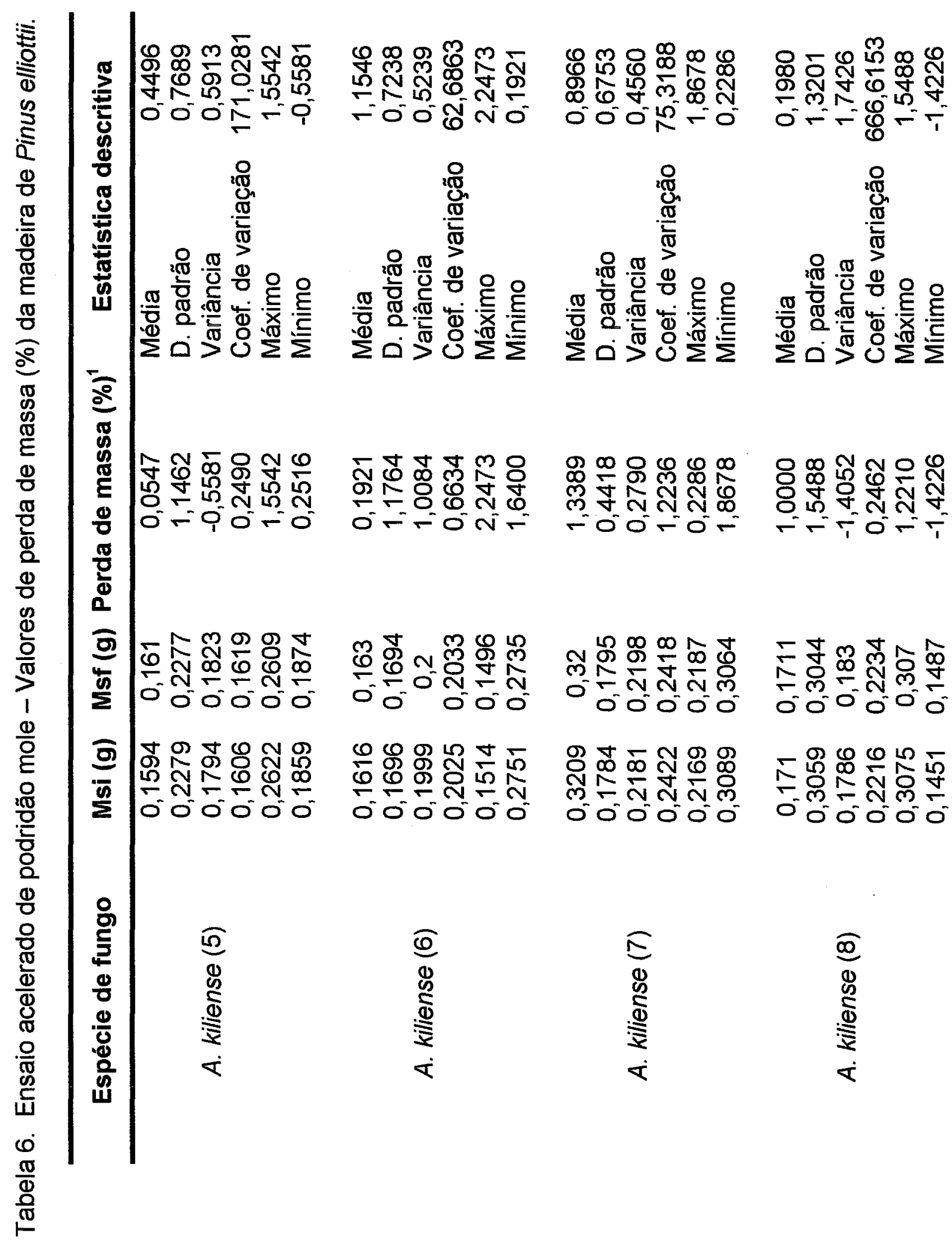




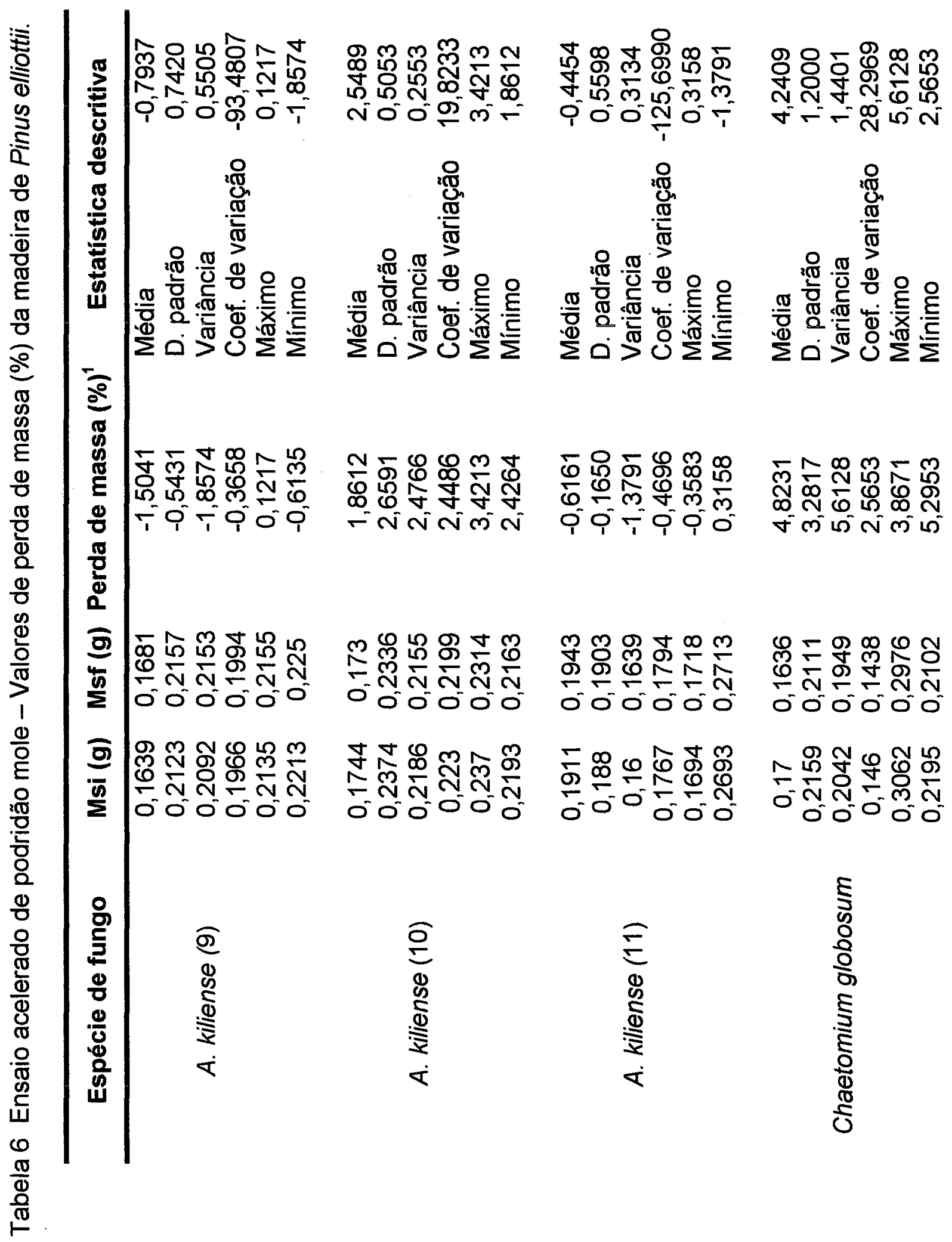




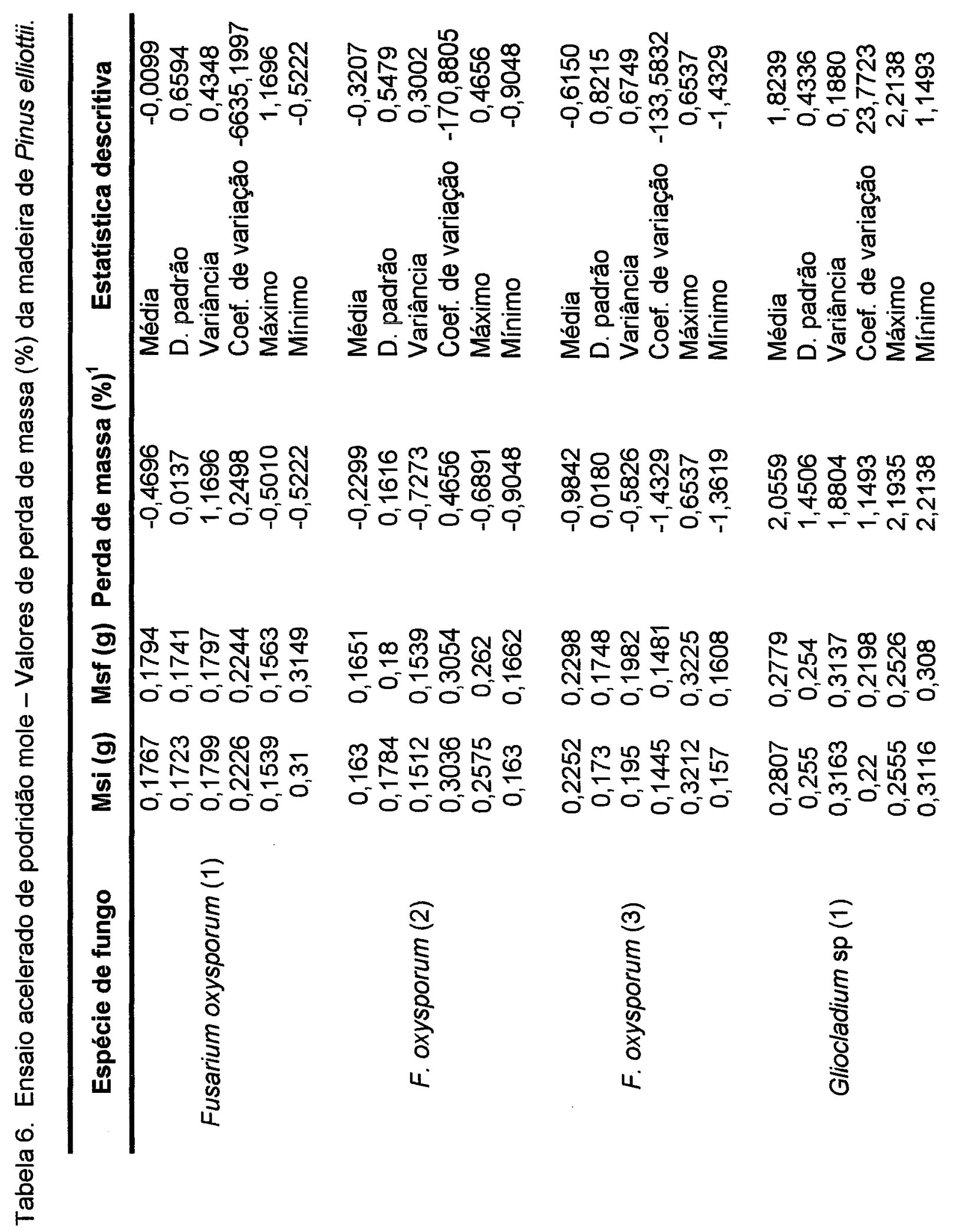




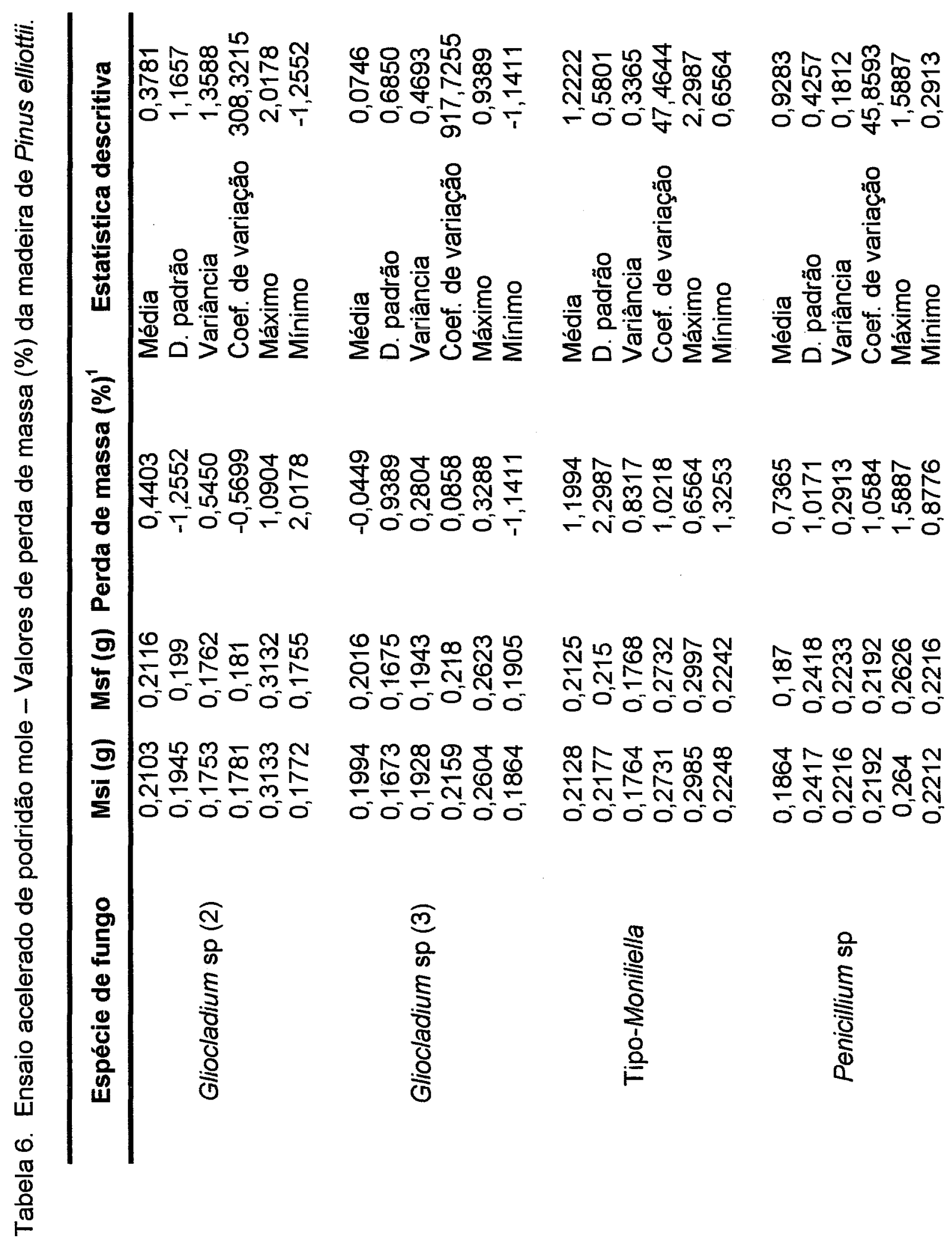




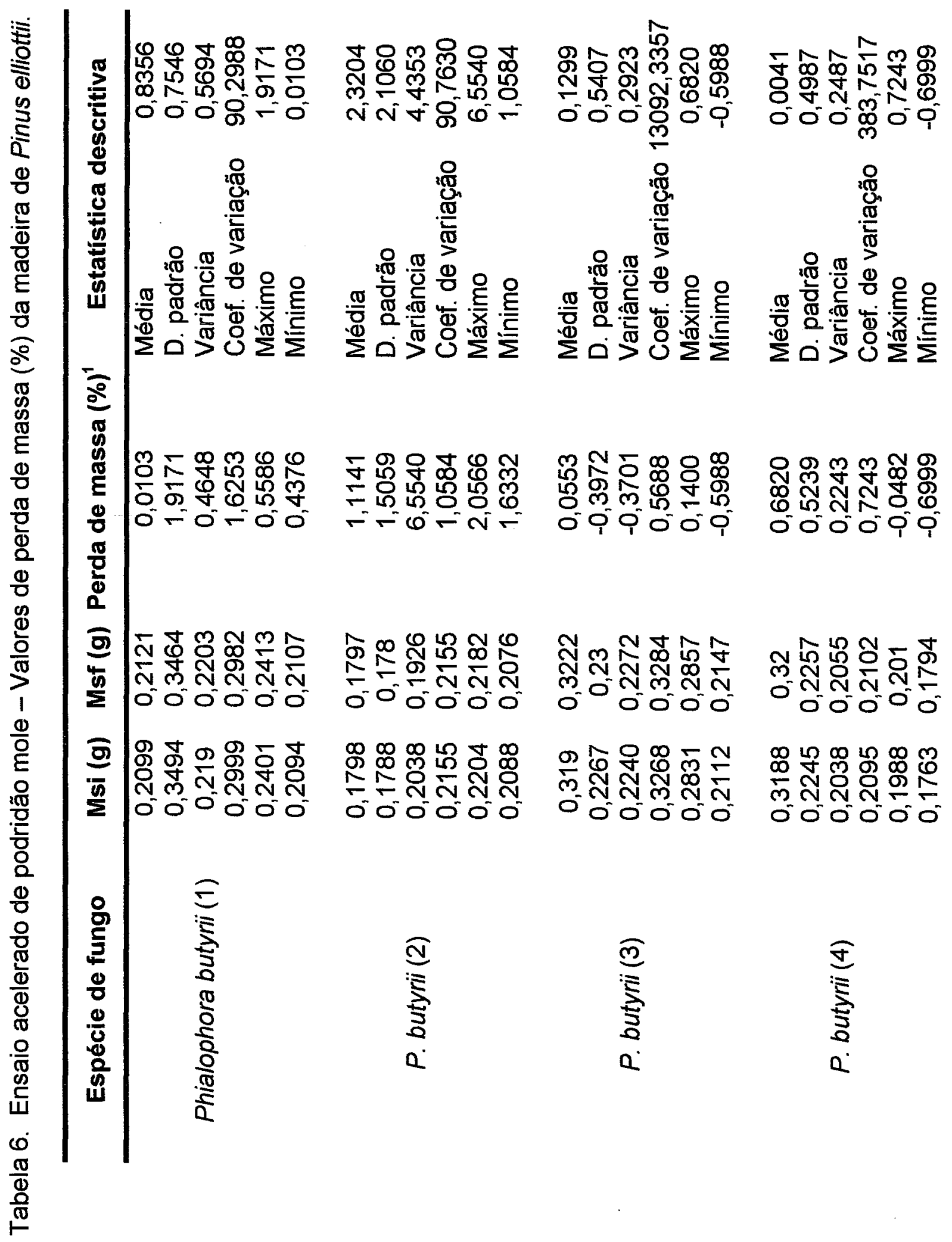




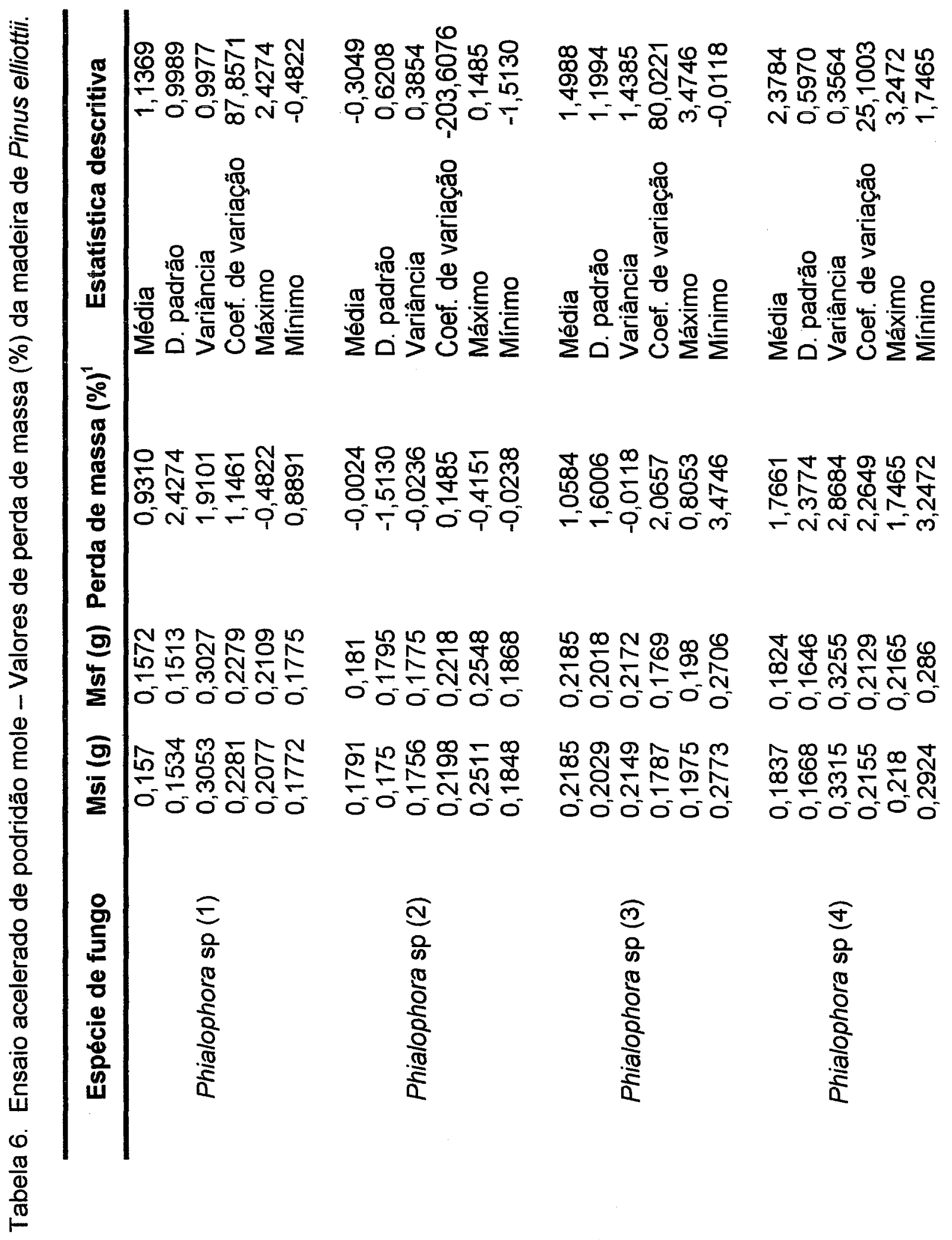




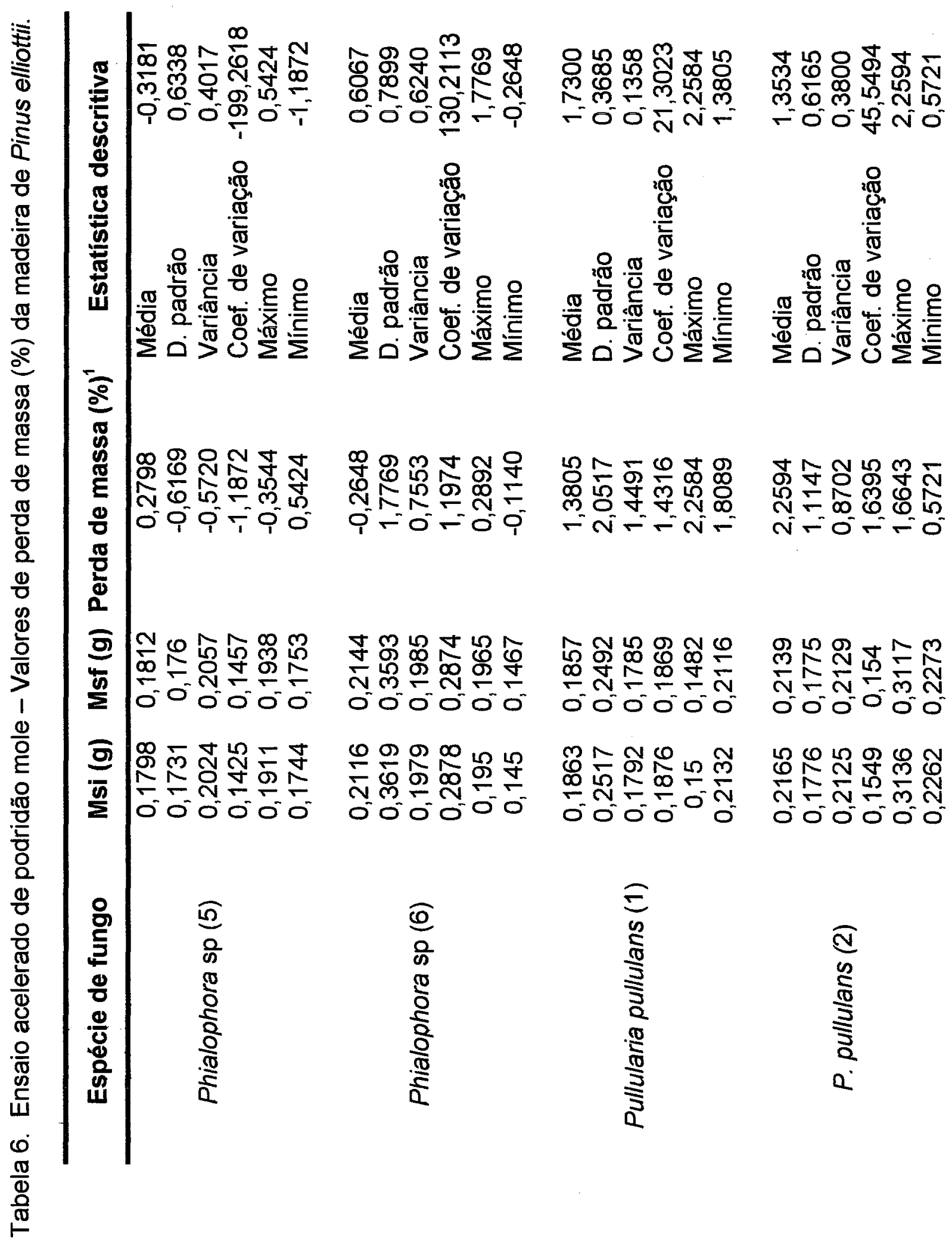




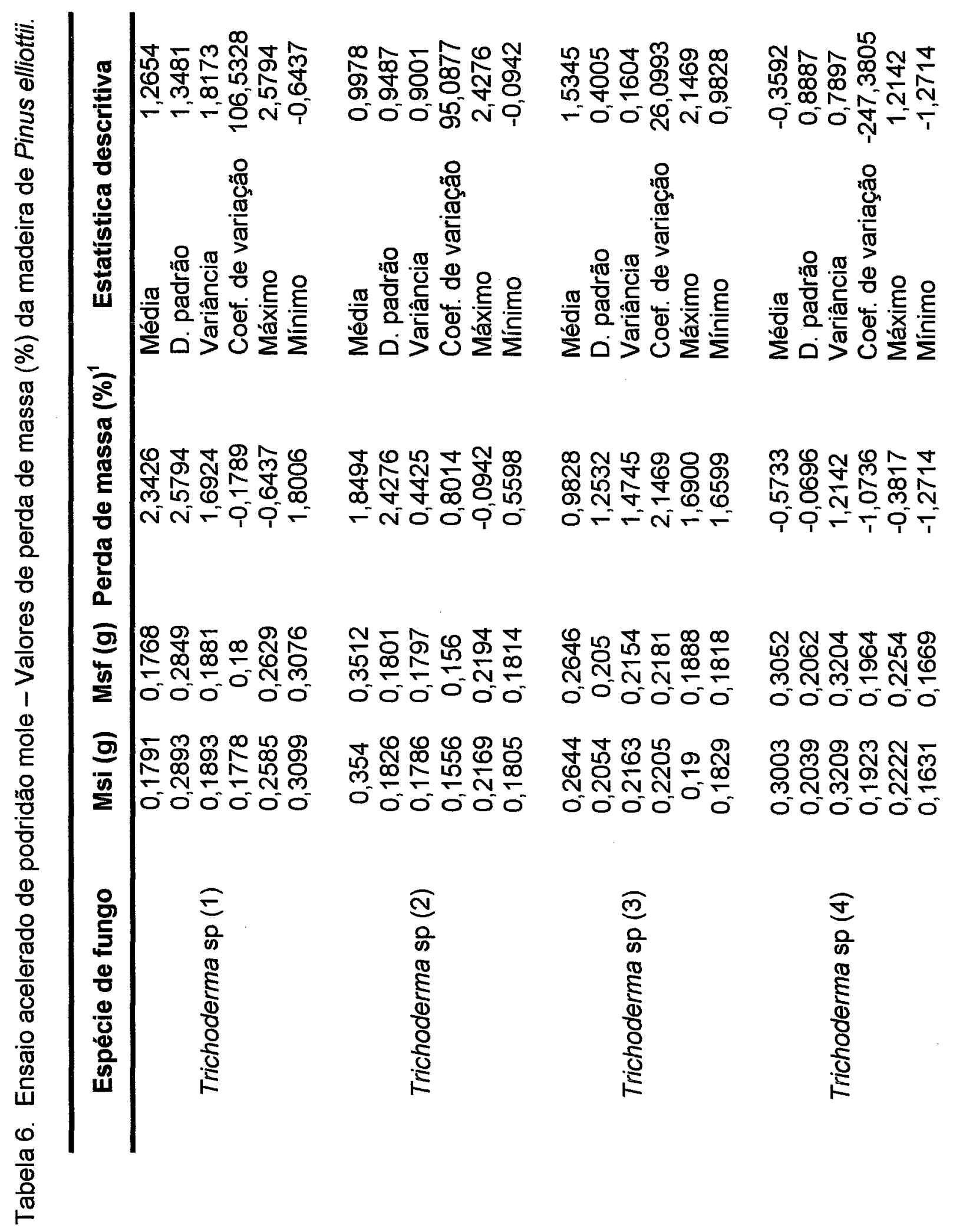




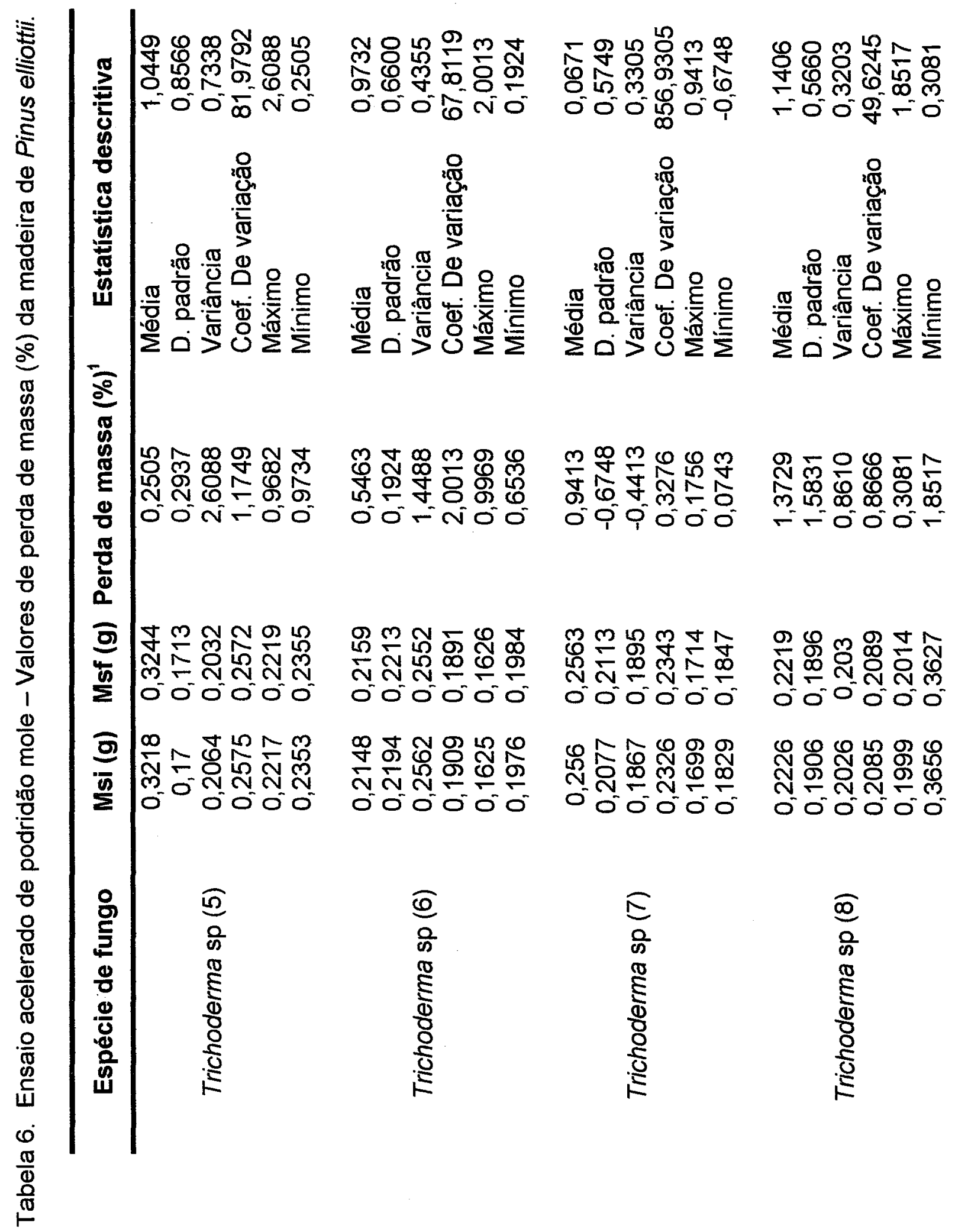




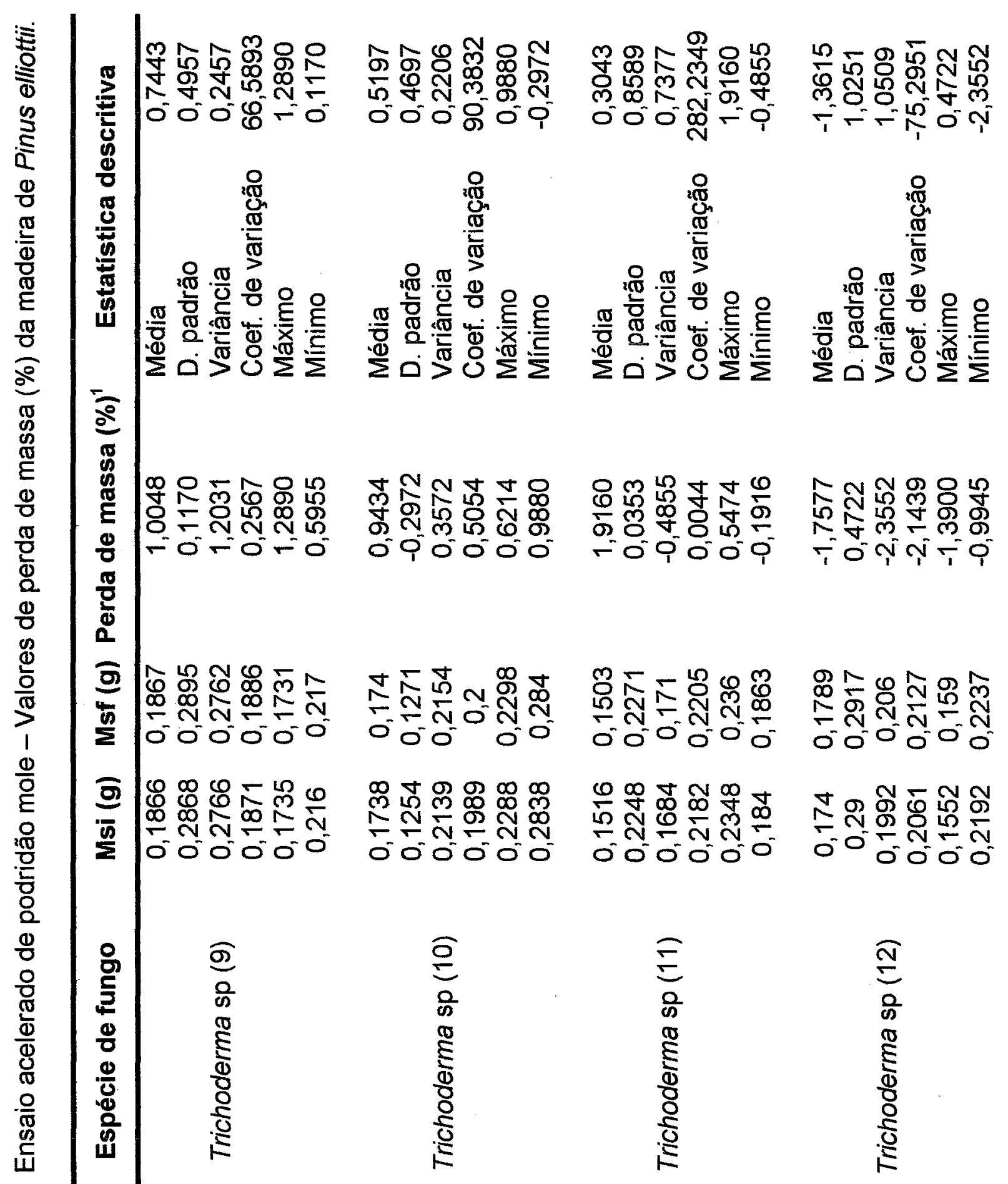




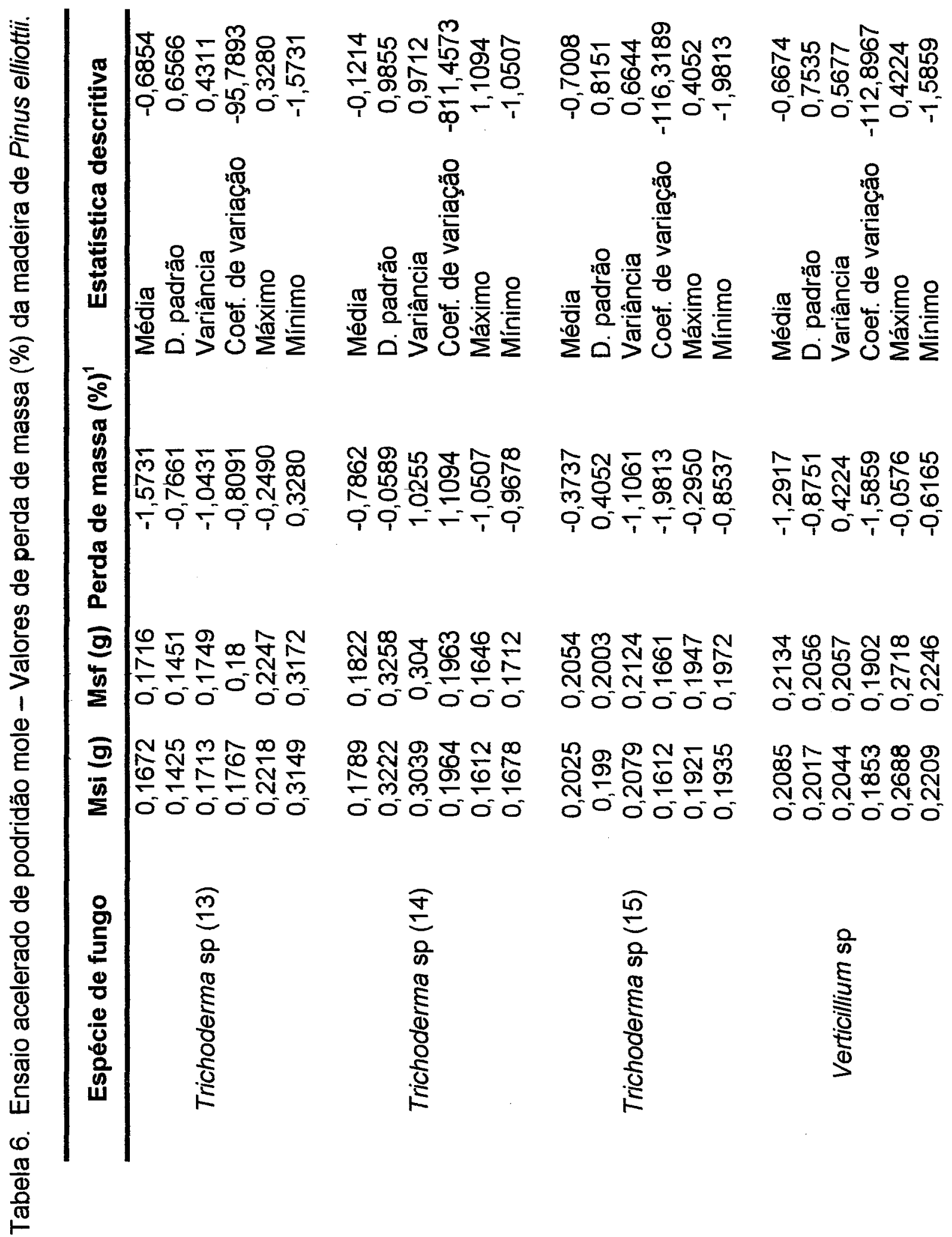




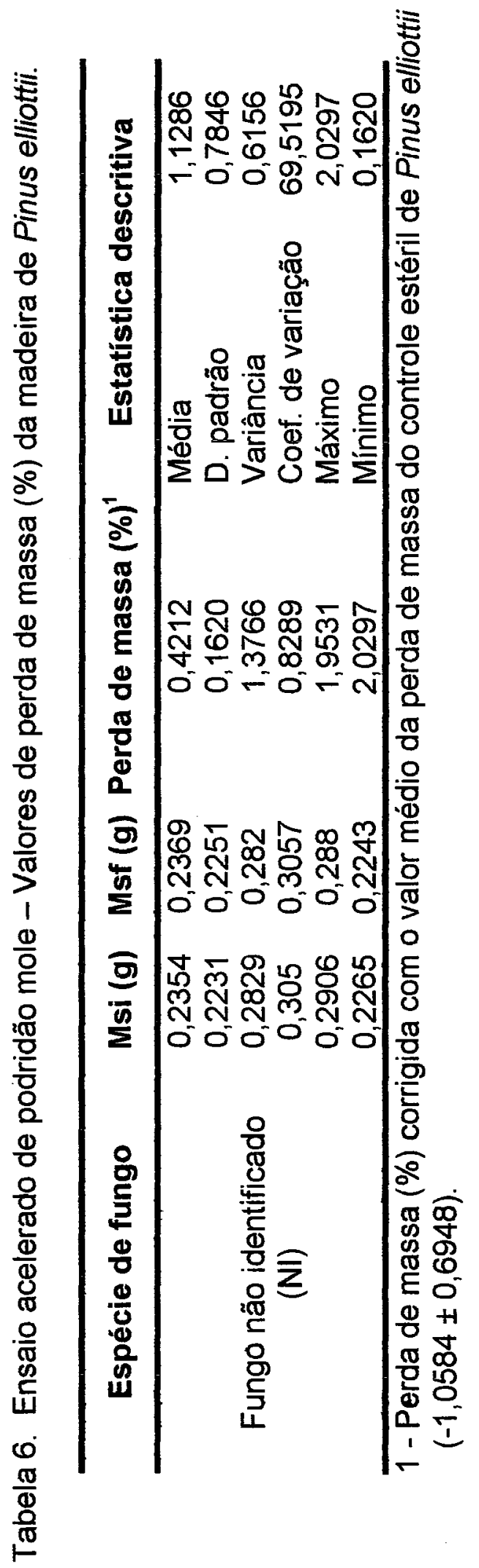




\title{
APÊNDICE 2
}

\author{
Análises estatísticas
}

Análise de variância fatorial e teste de comparação múltipla de médias de

Tukey para a interação dos fatores madeira e fungo.

Legenda:

* - diferença significativa ( $\alpha=5 \%$ );

\begin{tabular}{|c|c|}
\hline Espécie de fungo & Código \\
\hline Acremonium sp (1) & ER007 \\
\hline Acremonium sp (2) & ENOO2 \\
\hline Acremonium sp (3) & EN023 \\
\hline Acremonium sp (4) & ER018 \\
\hline A. kiliense (1) & EN005 \\
\hline A. kiliense (2) & ENOO6 \\
\hline A. kiliense (3) & EN010 \\
\hline A. kiliense (4) & EN013 \\
\hline A. kiliense (5) & ER022 \\
\hline A. kiliense (6) & EN009 \\
\hline A. kiliense (7) & EN014 \\
\hline A. kiliense (8) & EN012 \\
\hline A. kiliense (9) & EN015 \\
\hline A. kiliense (10) & ER019 \\
\hline A. kiliense (11) & EN026 \\
\hline Chaetomium globosum ${ }^{3}$ & M51 \\
\hline Gliocladium sp (1) & ER023 \\
\hline Phialophora butyrii (1) & EN001 \\
\hline P. butyrii (2) & ER020 \\
\hline$P$. butyrii (3) & ER006 \\
\hline P. butyrii (4) & ER001 \\
\hline Phialophora sp (1) & EN007 \\
\hline Phialophora sp (3) & ER009 \\
\hline Phialophora sp (4) & ER015 \\
\hline Phialophora sp (5) & ER031 \\
\hline Phialophora sp (6) & EN008 \\
\hline Trichoderma sp (10) & EN003 \\
\hline
\end{tabular}


STATISTICA: ANOVA/MANOVA.

data file: PM-PINEU.STA [ 324 cases with 4 variables ]

$\begin{array}{lll}\text { VARIABLES: } & \\ \text { 4: } & \text { PMASSA } & -9999 \\ \text { 1: } & \text { MADEIRA } & -9999 \\ \text { 2: } & \text { FUNGO } & -9999\end{array}$

INDEPENDENT VARIABLES (between-groups factors):

\begin{tabular}{|c|c|c|c|c|c|c|}
\hline MADEIRA & Number of Levels: & 2 & Codes: & $\begin{array}{l}\text { level } \\
\text { level }\end{array}$ & $\begin{array}{l}\text { 1: } \\
2:\end{array}$ & $\begin{array}{l}\text { 101-PINUS } \\
102-\text { EUCAI }\end{array}$ \\
\hline FUNGO & Number of Levels: & 27 & Codes: & level & 1: & 101-ERO01 \\
\hline & & & & level & 2: & 102-ER00 \\
\hline & & & & level & 3: & 103-ERO0 \\
\hline & & & & level & 4: & 104-EROO \\
\hline & & & & level & 5: & 105-ER01 \\
\hline & & & & level & 6: & 106-ER01 \\
\hline & & & & level & 7: & 107-ER01 \\
\hline & & & & level & 8: & 108-ERO2 \\
\hline & & & & level & 9: & 109-ER02 \\
\hline & & & & level & 10: & 110-ER02 \\
\hline & & & & level & 11: & 111-ER03 \\
\hline & & & & level & 12: & 112-ENOO \\
\hline & & & & level & 13: & 113-ENOO \\
\hline & - & & & level & 14: & 114-ENOO \\
\hline & & & & level & 15: & 115-ENOO \\
\hline & & & & level & 16: & 116-ENOO \\
\hline & & & & level & 17: & 117-ENOO \\
\hline & & & & level & 18: & 118-ENOO \\
\hline & & & & level & 19: & 119-ENOO \\
\hline & & & & level & 20: & 120-EN01 \\
\hline & & & & level & 21: & 121-ENO \\
\hline & & & & level & 22: & 122-ENO1 \\
\hline & & & & level & 23: & 123-ENO \\
\hline & & & & level & 24: & 124-ENO1 \\
\hline & & & & lever & 25: & $\begin{array}{l}\text { 125-ENO2 } \\
126-\text { ENO2 }\end{array}$ \\
\hline & & & & level & 26: & $\begin{array}{l}126-\mathrm{ENU} 26 \\
127-\mathrm{M} 51\end{array}$ \\
\hline
\end{tabular}

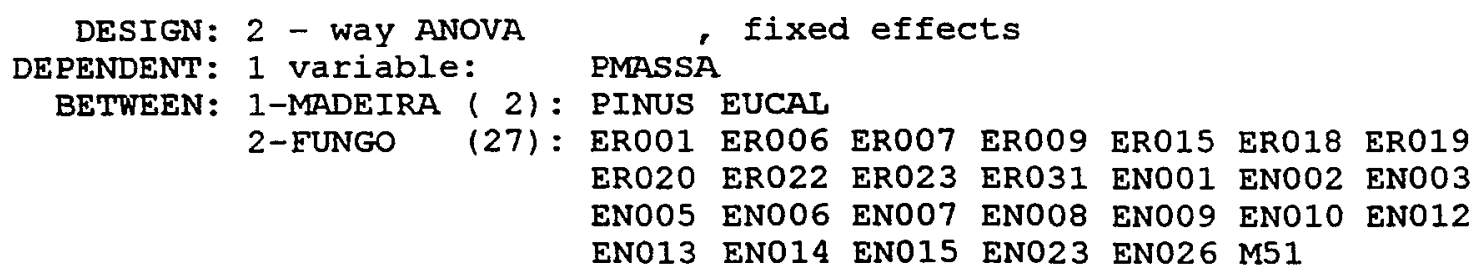


STATISTICA: ANOVA/MANOVA

WITHIN: none

\begin{tabular}{|c|c|c|c|c|c|c|}
\hline $\begin{array}{l}\text { STAT. } \\
\text { GENERAI }\end{array}$ & \multicolumn{6}{|c|}{$\begin{array}{l}\text { Summary of all Effects; design: (pm-pineu.sta) } \\
\text { 1-MADEIRA, 2-FUNGO }\end{array}$} \\
\hline Effect & $\begin{array}{l}\text { df } \\
\text { Effect }\end{array}$ & $\begin{array}{c}\text { MS } \\
\text { Effect }\end{array}$ & $\begin{array}{l}\text { df } \\
\text { Error }\end{array}$ & $\begin{array}{l}\text { MS } \\
\text { Error }\end{array}$ & F & p-level \\
\hline $\begin{array}{l}1 \\
2 \\
12\end{array}$ & $\begin{array}{l}1^{*} \\
26^{*} \\
26^{*}\end{array}$ & $\begin{array}{r}57,72059 * \\
6,05447^{*} \\
, 98518 *\end{array}$ & $\begin{array}{l}270^{*} \\
270^{*} \\
270^{*}\end{array}$ & $\begin{array}{l}.080200 * \\
.080200^{*} \\
.080200 *\end{array}$ & $\begin{array}{r}719,7053^{\star} \\
75,4919 * \\
12,2840^{\star}\end{array}$ & $\begin{array}{l}0,00 * \\
0,00 * \\
0,00 *\end{array}$ \\
\hline
\end{tabular}




\begin{tabular}{|c|c|c|c|c|c|c|c|}
\hline \multicolumn{3}{|l|}{$\begin{array}{l}\text { STAT. } \\
\text { GENERAI } \\
\text { MANOVA }\end{array}$} & \multicolumn{5}{|c|}{$\begin{array}{l}\text { Tukey HSD test; variable PMASSA (pm-pineu.sta) } \\
\text { Probabilities for Post Hoc Tests } \\
\text { INTERACTION: } 1 \times 2\end{array}$} \\
\hline MADEIRA & FUNGO & & $\begin{array}{l}\{1\} \\
1,416589\end{array}$ & $\begin{array}{c}\{2\} \\
1,472826\end{array}$ & $\begin{array}{c}\{3\} \\
1,934178\end{array}$ & $\begin{array}{c}\{4\} \\
1,976462\end{array}$ & $\begin{array}{c}\{5\} \\
2,283063\end{array}$ \\
\hline PINUS & ER001 & $\{1\}$ & & 1,000000 & 521021 & & \\
\hline PINUS & ER006 & $\{2\}$ & 1,000000 & & 808554 & 597533 & . $000938 *$ \\
\hline PINUS & ER007 & $\{3\}$ & 521021 & .808554 & & 1,000000 & 997907 \\
\hline PINUS & ER009 & $\{4\}$ &, 307390 & .597533 & 1,000000 & & 999916 \\
\hline PINUS & ER015 & $\{5\}$ &, $000199 *$ & $.000938 *$ &, 997907 & , 999916 & \\
\hline PINUS & ER018 & $\{6\}$ & 1,000000 & 1,000000 & .740940 & 6129 &, $000610 *$ \\
\hline $\begin{array}{l}\text { PINUS } \\
\text { PINUS }\end{array}$ & 019 & $\{7\}$ &, $000079 *$ & $.000211 *$ & 967548 &, 995794 & 1,000000 \\
\hline $\begin{array}{l}\text { PINUS } \\
\text { PINUS }\end{array}$ & $\begin{array}{l}\text { ER020 } \\
\text { ER022 }\end{array}$ & $\begin{array}{l}\{8\} \\
\{9\}\end{array}$ & ,001028* &, $005103 *$ &, 999984 & 1,000000 & 1,000000 \\
\hline PINUS & ER023 & $\{10\}$ & $\begin{array}{l}1,000000 \\
023505 *\end{array}$ & 1,000000 &, 999046 &, 988384 & $.026690 *$ \\
\hline PINUS & ER031 & $\{11\}$ & 1,000000 & 232 & 1,000000 & 1,000000 & 1,000000 \\
\hline PINUS & ENOO1 & $\{12\}$ & 999185 & $\begin{array}{l}100 \\
908\end{array}$ & $.033695 *$ & $.012021 *$ & $.000059 *$ \\
\hline PINUS & ENOO2 & $\{13\}$ & 217934 & $\begin{array}{r}99 \\
47\end{array}$ & 1,000000 & 1,000000 & 445898 \\
\hline PINUS & ENOO3 & $\{14\}$ & 1,000000 & 1,000 & 1,000000 & 1,000000 & , 999991 \\
\hline PINUS & EN005 & $\{15\}$ &, $000058 *$ & $.000058 *$ & , 000058 * & & $\begin{array}{l}57 \\
58 *\end{array}$ \\
\hline PINUS & EN006 & $\{16\}$ &, $000058 *$ &, $000058 *$ & $.000058 *$ & $000058 *$ & $\begin{array}{l}.000058 * \\
000058 *\end{array}$ \\
\hline PINUS & EN007 & $\{17\}$ &, 902742 & 988890 & 1,000000 & 1,000000 & 911108 \\
\hline PINUS & EN008 & $\{18\}$ & 1,000000 & 1,000000 & , 999997 &, 999806 & 104859 \\
\hline PINUS & EN009 & $\{19\}$ &, 837457 &, 973159 & 1,000000 & 1,000000 &, 953282 \\
\hline PINUS & EN010 & $\{20\}$ &, 992506 &, 999832 & 1,000000 & 1,000000 &, 640832 \\
\hline PINUS & EN012 & $\{21\}$ & 1,000000 & 1,000000 &, 560225 &, 339988 &, $000236 *$ \\
\hline PINUS & EN013 & $\{22\}$ &, 990296 & .999747 & 1,000000 & 1,000000 & .667449 \\
\hline PINUS & EN014 & $\{23\}$ &, 995775 & , 999933 & 1,000000 & 1,000000 & .584477 \\
\hline PINUS & EN015 & $\{24\}$ &, 730893 & .430457 &, $000059 *$ &, $000058 *$ &, $000058 *$ \\
\hline PINUS & ENO23 & $\{25\}$ & 1,000000 & 1,000000 &, 983486 &, 917826 & $.007648 *$ \\
\hline PINUS & EN026 & $\{26\}$ & 1,000000 & , 999996 & $.007139 *$ & $.002211 *$ &, $000058 *$ \\
\hline PINUS & M51 & $\{27\}$ &, $000058 *$ & $.000058 *$ &, $000171^{*}$ & $.000520 *$ &, 486094 \\
\hline EUCAL & ERO01 & $\{28\}$ & 1,000000 & 1,000000 & 842672 &, 643597 & $.001201 *$ \\
\hline EUCAI & ER006 & $\{29\}$ &, 055814 & .168755 & 1,000000 & 1,000000 & 1,000000 \\
\hline EUCAL & ER007 & $\{30\}$ &, $000058 *$ &, $000058 *$ & $.000060 *$ &, $000066 *$ &, 074202 \\
\hline EUCAI & ER009 & $\{31\}$ &, $000058 *$ & $.000058 *$ & $.000058 *$ &, $000059 *$ & $013189 *$ \\
\hline & ER015 & $\{32\}$ &, $000058 *$ &, $000058 *$ &, $000058 *$ &, $000058 *$ & $.000088 *$ \\
\hline EUCAL & ER018 & $\{33\}$ & 1,000000 & 1,000000 &, 128716 &, 054655 &, $000062 *$ \\
\hline EUCAL & ER019 & $\{34\}$ &, $000058 *$ & $.000058 *$ &, 156373 & 309868 & 1,000000 \\
\hline EUCAI & ER020 & $\{35\}$ &, $000058 *$ & $.000058 *$ &, $000058^{*}$ &, $000058 *$ & ,001864* \\
\hline EUCAI & ER022 & $\{36\}$ &, $000058 *$ & $.000058 *$ & $.000058 *$ &, $000058 *$ &, $005671 *$ \\
\hline EUCAI & ER023 & $\{37\}$ &, 454562 & .753113 & 1,000000 & 1,000000 &, 999084 \\
\hline EUCAL & ER031 & $\{38\}$ &, $000058 \star$ & $.000058 *$ & $.033020^{\star}$ &, 082996 & 999508 \\
\hline EU & ENO01 & $\{39\}$ &, $000058 *$ &, $000058 *$ & $.000058 *$ &, $000058 *$ &, $000612 *$ \\
\hline EUCAL & ENO02 & $\{40\}$ &, $000058 *$ &, $000058 *$ &, $003495 *$ & .010911* &, 947504 \\
\hline EUCAI & EN003 & $\{41\}$ &, 962798 & .804129 &, $000077^{*}$ &, $000062^{\star}$ &, $000058 *$ \\
\hline EUCAI & ENO05 & $\{42\}$ &, $000058 *$ & $.000058 *$ & $.000058 *$ &, $000058 *$ &, $000058 *$ \\
\hline EUCAI & EN006 & $\{43\}$ &, $000058 *$ & $.000058 *$ & $.000058 *$ & $.000058 *$ &, $000058 *$ \\
\hline EUCAI & EN007 & $\{44\}$ &, $000058 *$ &, $000058 *$ &, $002833^{*}$ &, $008985 *$ &, 932350 \\
\hline EUCAL & ENO08 & $\{45\}$ & $.000061 *$ & $.000086 *$ &, 850166 & 959221 & 1,000000 \\
\hline & EN009 & $\{46\}$ &, $000058 *$ &, $000058 *$ &, $000059 *$ & $.000061 *$ &, $044670 *$ \\
\hline EUCAL & EN010 & $\{47\}$ &, $000058 *$ & $.000058 *$ &, $000058 *$ & $.000058 *$ & $.000066 *$ \\
\hline EUCAI & EN012 & $\{48\}$ &, $000058 *$ & $.000058 *$ &, $000919 *$ &, $003103^{*}$ & 805610 \\
\hline EUCAL & EN013 & $\{49\}$ & $.000058 *$ & .000058 * & $.000058 *$ &, $000058 *$ &, $000282 *$ \\
\hline EUCAI & EN014 & $\{50\}$ &, $000058 *$ & $.000058 *$ &, $000207 *$ & $.000658 *$ & 530896 \\
\hline EUCAI & EN015 & $\{51\}$ &, $000058^{\star}$ & $.000058 *$ &, $008007 *$ &, $023303 *$ & 984760 \\
\hline EUCAL & EN023 & $\{52\}$ & $.000058 *$ &, $000058 *$ &, $012903 *$ & .035922* & ,993999 \\
\hline EUCAI & EN026 & $\{53\}$ & ,000072* & $.000169 *$ &, 953789 &, 992948 & 1,000000 \\
\hline EUCAI & M51 & $\{54\}$ &, $000058 *$ & $.000058^{*}$ &, $000058 *$ &, $000058 *$ &, $000058 *$ \\
\hline
\end{tabular}




\begin{tabular}{|c|c|c|c|c|c|c|c|}
\hline \multicolumn{3}{|l|}{$\begin{array}{l}\text { STAT. } \\
\text { GENERAL } \\
\text { MANOVA }\end{array}$} & \multicolumn{5}{|c|}{$\begin{array}{l}\text { Tukey HSD test; variable PMASSA (pm-pineu.sta) } \\
\text { Probabilities for Post Hoc Tests } \\
\text { INTERACTION: } 1 \times 2\end{array}$} \\
\hline MADEIRA & FUNGO & & $\begin{array}{c}\{6\} \\
1,457977\end{array}$ & $\begin{array}{c}\{7\} \\
2,336838\end{array}$ & $\begin{array}{c}\{8\} \\
2,223669\end{array}$ & $\begin{array}{c}\{9\} \\
1,597036\end{array}$ & $\begin{array}{c}(10) \\
2,107940\end{array}$ \\
\hline PINUS & ERO01 & $\{1\}$ & 1,000000 & $.000079 *$ & $.001028 *$ & 1,000000 &, $023505 \star$ \\
\hline PINUS & ER006 & $\{2\}$ & 1,000000 & $.000211^{\star}$ & $.005103^{*}$ & 1,000000 & 082232 \\
\hline PINUS & ER007 & (3) & .740940 & .967548 & .999984 &, 999046 & 1,000000 \\
\hline PINUS & ER009 & (4) & .516129 & 995794 & 1,000000 & 988384 & 1,000000 \\
\hline PINUS & ER015 & (5) & $.000610 *$ & 1,000000 & 1,000000 & $.026690 *$ & 1,000000 \\
\hline PINUS & ER018 & (6) & &, $000150 *$ &, $003371 *$ & 1,000000 &, 060282 \\
\hline PINUS & ER019 & $\{7\}$ &, $000150 *$ & & 1,000000 & $.006864 *$ & 1,000000 \\
\hline PINUS & ER020 & i8\} &, $003371^{*}$ & 1,000000 & & .097514 & 1,000000 \\
\hline PINUS & ER022 & $\{9\}$ & 1,000000 &, $006864 *$ &, 097514 & & 557674 \\
\hline PINUS & ER023 & $\{10\}$ & .060282 & 1,000000 & 1,000000 & 557674 & \\
\hline PINUS & ER031 & $\{11\}$ & 1,000000 &, $000058 *$ & $.000062 *$ & 998920 &, $000304 *$ \\
\hline PINUS & ENOO1 & $\{12\}$ &, 999976 & .207099 & .760294 & 1,000000 &, 996666 \\
\hline PINUS & ENOO2 & $\{13\}$ &, 397915 & .998985 & 1,000000 &, 968669 & 1,000000 \\
\hline PINUS & ENO03 & $\{14\}$ & 1,000000 & $.018781 *$ &, 199942 & 1,000000 & .762417 \\
\hline PINUS & ENO05 & (15) &, $000058 *$ & $.000058 *$ &, $000058 *$ &, $000058 *$ &, $000058 *$ \\
\hline PINUS & EN006 & $\{16\}$ &, $000058 *$ &, $000058 *$ &, $000058 *$ & $.000058 *$ &, $000058 *$ \\
\hline PINUS & EN007 & $\{17\}$ & .977917 &, 694412 & . 991890 & 1,000000 & 1,000000 \\
\hline PINUS & ENO08 & $\{18\}$ & 1,000000 & ,033197* & .291368 & 1,000000 & 861166 \\
\hline PINUS & ENOO9 & $\{19\}$ &, 952309 & .788271 &, 997314 & , 999997 & 1,000000 \\
\hline PINUS & ENO10 & $\{20\}$ &, 999455 & .355601 & 898428 & 1,000000 & 999726 \\
\hline PINUS & ENO12 & $\{21\}$ & 1,000000 & $.000085 *$ &, $001266 *$ & 1,000000 & $.027867 *$ \\
\hline PINUS & EN013 & $\{22\}$ & , 999213 & .379937 &, 912305 & 1,000000 & , 999818 \\
\hline PINUS & EN014 & $\{23\}$ &, 999757 &, 307736 & .865334 & 1,000000 &, 999392 \\
\hline PINUS & EN015 & $\{24\}$ &, 509811 & $.000058 *$ &, $000058 *$ &, $049857 \star$ &, 000058 * \\
\hline PINUS & ENO23 & $\{25\}$ & 1,000000 & $.001712 *$ &, $033487 \star$ & 1,000000 &, 304143 \\
\hline PINUS & EN026 & $\{26\}$ & , 999999 &, $000058 *$ & $.000058 *$ &, 969404 &, $000086 *$ \\
\hline PINUS & M51 & $\{27\}$ & $.000058 *$ & .769196 & .213742 & $.000058 *$ &, $019463 *$ \\
\hline EUCAI & ER001 & $\{28\}$ & 1,000000 & $.000262 *$ &, $006413 *$ & 1,000000 & .097542 \\
\hline EUCAI & ER006 & $\{29\}$ &, 128892 & 999999 & 1,000000 &, 755847 & 1,000000 \\
\hline EUCAL & ER007 & $\{30\}$ & $.000058 *$ &, 203629 & , 019291* &, $000058 *$ &, $000811 \star$ \\
\hline EUCAL & ER009 & $\{31\}$ & $.000058 *$ & $.047455 *$ & $.002660 *$ &, $000058 *$ & $.000121 *$ \\
\hline EUCAL & ER015 & $\{32\}$ &, $000058 *$ &, $000256 \star$ & $.000061^{\star}$ &, $000058 *$ &, $000058 *$ \\
\hline EUCAI & ER018 & $\{33\}$ & 1,000000 & $.000059 *$ &, $000100 *$ & , 999997 &, $001895 *$ \\
\hline EUCAI & ER019 & $\{34\}$ & $.000058 *$ & 1,000000 & , 999864 &, $000068 *$ &, 921053 \\
\hline EUCAI & ER020 & $\{35\}$ &, $000058 *$ &, $008263^{*}$ &, $000338 *$ &, $000058 *$ & $.000062^{\star}$ \\
\hline EUCAI & ER022 & $(36)$ &, $000058 *$ &, $022506 \star$ & $.001051 *$ &, $000058 *$ &, 000078 \\
\hline EUCAL & ER023 & $\{37\}$ &, 678696 &, 980662 & , 999996 &, 997829 & 1,000000 \\
\hline EUCAL & ER031 & $\{38\}$ &, $000058 *$ & , 999997 &, 983020 & $.000059 *$ & .600011 \\
\hline EUCAL & ENOO1 & $\{39\}$ &, $000058 *$ & $.002892 *$ &, $000134 *$ &, $000058 *$ &, $000059 *$ \\
\hline EUCAL & ENOO2 & $\{40\}$ &, $000058 *$ &, 995448 & .747138 & $.000058 *$ & 189351 \\
\hline EUCAL & EN003 & $\{41\}$ &, 862123 & $.000058 *$ & $.000058 *$ &, 202715 & $.000058 *$ \\
\hline EUCAI & EN005 & $\{42\}$ &, $000058 *$ & $.000058 *$ & $.000058 *$ &, $000058 *$ & $.000058 *$ \\
\hline EUCAL & EN006 & $\{43\}$ & $.000058 *$ & $.000058 *$ & $.000058 *$ &, $000058 *$ & $.000058 *$ \\
\hline EUCAL & EN007 & $\{44\}$ &, $000058 *$ & , 993114 & .710209 &, $000058 *$ &, 166330 \\
\hline EUCAL & EN008 & $\{45\}$ &, $000075^{\star}$ & 1,000000 & 1,000000 & $.001788 *$ & , 999996 \\
\hline EUCAL & ENO09 & $\{46\}$ &, $000058^{*}$ & .134451 & $.010652 *$ &, $000058 *$ &, $000412 *$ \\
\hline EUCAL & EN010 & $\{47\}$ &, $000058 *$ & $.000117^{*}$ & $.000059 *$ &, $000058 *$ &, $000058 *$ \\
\hline EUCAI & EN012 & $\{48\}$ &, $000058 *$ & 959681 &, 500031 & $.000058 *$ & 078844 \\
\hline EUCAL & EN013 & $\{49\}$ &, $000058^{*}$ & $.001301 *$ & $.000086^{*}$ &, $000058 *$ & .000058 \\
\hline EUCAI & EN014 & $\{50\}$ &, $000058 *$ & .805763 & .244012 &, $000058 *$ & ,023758* \\
\hline EUCAI & EN015 & $\{51\}$ &, $000058 *$ & . 999372 &, 872585 &, $000058 *$ & , 305798 \\
\hline EUCAL & EN023 & $\{52\}$ &, $000058 *$ &, 999855 &, 925293 &, $000058 *$ &, 393005 \\
\hline EUCAL & EN026 & $\{53\}$ & $.000125 *$ & 1,000000 & 1,000000 &, $005349 *$ & 1,000000 \\
\hline EUCAL & M51 & $\{54\}$ &, $000058 *$ & $.000058 *$ & $.000058 *$ &, $000058 *$ & $.000058 *$ \\
\hline
\end{tabular}




\begin{tabular}{|c|c|c|c|c|c|c|c|}
\hline \multicolumn{3}{|l|}{$\begin{array}{l}\text { STAT. } \\
\text { GENERAL } \\
\text { MANOVA }\end{array}$} & \multicolumn{5}{|c|}{$\begin{array}{l}\text { Tukey HSD test; variable PMASSA (pm-pineu.sta) } \\
\text { Probabilities for Post Hoc Tests } \\
\text { INTERACTION: } 1 \times 2\end{array}$} \\
\hline MADEIRA & FUNGO & & $\begin{array}{c}\{11\} \\
1,258110\end{array}$ & $\begin{array}{c}\{12\} \\
1,751518\end{array}$ & $\begin{array}{c}\{13\} \\
1,998813\end{array}$ & $\begin{array}{c}\{14\} \\
1,636242\end{array}$ & $\begin{array}{c}\{15\} \\
4,054705\end{array}$ \\
\hline PINUS & ER001 & $\{1\}$ & 1,000000 & , 999185 &, 217934 & 1,000000 & $.000058 *$ \\
\hline PINUS & ER006 & $\{2\}$ & 1,000000 &, 999995 & 475474 & 1,000000 & $58 *$ \\
\hline PINUS & ER007 & $\{3\}$ &, $033695 *$ & 1,000000 & 1,000000 &, 999963 & $000058 *$ \\
\hline PINUS & ER009 & $\{4\}$ & $.012021 *$ & 1,000000 & 1,000000 & 998819 & $000058 *$ \\
\hline RINUS & ER015 & $\{5\}$ & $.000059 *$ &, 445898 &, 999991 & .064457 & $.000058 *$ \\
\hline PINUS & ER018 & $\{6\}$ & 1,000000 &, 999976 &, 397915 & 1,000000 & $.000058 *$ \\
\hline PINUS & ER019 & (7) & $.000058 *$ & ,207099 &, 998985 & $.018781 *$ & $.000058 *$ \\
\hline PINUS & ER020 & $\{8\}$ &, $000062 *$ & .760294 & 1,000000 & 199942 & $.000058 *$ \\
\hline PINUS & ERO22 & $\{9\}$ &, 998920 & 1,000000 &, 968669 & 1,000000 &, $000058 *$ \\
\hline PINUS & ER023 & $\{10\}$ & $.000304 *$ &, 996666 & 1,000000 &, 762417 & $.000058^{\star}$ \\
\hline PINUS & ER031 & $\{11\}$ & &, 652859 &, $006701 *$ &, 989102 & $.000058 *$ \\
\hline PINUS & ENO01 & $\{12\}$ &, 652859 & & 1,000000 & 1,000000 &, $000058 *$ \\
\hline PINUS & ENO02 & $\{13\}$ &, $006701 *$ & 1,000000 & & .995230 & $.000058 *$ \\
\hline PINUS & ENO03 & $\{14\}$ & .989102 & 1,000000 & .995230 & & $.000058 *$ \\
\hline PINUS & ENO05 & $\{15\}$ & $.000058 *$ & $.000058 *$ &, $000058 *$ & $.000058 *$ & \\
\hline PINUS & ENO06 & $\{16\}$ &, $000058 *$ & $.000058 *$ & $.000058 *$ &, $000058 *$ & 1,000000 \\
\hline PINUS & EN007 & $\{17\}$ &, 181127 & 1,000000 & 1,000000 & 1,000000 & $.000058^{*}$ \\
\hline PINUS & ENOOB & $\{18\}$ &, 968370 & 1,000000 &, 998937 & 1,000000 & $.000058 *$ \\
\hline PINUS & EN009 & $\{19\}$ &, 127587 & 1,000000 & 1,000000 & 1,000000 & $.000058^{*}$ \\
\hline PINUS & EN010 & $\{20\}$ &, 457787 & 1,000000 & 1,000000 & 1,000000 &, $000058 *$ \\
\hline PINUS & EN012 & $\{21\}$ & 1,000000 &, 999518 & 244414 & 1,000000 & $.000058 *$ \\
\hline PINUS & EN013 & $\{22\}$ & 431485 & 1,000000 & 1,000000 & 1,000000 & $.000058 *$ \\
\hline PINUS & EN014 & $\{23\}$ &, 513686 & 1,000000 & 1,000000 & 1,000000 & $.000058 *$ \\
\hline PINUS & EN015 & $\{24\}$ &, 999743 & $.000860 *$ &, $000058 *$ & $.020057^{\star}$ & $.000058 *$ \\
\hline PINUS & EN023 & $\{25\}$ &, 999984 & 1,000000 &, 847852 & 1,000000 & $.000058 *$ \\
\hline PINUS & EN026 & $\{26\}$ & 1,000000 &, 326345 &, $001159 *$ & .885939 & $.000058 *$ \\
\hline PINUS & M51 & $\{27\}$ &, $000058 *$ &, $000058 *$ &, $000994 *$ &, $000058 *$ &, $000058 *$ \\
\hline AL & ER001 & $\{28\}$ & 1,000000 & , 999998 & 521556 & 1,000000 &, $000058 *$ \\
\hline EUCAL & ER006 & $\{29\}$ &, $000890 *$ &, 999766 & 1,000000 &, 905190 & $.000058 *$ \\
\hline EUCAL & ER007 & $\mid 30\}$ &, $000058 *$ &, $000058 *$ & $.000076 *$ &, $000058 *$ & $.000058 *$ \\
\hline$A L$ & ER009 & $\{31\}$ &, $000058 *$ & $.000058 *$ &, $000059 *$ &, $000058 *$ & $.000058 *$ \\
\hline & ER015 & $\{32\}$ &, $000058 *$ & $.000058 *$ &, $000058 *$ & $.000058 *$ & $.000226 *$ \\
\hline EUCAL & ER018 & $\{33\}$ & 1,000000 &, 916722 &, $033085 *$ &, 999836 &, $000058 *$ \\
\hline EUCAI & ER019 & $\{34\}$ &, $000058 *$ &, $001991 *$ & 417657 & $.000103^{*}$ & $.000058 *$ \\
\hline EUCAL & ER020 & $\{35\}$ &, $000058 *$ & $.000058 *$ &, $000058 *$ & $.000058 *$ & $.000060 *$ \\
\hline & ER022 & $\{36\}$ & $.000058 *$ &, $000058 *$ &, $000058 *$ &, $000058 *$ &, $000059 *$ \\
\hline AI & ER023 & $\{37\}$ &, $025234 *$ & 1,000000 & 1,000000 & 999884 & $.000058 *$ \\
\hline EUCAI & ER031 & $\{38\}$ &, $000058 *$ & $.000235 *$ & .128511 &, $000061 *$ & $.000058 *$ \\
\hline EUCAL & ENO01 & $\{39\}$ &, $000058 *$ &, $000058 *$ &, $000058 *$ &, $000058 *$ & $.000066^{*}$ \\
\hline EUCAL & ENOO2 & $\{40\}$ &, $000058 *$ &, $000066^{*}$ &, $019164 *$ &, $000058 *$ &, $000058 *$ \\
\hline $\mathrm{EU}$ & ENO03 & $\{41\}$ & 1,000000 &, $006634 *$ & $.000060 *$ & .099114 & $.000058 *$ \\
\hline EUCAL & EN005 & $\{42\}$ &, $000058 *$ & $.000058 *$ &, $000058 *$ &, $000058 *$ & $.010349 *$ \\
\hline & ENO06 & $\{43\}$ & $.000058 *$ & $.000058 *$ &, $000058 *$ &, $000058 *$ & 1,000000 \\
\hline EUCAL & EN007 & $\{44\}$ &, $000058 *$ &, $000064 *$ & .015913* &, $000058 *$ & $.000058 *$ \\
\hline EUCAL & EN008 & $\{45\}$ &, $000058 \star$ &, 084947 &, 983953 &, $005393 *$ &, $000058 *$ \\
\hline & EN009 & $\{46\}$ & $.000058 *$ & $.000058 *$ &, $000066 *$ &, $000058 *$ & $.000058 *$ \\
\hline EUCAI & EN010 & $\{47\}$ &, $000058 *$ & $.000058 *$ &, $000058 *$ &, $000058 *$ & $.000590 *$ \\
\hline EUCAL & EN012 & $\{48\}$ &, $000058 *$ & $.000059 *$ &, $005768 *$ &, $000058 *$ & $.000058 *$ \\
\hline EUCAL & EN013 & $\{49\}$ & $.000058 *$ & $.000058 *$ & $.000058 *$ & $.000058 *$ & $.000080 *$ \\
\hline EUCAL & EN014 & $\{50\}$ &, $000058 *$ & $.000058 *$ &, $001262 *$ &, $000058 *$ &, $000058 *$ \\
\hline EUCAL & EN015 & $\{51\}$ &, $000058 *$ & $.000082 *$ & , 039291* &, $000058 *$ & $.000058 \star$ \\
\hline EUCAL & EN023 & $\{52\}$ &, $000058 *$ & $.000105^{\star}$ &, 059035 &, $000059 *$ &, $000058 *$ \\
\hline EUCAL & EN026 & $\{53\}$ &, $000058 *$ & , 176855 & 998106 &, $014894 *$ & $.000058 *$ \\
\hline EUCAL & M51 & $\{54\}$ & $.000058 *$ & $.000058 *$ & $.000058 *$ &, $000058 *$ & 1,000000 \\
\hline
\end{tabular}




\begin{tabular}{|c|c|c|c|c|c|c|c|}
\hline \multicolumn{3}{|l|}{$\begin{array}{l}\text { STAT. } \\
\text { GENERAI } \\
\text { MANOVA }\end{array}$} & \multicolumn{5}{|c|}{$\begin{array}{l}\text { Tukey HSD test; variable PMASSA (pm-pineu.sta) } \\
\text { Probabilities for Post Hoc Tests } \\
\text { INTERACTION: } 1 \text { × } 2\end{array}$} \\
\hline MADEIRA & FUNGO & & $\begin{array}{c}\{16\} \\
3,871082\end{array}$ & $\begin{array}{c}\{17\} \\
1,851348\end{array}$ & $\begin{array}{c}\{18\} \\
1,660124\end{array}$ & $\begin{array}{c}\{19\} \\
1,870805\end{array}$ & $\begin{array}{c}\{20\} \\
1,787408\end{array}$ \\
\hline PINUS & ER001 & $\{1\}$ &, $000058 *$ &, 902742 & 1,000000 & & \\
\hline PINUS & ER006 & $\{2\}$ &, $000058 *$ & 988890 & 1,000000 & , 973159 & 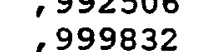 \\
\hline PINUS & ER007 & (3) & $.000058 *$ & 1,000000 &, 999997 & 1,000000 & 1,000000 \\
\hline PINUS & EROO9 & $\{4\}$ & $.000058 *$ & 1,000000 & 999806 & 1,000000 & 1,000000 \\
\hline PINUS & ER015 & $\{5\}$ & $.000058 *$ &, 911108 & .104859 &, 953282 & .640832 \\
\hline PINUS & ER018 & $\{6\}$ &, $000058 *$ & .977917 & 1,000000 &, 952309 &, 999455 \\
\hline PINUS & ER019 & $\{7\}$ & $.000058 *$ &, 694412 & $.033197 *$ &, 788271 & .355601 \\
\hline PINUS & ER020 & $\{8\}$ &, $000058 *$ &, 991890 & .291368 &, 997314 &, 898428 \\
\hline PINUS & ER022 & $\{9\}$ & $.000058 *$ & 1,000000 & 1,000000 & , 999997 & 1,000000 \\
\hline PINUS & ER023 & $\{10\}$ &, $000058^{*}$ & 1,000000 & .861166 & 1,000000 &, 999726 \\
\hline PINUS & ER031 & $\{11\}$ & $.000058 *$ & .181127 & .968370 &, 127587 &, 457787 \\
\hline PINUS & ENO01 & $\{12\}$ & $.000058 *$ & 1,000000 & 1,000000 & 1,000000 & 1,000000 \\
\hline PINUS & ENOO2 & $\{13\}$ &, $000058 *$ & 1,000000 &, 998937 & 1,000000 & 1,000000 \\
\hline PINUS & ENOO3 & $\{14\}$ &, $000058 *$ & 1,000000 & 1,000000 & 1,000000 & 1,000000 \\
\hline PINUS & ENOO5 & $\{15\}$ & 1,000000 &, $000058 *$ &, $000058 *$ & $.000058 *$ &, $000058 *$ \\
\hline PINUS & EN006 & $\{16\}$ & & $.000058 *$ & $.000058 *$ & $.000058 *$ & $.000058 *$ \\
\hline PINUS & ENOO7 & $\{17\}$ &, $000058 *$ & & 1,000000 & 1,000000 & 1,000000 \\
\hline PINUS & ENOO8 & $\{18\}$ &, $000058 *$ & 1,000000 & & 1,000000 & 1,000000 \\
\hline PINUS & ENOO9 & $\{19\}$ &, $000058 *$ & 1,000000 & 1,000000 & & 1,000000 \\
\hline PINUS & EN010 & $\{20\}$ &, $000058 *$ & 1,000000 & 1,000000 & 1,000000 & \\
\hline PINUS & EN012 & $\{21\}$ &, $000058 *$ &, 921613 & 1,000000 & .863803 &, 994925 \\
\hline PINUS & EN013 & $\{22\}$ &, $000058 *$ & 1,000000 & 1,000000 & 1,000000 & 1,000000 \\
\hline PINUS & EN014 & $\{23\}$ &, $000058 *$ & 1,000000 & 1,000000 & 1,000000 & 1,000000 \\
\hline PINUS & EN015 & $\{24\}$ &, $000058 *$ & $.000085^{*}$ & $.011005 *$ & $.000071 *$ &, $000310 *$ \\
\hline PINUS & ENO23 & $\{25\}$ &, $000058 *$ & , 999934 & 1,000000 & ,999655 & 1,000000 \\
\hline PINUS & EN026 & $\{26\}$ &, $000058 *$ &, 053492 & .796013 & $.034573 *$ &, 186432 \\
\hline PINUS & M51 & $\{27\}$ &, $000058 *$ & $.000063^{*}$ & $.000058 *$ &, $000069 *$ & $.000059 *$ \\
\hline EUCAI & EROO1 & $\{28\}$ &, $000058 *$ &, 992814 & 1,000000 &, 981389 & , 999920 \\
\hline EUCAL & ER006 & $\{29\}$ &, $000058 *$ & 1,000000 & .956985 & 1,000000 & , 999992 \\
\hline EUCAI & ER007 & $\{30\}$ &, $000066^{*}$ &, $000058 *$ &, $000058^{*}$ &, $000058 *$ &, $000058 *$ \\
\hline EUCAL & ER009 & $\{31\}$ &, $000169 *$ &, $000058 *$ &, $000058 *$ &, $000058 *$ & $.000058 *$ \\
\hline EUCAI & ER015 & $\{32\}$ &, $032488 *$ &, $000058 *$ &, $000058 \star$ &, $000058 *$ &, $000058 *$ \\
\hline CAL & ER018 & $\{33\}$ & $.000058 *$ &, 457278 & , 998975 &, 358378 &, 790832 \\
\hline EUCAL & ER019 & $\{34\}$ &, $000058 *$ & $.027717^{*}$ & $.000161 *$ & $.043377 *$ & $.005456^{\star}$ \\
\hline EUCAL & ER020 & $\{35\}$ &, $001211 *$ &, $000058 *$ & $.000058 \star$ &, $000058 *$ &, $000058 *$ \\
\hline EUCAI & ER022 & $\{36\}$ &, $000387 *$ & $.000058 *$ &, $000058 *$ & $.000058 *$ &, $000058 *$ \\
\hline EUCAL & ER023 & $\{37\}$ &, $000058 *$ & 1,000000 &, 999988 & 1,000000 & 1,000000 \\
\hline EUCAL & ER031 & $\{38\}$ &, $000058^{*}$ & $.003976 *$ &, $000064 *$ & $.006770 *$ & $.000634 *$ \\
\hline EUCAI: & ENOO1 & $\{39\}$ &, $003626 *$ & $.000058 *$ &, $000058 *$ &, $000058 *$ &, $000058 *$ \\
\hline EUCAL & ENOO2 & $\{40\}$ &, $000058 *$ &, $000327 *$ & $.000058 *$ &, $000564 *$ &, $000087 \star$ \\
\hline EUCAI & ENOO3 & $\{41\}$ &, $000058 *$ &, $000389 *$ & .060633 & $.000231 *$ &, $002452 *$ \\
\hline EUCAL & ENOO5 & $\{42\}$ &, $000091 *$ & $.000058 *$ & $.000058 *$ &, $000058 *$ &, $000058 *$ \\
\hline EUCAI & EN006 & $\{43\}$ &, 982855 &, $000058 *$ & $.000058 *$ &, $000058 *$ & $.000058 *$ \\
\hline CAL & EN007 & $\{44\}$ &, $000058 *$ & $.000268 *$ & $.000058 *$ &, $000455 *$ & $.000080 *$ \\
\hline EUCAI & EN008 & $\{45\}$ &, $000058 *$ &, 434649 & , 010152* &, 539410 &, 167792 \\
\hline EUCAL & ENOO9 & $\{46\}$ &, $000076 *$ & $.000058 *$ & $.000058 *$ &, $000058 *$ & $.000058 *$ \\
\hline DAL & EN010 & $\{47\}$ & .070465 & $.000058 *$ & $.000058 *$ &, $000058 *$ & $.000058 *$ \\
\hline EUCAL & ENO12 & $\{48\}$ &, $000058 *$ & $.000113 *$ & $.000058 *$ & $.000165 *$ & $.000063 *$ \\
\hline EUCAL & EN013 & $\{49\}$ &, $007744 *$ &, $000058 *$ & $.000058 *$ & $.000058 *$ &, $000058 *$ \\
\hline EUCAL & EN014 & 15 & $.000058 *$ & $.000066 *$ & $.000058 *$ &, $000073 \star$ &, $000059 *$ \\
\hline EUCAI & ENO15 & $\{51\}$ &, $000058 *$ & $.000774^{\star}$ & $.000059 *$ &, $001364 *$ & $.000144 *$ \\
\hline EUCAL & EN023 & $\{52\}$ &, $000058 *$ &, $001324 *$ &, $000060 *$ &, $002319 *$ &, $000220 \star$ \\
\hline EUCAI & EN026 & 153 &, $000058 *$ &, 645484 & .026698 * &, 745149 &, 312488 \\
\hline EUCAL & M51 & $\mid(2|z|$ & , 999934 &, $000058 *$ &, $000058 *$ & $.000058 *$ &, $000058 \star$ \\
\hline
\end{tabular}




\begin{tabular}{|c|c|c|c|c|c|c|c|}
\hline \multicolumn{3}{|l|}{$\begin{array}{l}\text { STAT. } \\
\text { GENERAI } \\
\text { MANOVA }\end{array}$} & \multicolumn{5}{|c|}{$\begin{array}{l}\text { Tukey HSD test; variable PMASSA (pm-pineu.sta) } \\
\text { Probabilities for Post Hoc Tests } \\
\text { INTERACTION: } 1 \times 2\end{array}$} \\
\hline MADEIRA & FUNGO & & $\begin{array}{c}\{21\} \\
1,423739\end{array}$ & $\begin{array}{c}\{22\} \\
1,792405\end{array}$ & $\begin{array}{c}\{23\} \\
1,777042\end{array}$ & $\begin{array}{c}\{24\} \\
.9383335\end{array}$ & $\begin{array}{c}\{25\} \\
1,547332\end{array}$ \\
\hline PINUS & ER001 & (1) & 1,000000 & , 990296 & .995775 & , 730893 & 1,000000 \\
\hline PINUS & ER006 & (2) & 1,000000 & .999747 & .999933 & .430457 & 1,000000 \\
\hline PINUS & ER007 & $\{3\}$ & .560225 & 1,000000 & 1,000000 &, $000059 *$ & 983486 \\
\hline RINUS & ER009 & \{4\} &, 339988 & 1,000000 & 1,000000 &, $000058^{*}$ & 917826 \\
\hline PINUS & ER015 & (5) & $.000236 \star$ & .667449 & 584477 & $.000058^{*}$ & $.007648 *$ \\
\hline PINUS & ER018 & $\{6\}$ & 1,000000 & .999213 & , 999757 &, 509811 & 1,000000 \\
\hline PINUS & ER019 & $\{7\}$ &, $000085^{\star}$ & , 379937 &, 307736 & $.000058 *$ & $.001712^{\star}$ \\
\hline PINUS & ER020 & $\{8\}$ & $.001266^{\star}$ & 912305 & .865334 & $.000058 *$ & $.033487 *$ \\
\hline PINUS & ER022 & \{9\} & 1,000000 & 1,000000 & 1,000000 & $.049857 *$ & 1,000000 \\
\hline PINUS & ER023 & $\{10\}$ &, $027867 *$ & , 999818 &, 999392 & $.000058 *$ & .304143 \\
\hline PINUS & ER031 & \{11\} & 1,000000 &, 431485 &, 513686 &, 999743 & , 999984 \\
\hline PINUS & ENOO1 & $\{12\}$ & , 999518 & 1,000000 & 1,000000 &, $000860 *$ & 1,000000 \\
\hline PINUS & ENO02 & $\{13\}$ & .244414 & 1,000000 & 1,000000 &, $000058 *$ &, 847852 \\
\hline PINUS & ENO03 & $\{14\}$ & 1,000000 & 1,000000 & 1,000000 & $.020057^{\star}$ & 1,000000 \\
\hline PINUS & ENO05 & $\{15\}$ & $.000058 *$ & $.000058 *$ &, $000058 *$ &, $000058 *$ &, $000058 *$ \\
\hline PINUS & ENO06 & $\{16\}$ &, $000058 *$ & $.000058 *$ & $.000058 *$ &, $000058 *$ &, $000058 *$ \\
\hline PINUS & ENO07 & $\{17\}$ &, 921613 & 1,000000 & 1,000000 &, $000085 *$ & , 999934 \\
\hline PINUS & ENO08 & (18) & 1,000000 & 1,000000 & 1,000000 &, $011005^{*}$ & 1,000000 \\
\hline PINUS & ENO09 & $\{19\}$ & .863803 & 1,000000 & 1,000000 &, $000071 *$ &, 999655 \\
\hline PINUS & ENO10 & $\{20\}$ &, 994925 & 1,000000 & 1,000000 &, $000310 *$ & 1,000000 \\
\hline PINUS & EN012 & $\{21\}$ & & ,993319 &, 997240 &, 694846 & 1,000000 \\
\hline PINUS & ENO13 & $\{22\}$ &, 993319 & & 1,000000 &, $000273 *$ & 1,000000 \\
\hline PINUS & EN014 & $\{23\}$ &, 997240 & 1,000000 & & $.000413^{\star}$ & 1,000000 \\
\hline PINUS & EN015 & (24\} &, 694846 &, $000273^{*}$ & $.000413 *$ & &, 136678 \\
\hline PINUS & ENO23 & $\{25\}$ & 1,000000 & 1,000000 & 1,000000 &, 136678 & \\
\hline PINUS & ENO26 & $\{26\}$ & 1,000000 &, 170985 &, 221630 & 1,000000 & , 997535 \\
\hline PINUS & M51 & $\{27\}$ &, $000058 *$ & $.000059 *$ & $.000058 *$ & $.000058^{*}$ & $.000058 *$ \\
\hline EUCAL & ER001 & $\{28\}$ & 1,000000 & .999876 & , 999970 &, 387114 & 1,000000 \\
\hline EUCAL & ER006 & $\{29\}$ &, 065048 &, 999995 & , 999977 &, $000058 *$ &, 492677 \\
\hline EUCAL & ER007 & $\{30\}$ &, $000058 *$ & $.000058 *$ & $.000058 *$ &, $000058 *$ &, $000058 *$ \\
\hline EUCAI & ER009 & (31) & $.000058 *$ &, $000058 *$ &, $000058 *$ &, $000058 *$ & $.000058 *$ \\
\hline EUCAL & ER015 & $\{32\}$ &, $000058 *$ & $.000058 *$ &, $000058 *$ &, $000058 *$ & $.000058 *$ \\
\hline EUCAI & ER018 & \{33\} & 1,000000 & .768225 & .834060 & 985788 & 1,000000 \\
\hline EUCAL & ER019 & $\{34\}$ &, $000058 *$ &, $006240 *$ & $.004092 *$ &, $000058 *$ & $.000060 *$ \\
\hline EUCAL & ER020 & $\{35\}$ & $.000058 *$ &, $000058 *$ &, $000058 *$ &, $000058 *$ & $.000058 *$ \\
\hline EUCAI & ER022 & $\{36\}$ &, $000058 *$ &, $000058 *$ & $.000058 *$ &, $000058 *$ & $.000058 *$ \\
\hline EUCAI & ER023 & (37) &, 492898 & 1,000000 & 1,000000 &, $000059 *$ & 971817 \\
\hline EUCAI, & ER031 & $\{38\}$ &, $000058 *$ &, $000733 *$ &, $000470 *$ &, $000058 *$ &, $000058 *$ \\
\hline EUCAI & ENO01 & $\{39\}$ &, $000058 *$ &, $000058 *$ &, $000058 *$ &, $000058 *$ &, $000058 *$ \\
\hline EUCAL & ENOO2 & $\{40\}$ & $.000058 *$ &, $000092 *$ &, $000078 *$ &, $000058 *$ &, $000058 *$ \\
\hline EUCAI & ENO03 & (41) &, 951480 &, $002127 \star$ &, $003287 *$ & 1,000000 & 417989 \\
\hline EUCAL & ENOO5 & $\{42\}$ &, $000058 *$ &, $000058 *$ & $.000058 *$ &, $000058 *$ & $.000058 *$ \\
\hline EUCAI & ENO06 & $\{43\}$ &, $000058^{*}$ & $.000058 *$ & $.000058 *$ & $.000058 *$ &, $000058 *$ \\
\hline EUCAL & EN007 & $\{44\}$ & $.000058 *$ &, $000084 *$ & $.000073 *$ &, $000058 *$ &, $000058 *$ \\
\hline EUCAI & EN008 & $\{45\}$ &, $000062 *$ &, 183028 &, 139233 &, $000058 *$ & $.000426 *$ \\
\hline EUCAL & ENO & $(46)$ & $.000058 *$ &, $000058 *$ & $.000058 *$ &, $000058 *$ & $.000058 *$ \\
\hline EUCAL & EN010 & $\{47\}$ & $.000058 *$ &, $000058 *$ &, $000058 *$ &, $000058 *$ &, $000058 *$ \\
\hline EUCAI & EN012 & $\{48\}$ &, $000058 *$ &, $000064 *$ & $.000061^{\star}$ &, $000058 *$ & $.000058 *$ \\
\hline EUCAL & ENO13 & $\{49\}$ & $.000058 *$ &, $000058 *$ &, $000058 *$ &, $000058 \star$ &, $000058 *$ \\
\hline EUCAI & ENO14 & $\{50\}$ &, $000058 *$ &, $000059 *$ &, $000059 *$ & $.000058 *$ & $.000058 *$ \\
\hline EUCAL & EN015 & $\{51\}$ & $.000058 *$ &, $000160 *$ & $.000118 *$ &, $000058 *$ & $.000058 *$ \\
\hline EUCAI & ENO23 & $\{52\}$ & $.000058 *$ &, $000249 *$ &, $000171 *$ &, $000058 *$ & $.000058 *$ \\
\hline EUCAL & ENO26 & & $.000077 *$ &, 335282 &, 268124 &, $000058 *$ & $.001309 *$ \\
\hline EUCAL & M51 & $\{54\}$ & $.000058 *$ &, $000058 *$ &, $000058 *$ & $.000058 *$ &, $000058 *$ \\
\hline
\end{tabular}




\begin{tabular}{|c|c|c|c|c|c|c|c|}
\hline \multicolumn{3}{|l|}{$\begin{array}{l}\text { STAT. } \\
\text { GENERAL } \\
\text { MANOVA }\end{array}$} & \multicolumn{5}{|c|}{$\begin{array}{l}\text { Tukey HSD test; variable PMASSA (pm-pineu.sta) } \\
\text { Probabilities for Post Hoc Tests } \\
\text { INTERACTION: } 1 \times 2\end{array}$} \\
\hline MADEIRA & EUNGO & & $\begin{array}{c}\{26\} \\
1,195850\end{array}$ & $\begin{array}{c}\{27\} \\
2,807078\end{array}$ & $\begin{array}{c}\{28\} \\
1,481322\end{array}$ & $\begin{array}{c}\{29\} \\
2,070129\end{array}$ & $\begin{array}{c}\{30\} \\
2,923172\end{array}$ \\
\hline PINUS & ERO01 & $\{1\}$ & 1,000000 & $.000058 *$ & 1,000000 & .055814 &, $000058 *$ \\
\hline RINUS & ER006 & $\{2\}$ & .999996 & $.000058 *$ & 1,000000 & 168755 & $.000058 *$ \\
\hline PINUS & ER007 & \{3\} & $.007139 *$ & $.000171 *$ & .842672 & 1,000000 & $.000060 *$ \\
\hline PINUS & ER009 & \{4\} & $.002211 *$ & $.000520 *$ &, 643597 & 1,000000 & $.000066 *$ \\
\hline RINUS & ER015 & $\{5\}$ & $.000058 *$ & .486094 & $.001201 *$ & 1,000000 & .074202 \\
\hline PINUS & ER018 & $\{6\}$ &, 999999 & $.000058 *$ & 1,000000 & .128892 & $.000058 *$ \\
\hline PINUS & ER019 & $\{7\}$ & $.000058 *$ & .769196 & $.000262 *$ & ,999999 &, 203629 \\
\hline PINUS & ER020 & (8) &, $000058 *$ & .213742 & $.006413 *$ & 1,000000 & $.019291 *$ \\
\hline PINUS & ER022 & 19\} &, 969404 &, $000058 *$ & 1,000000 & .755847 & $.000058 *$ \\
\hline PINUS & ER023 & $\{10\}$ &, $000086^{\star}$ &, $019463 *$ &, 097542 & 1,000000 & $.000811 *$ \\
\hline PINUS & ER031 & \{11\} & 1,000000 & $.000058 *$ & 1,000000 &, $000890 *$ & $.000058 *$ \\
\hline PINUS & EN001 & $\{12\}$ &, 326345 & $.000058 *$ & .999998 &, 999766 & $.000058 *$ \\
\hline PINUS & ENOO2 & (13) & $.001159 *$ &, $000994 *$ & .521556 & 1,000000 & $.000076^{\star}$ \\
\hline PINUS & ENOO3 & $\{14\}$ & .885939 & $.000058 *$ & 1,000000 & .905190 & $.000058 *$ \\
\hline PINUS & ENO05 & (15) & $.000058 *$ & $.000058 *$ &, $000058 *$ & $.000058 *$ & $.000058 *$ \\
\hline PINUS & ENO06 & $\{16\}$ &, $000058 *$ & $.000058 *$ & $.000058 *$ & $.000058 *$ & $.000066 *$ \\
\hline PINUS & EN007 & \{17\} & .053492 & $.000063 *$ & .992814 & 1,000000 & $.000058 *$ \\
\hline PINUS & ENO08 & $\{18\}$ & .796013 & $.000058 *$ & 1,000000 &, 956985 & $.000058 *$ \\
\hline PINUS & ENOO9 & \{19\} &, $034573^{\star}$ &, $000069 *$ & , 981389 & 1,000000 & $.000058 *$ \\
\hline PINUS & EN010 & $\{20\}$ &, 186432 & $.000059 *$ & , 999920 & , 999992 &, $000058 *$ \\
\hline PINUS & EN012 & $\{21\}$ & 1,000000 & $.000058 *$ & 1,000000 & .065048 &, $000058 *$ \\
\hline PINUS & EN013 & $\{22\}$ & .170985 & $.000059 *$ & , 999876 & , 999995 & $.000058 *$ \\
\hline PINUS & EN014 & $\{23\}$ & .221630 & $.000058 *$ &, 999970 & .999977 &, $000058 *$ \\
\hline PINUS & ENO15 & $\{24\}$ & 1,000000 &, $000058 *$ &, 387114 &, $000058 *$ &, $000058 *$ \\
\hline PINUS & EN023 & $\{25\}$ & .997535 & $.000058 *$ & 1,000000 & , 492677 &, $000058 *$ \\
\hline PINUS & EN026 & $\{26\}$ & & $.000058 *$ & , 999989 & $.000165 *$ & $.000058 *$ \\
\hline PINUS & M51 & $\{27\}$ &, $000058 *$ & & $.000058 *$ &, $007405^{*}$ & 1,000000 \\
\hline EUCAL & ER001 & $\{28\}$ & .999989 & $.000058 *$ & &, 195351 & $.000058 *$ \\
\hline EUCAL & ER006 & $\{29\}$ &, $000165 *$ & $.007405 *$ & .195351 & & $.000280 *$ \\
\hline EUCAL & ER007 & $\{30\}$ & $.000058 *$ & 1,000000 &, $000058 *$ &, $000280 *$ & \\
\hline EUCAL & ER009 & $\{31\}$ &, $000058 *$ & 1,000000 &, $000058 *$ & $.000074 *$ & 1,000000 \\
\hline EUCAI & ER015 & $\{32\}$ & $.000058 *$ &, 983852 & $.000058 *$ & $.000058 *$ & , 999998 \\
\hline EUCAL & ER018 & $\{33\}$ & 1,000000 & $.000058 *$ & 1,000000 &, $005484 *$ &, $000058 *$ \\
\hline EUCAL & ER019 & $\{34\}$ & $.000058 *$ & , 999998 &, $000058 *$ & .789973 &, 983067 \\
\hline EUCAL & ER020 & $\{35\}$ & $.000058 *$ & , 999999 &, $000058 *$ &, $000059 *$ & 1,000000 \\
\hline EUCAL & ER022 & $\{36\}$ & $.000058 *$ & 1,000000 & $.000058 *$ & $.000063 *$ & 1,000000 \\
\hline EUCAL & ER023 & $\{37\}$ & $.005130 *$ &, $000229 *$ & .792070 & 1,000000 & $.000060 *$ \\
\hline EUCAL & ER031 & $\{38\}$ & $.000058 *$ & 1,000000 &, $000058 *$ & .397117 & , 999865 \\
\hline EUCAL & EN001 & $\{39\}$ &, $000058 *$ &, 999950 & $.000058 *$ &, $000058 *$ & 1,000000 \\
\hline EUCAL & ENO02 & $\{40\}$ & $.000058 *$ & 1,000000 &, $000058^{*}$ & .094043 & 1,000000 \\
\hline EUCAI & EN003 & $\{41\}$ & 1,000000 &, $000058 *$ & .766188 & $.000058 *$ & $.000058 *$ \\
\hline EUCAL & EN005 & $\{42\}$ &, $000058 *$ &, $000058 *$ &, $000058 *$ &, $000058 *$ & $.000058 *$ \\
\hline EUCAL & EN006 & $\{43\}$ & $.000058 *$ & $.000058 *$ &, $000058 *$ &, $000058 *$ &, $000058^{*}$ \\
\hline EUCAL & EN007 & $\{44\}$ & $.000058 *$ & 1,000000 & $.000058 *$ &, 080863 & 1,000000 \\
\hline EUCAL & EN008 & $\{45\}$ &, $000058 *$ & .934450 &, $000097 *$ &, 999828 &, 411644 \\
\hline EUCAL & ENOO9 & $\{46\}$ &, $000058 *$ & 1,000000 &, $000058 *$ &, $000157 *$ & 1,000000 \\
\hline EUCAL & EN010 & $\{47\}$ & $.000058 *$ &, 935797 &, $000058 *$ &, $000058 *$ &, 999925 \\
\hline EUCAL & EN012 & $\{48\}$ & $.000058 *$ & 1,000000 &, $000058 *$ & $.034552 *$ & 1,000000 \\
\hline EUCAL & EN013 & $\{49\}$ & $.000058 *$ & , 999482 &, $000058 *$ &, $000058^{\star}$ & 1,000000 \\
\hline EUCAL & EN014 & $\{50\}$ & $.000058 *$ & 1,000000 &, $000058 *$ & $.009194 *$ & 1,000000 \\
\hline EUCAL & EN015 & $\{51\}$ &, $000058 *$ & 1,000000 &, $000058 *$ &, 166568 & 1,000000 \\
\hline EUCAL & EN023 & $\{52\}$ &, $000058 *$ & 1,000000 &, $000058 *$ & .227333 & , 999997 \\
\hline EUCAL & EN026 & $\{53\}$ & $.000058 *$ &, 810285 &, $000207 *$ & , 999996 & .236947 \\
\hline EUCAL & M51 & $\{54\}$ & $.000058 *$ & $.000058 *$ &, $000058 *$ &, $000058 *$ & $.000058 *$ \\
\hline
\end{tabular}




\begin{tabular}{|c|c|c|c|c|c|c|c|}
\hline \multicolumn{3}{|l|}{$\begin{array}{l}\text { STAT. } \\
\text { GENERAI } \\
\text { MANOVA }\end{array}$} & \multicolumn{5}{|c|}{$\begin{array}{l}\text { Tukey HSD test; variable PMASSA (pm-pineu.sta) } \\
\text { Probabilities for Post Hoc Tests } \\
\text { INTERACTION: } 1 \times 2\end{array}$} \\
\hline MADEIRA & FUNGO & & $\begin{array}{c}\{31\} \\
2,997777\end{array}$ & $\begin{array}{c}\{32\} \\
3,193436\end{array}$ & $\begin{array}{c}\{33\} \\
1,321954\end{array}$ & $\begin{array}{c}\{34\} \\
2,535778\end{array}$ & $\begin{array}{c}\{35\} \\
3,069631\end{array}$ \\
\hline PINUS & ERO01 & $\{1\}$ & $.000058 *$ &, $000058 *$ & 1,000000 & $000058 *$ & $000058 *$ \\
\hline PINUS & ER006 & $\{2\}$ & $.000058 *$ & $.000058 *$ & 1,000000 &, $000058 *$ & 000058 * \\
\hline PINUS & ER007 & $\{3\}$ &, $000058 *$ & $.000058 *$ &, 128716 & .156373 & $.000058 *$ \\
\hline RINUS & ERO09 & $\{4\}$ & $.000059 *$ & $.000058 *$ &, 054655 & .309868 & $.000058 *$ \\
\hline PINUS & ER015 & $\{5\}$ & , 013189* & $.000088 *$ & $.000062^{*}$ & 1,000000 & .001864 * \\
\hline PINUS & ER018 & $\{6\}$ & $.000058^{\star}$ & $.000058 *$ & 1,000000 & $.000058 *$ & $.000058 *$ \\
\hline PINUS & ER019 & \{7\} & $.047455^{*}$ & $.000256 *$ & $.000059 *$ & 1,000000 & $.008263 *$ \\
\hline PINUS & ER020 & $\{8\}$ &, $002660 *$ & $\therefore 000061 *$ &, $000100^{*}$ &, 999864 & $.000338 *$ \\
\hline PINUS & ER022 & $\{9\}$ &, $000058^{*}$ & $.000058 *$ & , 999997 &, $000068 *$ & $.000058 *$ \\
\hline PINUS & ER023 & $\{10\}$ & $.000121 *$ & $.000058 *$ & $001895 *$ & 921053 & $.000062 *$ \\
\hline PINUS & ER031 & $\{11\}$ & $.000058 *$ & $.000058 *$ & 1,000000 &, $000058 *$ & $.000058 *$ \\
\hline PINUS & ENOO1 & $\{12\}$ &, $000058 *$ &, $000058 *$ &, 916722 & $001991 *$ & $.000058 *$ \\
\hline PINUS & ENOO2 & $\{13\}$ & $.000059 *$ & $.000058 *$ &, $033085^{\star}$ & 417657 & $.000058 *$ \\
\hline PINUS & ENO03 & $\{14\}$ & $.000058 *$ & $.000058 *$ & .999836 &, $000103 *$ &, $000058 *$ \\
\hline PINUS & ENOO5 & $\{15\}$ &, $000058 *$ & $.000226 *$ &, $000058 *$ & $.000058 *$ & $.000060 *$ \\
\hline PINUS & ENO06 & $\{16\}$ &, $000169 *$ & $.032488 *$ & $.000058 *$ &, $000058 *$ & $.001211 *$ \\
\hline PINUS & EN007 & $\{17\}$ & $.000058 *$ & $.000058 *$ &, 457278 &, $027717^{*}$ & $.000058 *$ \\
\hline PINUS & ENO08 & $\{18\}$ &, $000058 *$ & $.000058 *$ & , 998975 &, $000161 *$ &, $000058 *$ \\
\hline PINUS & ENO09 & $\{19\}$ &, $000058 *$ & $.000058 *$ & 358378 & $043377^{*}$ & $.000058 *$ \\
\hline PINUS & EN010 & $\{20\}$ & $.000058 *$ &, $000058 *$ &, 790832 &, $005456 \star$ &, $000058 *$ \\
\hline PINUS & EN012 & $\{21\}$ & $.000058 *$ & $.000058 *$ & 1,000000 &, $000058 *$ &, $000058 *$ \\
\hline PINUS & EN013 & $\{22\}$ &, $000058 *$ & $.000058 *$ &, 768225 &, $006240 *$ & $.000058 *$ \\
\hline PINUS & EN014 & $\{23\}$ &, $000058 *$ & $.000058 *$ &, 834060 &, $004092 *$ &, $000058 *$ \\
\hline PINUS & EN015 & $\{24\}$ &, $000058 *$ & $.000058 *$ & 985788 &, $000058 *$ & $.000058^{\star}$ \\
\hline PINUS & ENO23 & $\{25\}$ & $.000058 *$ & $.000058 *$ & 1,000000 &, $000060 *$ &, $000058 *$ \\
\hline PINUS & ENO26 & $\{26\}$ &, $000058 *$ & $.000058 *$ & 1,000000 &, $000058 *$ & .000058 \\
\hline PINUS & M51 & $\{27\}$ & 1,000000 & ,983852 &, $000058 *$ & , 999998 & ,999999 \\
\hline EUCAI & ER001 & $\{28\}$ &, $000058 *$ & $.000058 *$ & 1,000000 &, $000058 *$ &, $000058 *$ \\
\hline EUCAL & ER006 & $\{29\}$ &, $000074 *$ &, $000058 *$ &, $005484 *$ &, 789973 &, $000059 *$ \\
\hline EUCAL & ER007 & $\{30\}$ & 1,000000 & , 999998 & $.000058 *$ & 983067 & 1,000000 \\
\hline EUCAI & ER009 & $\{31\}$ & & 1,000000 & $.000058 *$ &, 805813 & 1,000000 \\
\hline EUCAI & ER015 & $\{32\}$ & 1,000000 & &, $000058 *$ &, 051013 & 1,000000 \\
\hline EUCAL & ER018 & $\{33\}$ &, $000058 *$ & $.000058 *$ & &, $000058 *$ &, $000058 *$ \\
\hline EUCAI & ER019 & $\{34\}$ & .805813 & .051013 & $.000058 *$ & & 433788 \\
\hline EUCAI & ER020 & $\{35\}$ & 1,000000 & 1,000000 &, $000058 \star$ &, 433788 & \\
\hline EUCAL & ER022 & $\{36\}$ & 1,000000 & 1,000000 &, $000058 *$ &, 648545 & 1,000000 \\
\hline EUCAL & ER023 & $\{37\}$ &, $000058 *$ & $.000058 *$ & .101622 &, 193789 &, $000058 *$ \\
\hline EUCAL & ER031 & $\{38\}$ &, 983632 & .217616 & $.000058 *$ & 1,000000 & .820378 \\
\hline EUCAL & EN001 & $\{39\}$ & 1,000000 & 1,000000 & $.000058 *$ &, 255567 & 1,000000 \\
\hline EUCAL & ENOO2 & $\{40\}$ & , 999958 &, 645159 & $.000058 *$ & 1,000000 &, 992416 \\
\hline AI & ENOO3 & $\{41\}$ & $.000058 *$ & $.000058 *$ & .999871 & $.000058 *$ & $.000058 *$ \\
\hline EUCAI & EN005 & $\{42\}$ &, $000058 *$ &, $000058 *$ & $.000058^{*}$ &, $000058 *$ & $.000058 *$ \\
\hline EUCAL & EN006 & $\{43\}$ &, $000058 *$ & $.000058 *$ & $.000058 *$ &, $000058 *$ &, $000058 *$ \\
\hline EUCAL & EN007 & $\{44\}$ &, 999980 & .684675 & $.000058 *$ & 1,000000 &, 994954 \\
\hline EUCAI & EN008 & $\{45\}$ &, 127479 &, $000990 *$ & $.000058 *$ & 1,000000 &, $027610^{\star}$ \\
\hline EUCAL & EN009 & $\{46\}$ & 1,000000 & 1,000000 & $.000058 *$ & .955467 & 1,000000 \\
\hline EUCAI & EN010 & $\{47\}$ & 1,000000 & 1,000000 &, $000058 *$ &, $022747 *$ & 1,000000 \\
\hline EUCAI & ENO12 & $\{48\}$ & 1,000000 & .859355 & $.000058 *$ & 1,000000 &, 999625 \\
\hline EUCAI & EN013 & $\{49\}$ & 1,000000 & 1,000000 & $.000058 *$ & 160760 & 1,000000 \\
\hline EUCAI & EN014 & $\{50\}$ & 1,000000 & 976730 & $.000058 *$ & ,999999 &, 999998 \\
\hline EUCAI & ENOI5 & $\{51\}$ &, 999448 & .479366 & $.000058 *$ & 1,000000 & 969067 \\
\hline EUCAI & EN023 & $\{52\}$ & 998019 &, 383645 &, $000058 *$ & 1,000000 & 939011 \\
\hline EUCAI & EN026 & $\{53\}$ &, 058151 & $.000326^{\star}$ & $.000059 *$ & 1,000000 & $.010532 *$ \\
\hline CAL & M51 & $\{54\}$ & $.000058 *$ &, $000060 *$ & $.000058 *$ &, 000058 * &, $000058 *$ \\
\hline
\end{tabular}




\begin{tabular}{|c|c|c|c|c|c|c|c|}
\hline \multicolumn{3}{|l|}{$\begin{array}{l}\text { STAT. } \\
\text { GENERAL } \\
\text { MANOVA }\end{array}$} & \multicolumn{5}{|c|}{$\begin{array}{l}\text { Tukey HSD test; variable PMASSA (pm-pineu.sta) } \\
\text { Probabilities for Post Hoc Tests } \\
\text { INTERACTION: } 1 \times 2\end{array}$} \\
\hline MADEIRA & FUNGO & & $\begin{array}{c}\{36\} \\
3,029994\end{array}$ & $\begin{array}{c}\{37\} \\
1,946495\end{array}$ & $\begin{array}{c}\{38\} \\
2,611123\end{array}$ & $\begin{array}{c}\{39\} \\
3,107994\end{array}$ & $\begin{array}{c}\{40\} \\
2,698587\end{array}$ \\
\hline PINUS & ER001 & \{1\} &, $000058 *$ & .454562 &, $000058 *$ & $.000058 *$ & $000058 \star$ \\
\hline PINUS & ER006 & $\{2\}$ &, $000058 *$ & .753113 & $.000058 *$ &, $000058 *$ & $000058 *$ \\
\hline PINUS & ER007 & $\{3\}$ & $.000058 *$ & 1,000000 & $.033020 *$ & $.000058 *$ & $003495 *$ \\
\hline PINUS & ER009 & $\{4\}$ & .000058 * & 1,000000 & .082996 &, $000058 *$ & $010911^{\star}$ \\
\hline PINUS & ER015 & $\{5\}$ & $.005671^{\star}$ &, 999084 & , 999508 & $.000612 *$ & 947504 \\
\hline PINUS & ER018 & $\{6\}$ &, $000058 *$ & .678696 & $.000058 *$ & $.000058 *$ & $.000058 *$ \\
\hline PINUS & ER019 & (7) & $.022506^{*}$ & .980662 & .999997 & $.002892^{\star}$ & 995448 \\
\hline PINUS & ER020 & $\{8\}$ & $.001051 *$ & , 999996 & .983020 & $.000134 *$ &, 747138 \\
\hline PINUS & ER022 & $\{9\}$ & $.000058 *$ &, 997829 & $.000059 *$ & $.000058 *$ &, $000058 *$ \\
\hline PINUS & ER023 & $\{10\}$ & $.000078 *$ & 1,000000 &, 600011 & $.000059 *$ & , 189351 \\
\hline PINUS & ER031 & (11) & $.000058 *$ &, $025234 *$ & $.000058 *$ &, $000058 *$ &, $000058 *$ \\
\hline PINUS & ENO01 & $\{12\}$ &, $000058 *$ & 1,000000 & $.000235 *$ &, $000058 *$ & $.000066 *$ \\
\hline PINUS & ENO02 & $\{13\}$ & $.000058 *$ & 1,000000 & .128511 & $.000058 *$ & , 019164* \\
\hline PINUS & EN003 & $\{14\}$ & $.000058 *$ &, 999884 & $.000061 *$ &, $000058 *$ &, $000058 *$ \\
\hline PINUS & ENOOS & $\{15\}$ & $.000059 *$ &, $000058 *$ & $.000058 *$ &, $000066 \star$ &, $000058 *$ \\
\hline PINUS & EN006 & $\{16\}$ & $.000387 *$ &, $000058 *$ & $.000058 *$ & $.003626^{*}$ &, $000058 *$ \\
\hline PINUS & EN007 & $\{17\}$ & $.000058 *$ & 1,000000 & $.003976^{\star}$ &, $000058 *$ &, $000327 *$ \\
\hline PINUS & EN008 & $\{18\}$ & $.000058 *$ & , 999988 & $.000064 *$ &, $000058 *$ & $.000058 *$ \\
\hline PINUS & ENOO9 & $\{19\}$ & $.000058 *$ & 1,000000 & $.006770^{*}$ & $.000058 *$ & $.000564 *$ \\
\hline PINUS & EN010 & $\{20\}$ & $.000058 *$ & 1,000000 & $.000634 *$ & $.000058 *$ &, $000087 *$ \\
\hline PINUS & EN012 & $\{21\}$ & $.000058 *$ &, 492898 & $.000058 *$ & $.000058 *$ &, $000058 *$ \\
\hline PINUS & EN013 & $\{22\}$ & $.000058 *$ & 1,000000 & $.000733^{*}$ &, $000058 *$ & $.000092 *$ \\
\hline PINUS & EN014 & $\{23\}$ &, $000058 *$ & 1,000000 & $.000470 *$ & $.000058 *$ &, $000078 *$ \\
\hline PINUS & EN015 & $\{24\}$ & $.000058 *$ &, $000059 *$ & $.000058 *$ & $.000058 *$ &, $000058 *$ \\
\hline PINUS & ENO23 & $\{25\}$ &, $000058 *$ & , 971817 & $.000058 *$ &, $000058 *$ &, $000058 *$ \\
\hline PINUS & ENO26 & $\{26\}$ & $.000058 *$ &, $005130 *$ &, $000058 *$ &, $000058 *$ &, $000058 *$ \\
\hline PINUS & M51 & $\{27\}$ & 1,000000 &, $000229 \star$ & 1,000000 &, 999950 & 1,000000 \\
\hline EUCAL & ERO01 & $\{28\}$ &, $000058 *$ & .792070 & $.000058 *$ &, $000058 *$ &, $000058 *$ \\
\hline EUCAL & ER006 & $\{29\}$ & $.000063^{*}$ & 1,000000 &, 397117 &, $000058 *$ & 094043 \\
\hline EUCAL & ER007 & $\{30\}$ & 1,000000 & $.000060 *$ & , 999865 & 1,000000 & 1,000000 \\
\hline EUCAL & ER009 & $\{31\}$ & 1,000000 & $.000058 *$ & .983632 & 1,000000 & , 999958 \\
\hline EUCAL & ER015 & $\{32\}$ & 1,000000 &, $000058 *$ & .217616 & 1,000000 &, 645159 \\
\hline EU & ER018 & $\{33\}$ & $.000058 *$ &, 101622 & $.000058 *$ &, $000058 *$ &, $000058 *$ \\
\hline EUCAL & ER019 & $\{34\}$ & .648545 &, 193789 & 1,000000 & .255567 & 1,000000 \\
\hline EUCAL & ER020 & $\{35\}$ & 1,000000 & $.000058^{*}$ & .820378 & 1,000000 & , 992416 \\
\hline & ER022 & $\{36\}$ & &, $000058 *$ & .941060 & 1,000000 & , 999368 \\
\hline EUCAL & ER023 & $\{37\}$ &, $000058 *$ & & $.043713^{*}$ &, $000058 *$ & $.004932 *$ \\
\hline EUCAL & ER031 & $\{38\}$ & 941060 & $.043713^{*}$ & &, 634291 & 1,000000 \\
\hline$E U$ & ENOO1 & $\{39\}$ & 1,000000 &, $000058 *$ & .634291 & &, 957931 \\
\hline EU & ENOO2 & $\{40\}$ &, 999368 &, $004932 *$ & 1,000000 &, 957931 & \\
\hline EUCAL & ENOO3 & $\{41\}$ & $.000058 *$ &, $000069 *$ & $.000058 *$ &, $000058 *$ &, $000058 *$ \\
\hline EUCAL & ENOO5 & $\{42\}$ & $.000058 *$ &, $000058 *$ &, $000058 *$ &, $000058 *$ &, $000058 *$ \\
\hline EUCAL & ENO06 & $\{43\}$ & $.000058^{\star}$ &, $000058 *$ & $.000058 *$ & $.000058^{*}$ & $.000058 *$ \\
\hline EUCAI & ENOO7 & $\{44\}$ & , 999642 &, $003999 *$ & 1,000000 & 968478 & 1,000000 \\
\hline EUCAL & ENO08 & $\{45\}$ & .067046 &, 891648 & 1,000000 &, $010679 *$ & , 999846 \\
\hline EUCAL & ENO09 & $\{46\}$ & 1,000000 & $.000059 *$ &, 999145 & 1,000000 & 1,000000 \\
\hline EUCAI & EN010 & (47) & 1,000000 &, $000058 *$ &, 116779 & 1,000000 &, 454563 \\
\hline EUCAL & EN012 & $\{48\}$ & , 999990 &, $001316^{*}$ & 1,000000 & , 995145 & 1,000000 \\
\hline EUCAL & EN013 & $\{49\}$ & 1,000000 & $.000058 *$ & .482383 & 1,000000 &, 895556 \\
\hline EUCAL & EN014 & $\{50\}$ & 1,000000 &, $000285^{\star}$ & 1,000000 & , 999895 & 1,000000 \\
\hline EUCAL & EN015 & $\{51\}$ &, 995429 & $.011036 *$ & 1,000000 & 887719 & 1,000000 \\
\hline EUCAI & EN023 & $\{52\}$ &, 987912 & $017574^{\star}$ & 1,000000 & .821458 & 1,000000 \\
\hline EUCAL & EN026 & $\{53\}$ & $.028094 *$ & .971260 & ,999999 & $.003752 *$ &, 997382 \\
\hline EUCAL & M51 & $\{54\}$ &, $000058 *$ &, $000058 *$ & $.000058 *$ &, $000058 *$ &, $000058 *$ \\
\hline
\end{tabular}




\begin{tabular}{|c|c|c|c|c|c|c|c|}
\hline \multicolumn{3}{|l|}{$\begin{array}{l}\text { STAT. } \\
\text { GENERAL } \\
\text { MANOVA }\end{array}$} & \multicolumn{5}{|c|}{$\begin{array}{l}\text { Tukey HSD test; variable PMASSA (pm-pineu.sta) } \\
\text { Probabilities for Post Hoc Tests } \\
\text { INTERACTION: } 1 \times 2\end{array}$} \\
\hline MADEIRA & FUNGO & & $\begin{array}{c}\{41\} \\
1,010432\end{array}$ & $\begin{array}{c}\{42\} \\
4,778875\end{array}$ & $\begin{array}{c}\{43\} \\
4,258749\end{array}$ & $\begin{array}{c}\{44\} \\
2,706065\end{array}$ & $\begin{array}{c}\{45\} \\
2,385036\end{array}$ \\
\hline RINUS & ER001 & $\{1\}$ &, 962798 &, $000058 *$ &, $000058 \star$ & & \\
\hline PINUS & ER006 & $\{2\}$ & 804129 & $.000058 *$ & 000058 * & $000058 \star$ &, $000086 *$ \\
\hline PINUS & ER007 & $\{3\}$ &, $000077 *$ & $000058 *$ & $.000058 *$ & $002833^{\star}$ & 850166 \\
\hline PINUS & ER009 & $\{4\}$ &, $000062 *$ & $.000058 *$ & $.000058 *$ & $008985 *$ & 959221 \\
\hline PINUS & ER015 & $\{5\}$ &, $000058 *$ & $.000058 *$ & $.000058 *$ & 932350 & 1,000000 \\
\hline PINUS & ER018 & $\{6\}$ & 862123 & $.000058 *$ & $.000058 *$ &, $000058 *$ &, $000075 *$ \\
\hline PINUS & ER019 & $\{7\}$ &, $000058 *$ & $.000058 *$ & $.000058 *$ & .993114 & 1,000000 \\
\hline PINUS & ER020 & $\{8\}$ & $.000058 *$ & $.000058 *$ & $.000058 *$ & .710209 & 1,000000 \\
\hline PINUS & ER022 & $\{9\}$ &, 202715 &, $000058 *$ & $.000058 *$ &, $000058 *$ &, $001788 *$ \\
\hline PINUS & ER023 & $\{10\}$ &, $000058 *$ & $.000058 *$ & $.000058 *$ & .166330 & , 999996 \\
\hline PINUS & ER031 & $\{11\}$ & 1,000000 &, $000058 *$ & $.000058 *$ &, $000058 *$ & $.000058 *$ \\
\hline PINUS & ENOO1 & $\{12\}$ &, $006634 *$ &, $000058 *$ & $.000058 *$ &, $000064 *$ & .084947 \\
\hline PINUS & ENOO2 & $\{13\}$ &, $000060 *$ & $.000058^{*}$ & $.000058 *$ & $.015913 *$ & , 983953 \\
\hline PINUS & ENOO3 & $\{14\}$ &, 099114 &, $000058 *$ & $.000058 *$ &, $000058 *$ &, $005393 *$ \\
\hline PINUS & ENOO5 & $\{15\}$ & $.000058 *$ &, $010349 *$ & 1,000000 &, $000058 *$ &, $000058 *$ \\
\hline PINUS & ENO06 & $\{16\}$ &, $000058 *$ &, $000091 *$ &, 982855 & $.000058 *$ & $.000058 *$ \\
\hline PINUS & ENO07 & $\{17\}$ &, $000389 *$ &, $000058 *$ & $.000058 *$ & $.000268 *$ &, 434649 \\
\hline PINUS & ENOO8 & $\{18\}$ & .060633 &, $000058 *$ & $.000058 *$ &, $000058 *$ & $.010152 *$ \\
\hline PINUS & ENOO9 & $\{19\}$ & $.000231 *$ &, $000058 *$ & $.000058 *$ & $.000455 *$ &, 539410 \\
\hline PINUS & EN010 & $\{20\}$ &, $002452 \star$ &, $000058 *$ & $.000058 *$ & $.000080 *$ &, 167792 \\
\hline PINUS & ENO12 & $\{21\}$ &, 951480 &, $000058 *$ & $.000058 *$ &, $000058 *$ & $.000062 *$ \\
\hline PINUS & EN013 & $\{22\}$ &, $002127 *$ & $.000058 *$ & $.000058 *$ & $.000084 *$ &, 183028 \\
\hline PINUS & ENO14 & $\{23\}$ &, $003287^{\star}$ &, $000058 *$ & $.000058 *$ &, $000073 *$ & , 139233 \\
\hline PINUS & ENO15 & $\{24\}$ & 1,000000 &, $000058 *$ & $.000058 *$ & $.000058 *$ &, $000058 *$ \\
\hline PINUS & ENO23 & $\{25\}$ &, 417989 &, $000058 *$ &, $000058 *$ &, $000058 *$ &, $000426 *$ \\
\hline PINUS & ENO26 & $\{26\}$ & 1,000000 &, $000058 *$ &, $000058 *$ & $.000058 *$ &, $000058 *$ \\
\hline PINUS & M51 & $\{27\}$ &, $000058 *$ &, $000058 *$ & $.000058 *$ & 1,000000 & .934450 \\
\hline EUCAL & ER001 & $\{28\}$ &, 766188 &, $000058 *$ &, $000058 *$ &, $000058 *$ &, $000097 *$ \\
\hline EUCAL & ER006 & $\{29\}$ &, $000058 *$ &, $000058 *$ & $.000058 *$ &, 080863 &, 999828 \\
\hline EUCAL & ER007 & $\{30\}$ &, $000058 *$ &, $000058 *$ & $.000058 *$ & 1,000000 &, 411644 \\
\hline EUCAI & ER009 & $\{31\}$ &, $000058 *$ &, $000058 *$ & $.000058 *$ & , 999980 &, 127479 \\
\hline EUCAL & ER015 & $\{32\}$ &, $000058 *$ &, $000058 *$ &, $000058 *$ & 684675 & , 000990* \\
\hline EUCAI & ER018 & $\{33\}$ &, 999871 &, $000058 *$ &, $000058 *$ &, $000058 *$ &, $000058 *$ \\
\hline EUCAI & ER019 & $\{34\}$ &, $000058 *$ &, $000058 *$ &, $000058 *$ & 1,000000 & 1,000000 \\
\hline EUCAI & ER020 & $\{35\}$ &, $000058 *$ &, $000058 *$ &, $000058 *$ &, 994954 &, $027610^{*}$ \\
\hline EUCAL & ER022 & $\{36\}$ &, $000058 *$ &, $000058 *$ &, $000058 *$ &, 999642 &, 067046 \\
\hline EUCAL & ER023 & $\{37\}$ &, $000069 *$ &, $000058 *$ & $.000058 *$ &, $003999 *$ &, 891648 \\
\hline EUCAI & ER031 & $\{38\}$ &, $000058 *$ & $.000058 *$ &, $000058 *$ & 1,000000 & 1,000000 \\
\hline EUCAT & ENOO1 & $\{39\}$ & $.000058 *$ & $.000058 *$ & $.000058 *$ &, 968478 & $.010679 *$ \\
\hline & ENO02 & $\{40\}$ & $.000058 *$ &, $000058 *$ & $.000058 *$ & 1,000000 &, 999846 \\
\hline EUCAI & ENO03 & $\{41\}$ & &, $000058 *$ &, $000058 *$ &, $000058 *$ &, $000058^{\star}$ \\
\hline EUCAL & ENO05 & $\{42\}$ & $.000058 *$ & &, 507186 &, $000058 *$ &, $000058 *$ \\
\hline EUCAI & ENO06 & $\{43\}$ &, $000058 *$ & .507186 & &, $000058 *$ &, $000058 *$ \\
\hline EUCAI & ENO07 & $\{44\}$ &, $000058 *$ &, $000058 *$ & $.000058 *$ & & , 999715 \\
\hline EUCAI & ENO08 & $\{45\}$ &, $000058 *$ &, $000058 *$ & $.000058 *$ & 999715 & \\
\hline EUCAL & ENO09 & $\{46\}$ &, $000058 *$ &, $000058 *$ &, $000058 *$ & 1,000000 &, 299413 \\
\hline EUCAI & ENO10 & $\{47\}$ &, $000058^{*}$ &, $000058 *$ & $.000058 *$ &, 494678 & $.000362^{\star}$ \\
\hline EUCAI & EN012 & $\{48\}$ &, $000058 *$ & $.000058 *$ &, $000058 *$ & 1,000000 & , 995867 \\
\hline EUCAI & ENO13 & $\{49\}$ &, $000058^{*}$ & $.000058^{*}$ &, $000058 *$ & , 916220 &, $005109 *$ \\
\hline EUCAL & ENO14 & $\{50\}$ & $.000058 *$ & $.000058 *$ & , $000058 *$ & 1,000000 & ,950595 \\
\hline EUCAI & ENO15 & $\{51\}$ &, $000058 *$ & $.000058 *$ & $.000058 *$ & 1,000000 & , 999992 \\
\hline EUCAI & ENO23 & $\{52\}$ & $.000058 *$ &, $000058 *$ &, $000058 *$ & 1,000000 & , 999999 \\
\hline EUCAI & ENO26 & $\{53\}$ &, $000058 *$ & $.000058 *$ & $.000058 *$ & , 995901 & 1,000000 \\
\hline EUCAI & M51 & $\{54\}$ &, $000058^{*}$ & .150435 & 1,000000 & $.000058 *$ & $.000058 *$ \\
\hline
\end{tabular}




\begin{tabular}{|c|c|c|c|c|c|c|c|}
\hline \multicolumn{3}{|l|}{$\begin{array}{l}\text { STAT. } \\
\text { GENERAL } \\
\text { MANOVA }\end{array}$} & \multicolumn{5}{|c|}{$\begin{array}{l}\text { Tukey HSD test; variable PMASSA (pm-pineu.sta) } \\
\text { Probabilities for Post Hoc Tests } \\
\text { INTERACTION: } 1 \times 2\end{array}$} \\
\hline MADEIRA & FUNGO & & $\begin{array}{c}\{46\} \\
2,946723\end{array}$ & $\begin{array}{c}\{47\} \\
3,228493\end{array}$ & $\begin{array}{c}\{48\} \\
2,745110\end{array}$ & $\begin{array}{c}\{49\} \\
3,135826\end{array}$ & $\begin{array}{c}\{50\} \\
2,798848\end{array}$ \\
\hline PINUS & ER001 & $\{1\}$ &, $000058 *$ &, $000058 *$ &, $000058 *$ & $000058 *$ & $.000058 *$ \\
\hline PINUS & ER006 & $\{2\}$ & $.000058 *$ &, $000058^{*}$ &, $000058 *$ & $000058 \star$ & $000058 *$ \\
\hline PINUS & ER007 & $\{3\}$ & $.000059 *$ & $.000058 *$ & $.000919 *$ &, $000058 *$ & $000207 *$ \\
\hline PINUS & ER009 & $\{4\}$ &, $000061 *$ &, $000058 *$ & $.003103 *$ &, $000058 *$ & .000658 * \\
\hline PINUS & ER015 & \{5\} & $.044670^{*}$ &, $000066^{*}$ & 805610 &, $000282 *$ & 530896 \\
\hline PINUS & ER018 & $\{6\}$ & $.000058 *$ &, $000058 *$ & $.000058 *$ &, $000058 *$ & $.000058 *$ \\
\hline PINUS & ER019 & $\{7\}$ & .134451 &, $000117 *$ & ,959681 &, $001301 *$ & 805763 \\
\hline PINUS & ER020 & $\{8\}$ & $.010652^{*}$ &, $000059 *$ &, 500031 &, $000086 *$ & 244012 \\
\hline PINUS & ER022 & $\{9\}$ & $.000058 *$ & $.000058 *$ &, $000058 *$ &, $000058 *$ & $.000058 *$ \\
\hline PINUS & ER023 & $\{10\}$ & $.000412 *$ &, $000058 *$ & .078844 &, $000058 *$ & $023758 *$ \\
\hline PINUS & ER031 & $\{11\}$ & $.000058 *$ &, $000058^{*}$ &, $000058 *$ &, $000058 *$ & $.000058 *$ \\
\hline PINUS & ENO01 & $\{12\}$ & $.000058 *$ &, $000058 *$ &, $000059 *$ &, $000058 *$ &, $000058 *$ \\
\hline PINUS & ENO02 & $\{13\}$ & $.000066 *$ &, $000058 *$ & $005768 *$ &, $000058 *$ & $001262 *$ \\
\hline PINUS & EN003 & $\{14\}$ & $.000058 *$ &, $000058 *$ &, $000058 *$ &, $000058^{\star}$ &, $000058 *$ \\
\hline PINUS & EN005 & $\{15\}$ & $.000058 *$ &, $000590 *$ & $.000058 *$ &, $000080 *$ &, $000058 *$ \\
\hline PINUS & EN006 & $\{16\}$ &, $000076 *$ &, 070465 &, $000058 *$ &, $007744 *$ &, $000058^{\star}$ \\
\hline PINUS & EN007 & $\{17\}$ &, $000058 *$ & $.000058 *$ & $.000113^{*}$ &, $000058 *$ &, $000066^{*}$ \\
\hline PINUS & EN008 & $\{18\}$ & $.000058 *$ &, $000058 *$ & $.000058 *$ &, $000058 *$ &, $000058 *$ \\
\hline PINUS & EN009 & $\{19\}$ & $.000058 *$ &, $000058 *$ &, $000165 *$ &, $000058 *$ &, $000073^{*}$ \\
\hline PINUS & EN010 & $\{20\}$ & $.000058 *$ &, $000058 *$ & $.000063^{*}$ &, $000058 *$ &, $000059 *$ \\
\hline PINUS & EN012 & $\{21\}$ &, $000058 *$ & $.000058 *$ &, $000058 *$ &, $000058 *$ &, $000058 *$ \\
\hline PINUS & EN013 & $\{22\}$ & $.000058 *$ &, $000058 *$ &, $000064 *$ &, $000058 *$ &, $000059 *$ \\
\hline PINUS & ENO14 & $\{23\}$ &, $000058 *$ & $.000058 *$ &, $000061 *$ &, $000058 *$ & $.000059 *$ \\
\hline PINUS & EN015 & $\{24\}$ &, $000058 *$ &, $000058 *$ &, $000058 *$ &, $000058 *$ &, 000058 * \\
\hline PINUS & EN023 & $\{25\}$ & $.000058 *$ &, $000058 *$ &, $000058 *$ &, $000058 *$ &, $000058 *$ \\
\hline PINUS & EN026 & $\{26\}$ & $.000058 *$ &, $000058 *$ &, $000058 *$ & $.000058 *$ & $.000058 *$ \\
\hline PINUS & M51 & $\{27\}$ & 1,000000 &, 935797 & 1,000000 &, 999482 & 1,000000 \\
\hline EUCAL & ER001 & $\{28\}$ & $.000058 *$ &, $000058 *$ &, $000058 *$ &, $000058 *$ &, $000058 *$ \\
\hline EUCAL & ER006 & $\{29\}$ &, $000157 *$ &, $000058 *$ &, $034552^{\star}$ &, $000058 *$ &, $009194 *$ \\
\hline EUCAI & ER007 & $\{30\}$ & 1,000000 &, 999925 & 1,000000 & 1,000000 & 1,000000 \\
\hline EUCAL & ER009 & $\{31\}$ & 1,000000 & 1,000000 & 1,000000 & 1,000000 & 1,000000 \\
\hline EUCAI & ER015 & $\{32\}$ & 1,000000 & 1,000000 & 859355 & 1,000000 & 976730 \\
\hline EUCAI & ER018 & $\{33\}$ & $.000058 *$ &, $000058 *$ &, $000058 *$ &, $000058 *$ &, $000058 *$ \\
\hline EUCAI & ER019 & $\{34\}$ & 955467 & $.022747 *$ & 1,000000 & 160760 & ,999999 \\
\hline EUCAL & ER020 & $\{35\}$ & 1,000000 & 1,000000 &, 999625 & 1,000000 & ,999998 \\
\hline EUCAL & ER022 & $\{36\}$ & 1,000000 & 1,000000 &, 999990 & 1,000000 & 1,000000 \\
\hline EUCAL & ER023 & $\{37\}$ &, $000059 *$ &, $000058 *$ &, $001316 *$ &, $000058 *$ & $.000285^{\star}$ \\
\hline EUCAL & ER031 & $\{38\}$ &, 999145 & .116779 & 1,000000 & 482383 & 1,000000 \\
\hline EUCAI & EN001 & $\{39\}$ & 1,000000 & 1,000000 & 995145 & 1,000000 & , 999895 \\
\hline EUCAL & ENO02 & $\{40\}$ & 1,000000 &, 454563 & 1,000000 & 895556 & 1,000000 \\
\hline EUCAL & ENO03 & $\{41\}-$ &, $000058 *$ &, $000058 *$ & $.000058 *$ &, $000058 *$ &, $000058 *$ \\
\hline EUCAL & ENO05 & $\{42\}$ & $.000058 *$ &, $000058 *$ & $.000058 *$ &, $000058 *$ &, $000058 *$ \\
\hline EUCAL & EN006 & $\{43\}$ &, $000058 *$ &, $000058 *$ &, $000058 *$ &, $000058 *$ &, 000058 \\
\hline EUCAL & ENO07 & $\{44\}$ & 1,000000 & 494678 & 1,000000 & 916220 & 1,000000 \\
\hline EUCAI & EN008 & $\{45\}$ &, 299413 &, $000362 *$ &, 995867 &, $005109 *$ &, 950595 \\
\hline EUCAI & EN009 & $\{46\}$ & & .999993 & 1,000000 & 1,000000 & 1,000000 \\
\hline EUCAL & EN010 & $\{47\}$ & , 999993 & & 705200 & 1,000000 & 916517 \\
\hline EUCAL & EN012 & $\{48\}$ & 1,000000 &, 705200 & &, 980339 & 1,000000 \\
\hline EUCAL & EN013 & $\{49\}$ & 1,000000 & 1,000000 &, 980339 & &, 999057 \\
\hline EUCAI & EN014 & $\{50\}$ & 1,000000 &, 916517 & 1,000000 &, 999057 & \\
\hline EUCAL & EN015 & $\{51\}$ & , 999995 &, 305415 & 1,000000 &, 781017 & 1,000000 \\
\hline EUCAL & EN023 & $\{52\}$ & 999966 &, 230576 & 1,000000 & 691395 & 1,000000 \\
\hline EUCAL & EN026 & $\{53\}$ & , 159227 &, $000139 *$ &, 972035 & $.001703^{*}$ &, 843222 \\
\hline EUCAL & M51 & $\{54\}$ &, $000058 *$ & $.000066^{*}$ &, $000058 *$ &, $000058 *$ &, $000058 *$ \\
\hline
\end{tabular}




\begin{tabular}{|c|c|c|c|c|c|c|}
\hline \multicolumn{3}{|l|}{$\begin{array}{l}\text { STAT } \\
\text { GENERAL } \\
\text { MANOVA }\end{array}$} & \multicolumn{4}{|c|}{$\begin{array}{l}\text { Tukey HSD test; variable PMASSA (pm-pineu.sta } \\
\text { Probabilities for Post Hoc Tests } \\
\text { INTERACTION: } 1 \times 2\end{array}$} \\
\hline MADE IRA & EUNGO & & $\begin{array}{c}\{51\} \\
2,668173\end{array}$ & $\begin{array}{c}\{52\} \\
2,649751\end{array}$ & $\begin{array}{c}\{53\} \\
2,346136\end{array}$ & $\begin{array}{c}\{54\} \\
4,175124\end{array}$ \\
\hline RINUS & ER001 & $\{1\}$ &, $000058 *$ &, $000058 *$ & $000072 *$ & $000058 *$ \\
\hline PINUS & ER006 & $\{2\}$ &, $000058 *$ & $.000058 *$ & $.000169 *$ & $.000058 *$ \\
\hline PINUS & ERO0 7 & $\{3\}$ &, $008007 *$ & $012903 *$ & 953789 &, $000058 *$ \\
\hline PINUS & ERO09 & $\{4\}$ & $.023303^{*}$ & $.035922^{\star}$ &, 992948 & $.000058 *$ \\
\hline PINUS & ER015 & $\{5\}$ &, 984760 & 993999 & 1,000000 & $.000058 *$ \\
\hline PINUS & ERO18 & $\{6\}$ &, $000058 *$ &, $000058 *$ & $.000125 *$ &, $000058 *$ \\
\hline PINUS & ERO19 & $\{7\}$ &, 999372 & .999855 & 1,000000 & $.000058 *$ \\
\hline PINUS & ERO20 & $\{8\}$ &, 872585 &, 925293 & 1,000000 &, $000058 *$ \\
\hline PINUS & ER022 & $\{9\}$ &, $000058 *$ & $.000058 *$ &, $005349^{*}$ & $.000058 *$ \\
\hline PINUS & ER023 & $\{10\}$ &, 305798 &, 393005 & 1,000000 & $.000058 *$ \\
\hline PINUS & ER031 & $\{11\}$ &, $000058 *$ & .000058 * & $.000058 *$ & $.000058 *$ \\
\hline PINUS & ENO01 & $\{12\}$ &, $000082 *$ & $.000105 *$ &, 176855 & $.000058 *$ \\
\hline PINUS & ENO02 & $\{13\}$ & $.039291 *$ &, 059035 &, 998106 & $.000058 *$ \\
\hline PINUS & ENO03 & $\{14\}$ &, $000058 *$ &, $000059 *$ & $.014894 *$ & $.000058 *$ \\
\hline PINUS & ENOO5 & $\{15\}$ &, $000058 *$ &, $000058 *$ & $.000058 *$ & 1,000000 \\
\hline PINUS & EN006 & $\{16\}$ &, $000058 *$ & $.000058 *$ &, $000058 *$ &, 999934 \\
\hline PINUS & EN007 & $\{17\}$ & $.000774 *$ &, $001324^{*}$ & .645484 & $.000058 *$ \\
\hline PINUS & ENOO8 & $\{18\}$ &, $000059 *$ & $.000060^{*}$ &, $026698 *$ & $.000058 *$ \\
\hline PINUS & ENO09 & $\{19\}$ & $.001364 *$ &, $002319 *$ &, 745149 & $.000058 *$ \\
\hline PINUS & ENO10 & $\{20\}$ &, $000144 *$ & $.000220^{\star}$ &, 312488 & $.000058 *$ \\
\hline PINUS & ENO12 & $\{21\}$ &, $000058 *$ & $.000058 *$ &, $000077 *$ &, $000058 *$ \\
\hline PINUS & EN013 & $\{22\}$ &, $000160 *$ & $.000249 *$ & .335282 &, $000058 *$ \\
\hline PINUS & EN014 & $\{23\}$ &, $000118 *$ & $.000171 *$ & .268124 & $.000058 *$ \\
\hline PINUS & EN015 & $\{24\}$ &, $000058 *$ &, $000058 *$ & $.000058 *$ &, $000058 *$ \\
\hline PINUS & ENO23 & $\{25\}$ &, $000058 *$ & $.000058^{*}$ &, $001309 *$ &, $000058 \star$ \\
\hline PINUS & EN026 & $\{26\}$ &, $000058 *$ & $.000058 *$ & $.000058 *$ & $.000058 *$ \\
\hline PINUS & M51 & $\{27\}$ & 1,000000 & 1,000000 & 810285 & $.000058 *$ \\
\hline EUCAL & ERO01 & $\{28\}$ &, $000058 *$ & $.000058 *$ &, $000207 *$ &, 000058 * \\
\hline EUCAT & ER006 & $\{29\}$ &, 166568 &, 227333 & .999996 & $.000058 *$ \\
\hline EUCAI & ER007 & $\{30\}$ & 1,000000 &, 999997 & .236947 & $.000058 *$ \\
\hline EUCAL & ER009 & $\{31\}$ &, 999448 & .998019 & .058151 & $.000058 *$ \\
\hline EUCAI & ER015 & $\{32\}$ &, 479366 &, 383645 & $.000326 *$ & $.000060 *$ \\
\hline EUCAI & ER018 & $\{33\}$ &, $000058 *$ &, $000058 *$ & $.000059 *$ &, $000058 *$ \\
\hline EUCAL & ER019 & $\{34\}$ & 1,000000 & 1,000000 & 1,000000 & $.000058 *$ \\
\hline EUCAI & ERO20 & $\{35\}$ &, 969067 & 939011 & $010532 \star$ &, $000058 *$ \\
\hline EUCAL & ER022 & $\{36\}$ &, 995429 &, 987912 & $.028094 *$ & .000058 * \\
\hline EUCAI & ER023 & $\{37\}$ &, $011036^{*}$ &, $017574 *$ &, 971260 &, $000058 *$ \\
\hline EUCAL & ER031 & $\{38\}$ & 1,000000 & 1,000000 &, 999999 &, $000058 *$ \\
\hline EUCAT & ENOO1 & $\{39\}$ &, 887719 & .821458 & $.003752 *$ &, 000058 * \\
\hline EUCAL & ENO02 & $\{40\}$ & 1,000000 & 1,000000 &, 997382 & $000058 *$ \\
\hline EUCAI & ENO03 & $\{41\}$ &, $000058 *$ & $.000058 *$ &, $000058 *$ &, $000058 *$ \\
\hline EUCAL & ENOO5 & $\{42\}$ &, $000058 *$ & $.000058 *$ & $.000058 *$ & 150435 \\
\hline EUCAL & EN006 & $\{43\}$ &, $000058 *$ & $.000058 *$ & $.000058 *$ & 1,000000 \\
\hline EUCAL & ENO07 & $\{44\}$ & 1,000000 & 1,000000 &, 995901 & 000058 * \\
\hline EUCAI & ENO08 & $\{45\}$ &, 999992 & 999999 & 1,000000 &, $000058 *$ \\
\hline EUCAI & ENO09 & $\{46\}$ &, 999995 & 999966 &, 159227 &, $000058 *$ \\
\hline EUCAL & ENO10 & $\{47\}$ &, 305415 &, 230576 & $.000139 *$ & $000066 *$ \\
\hline EUCAI & EN012 & $\{48\}$ & 1,000000 & 1,000000 &, 972035 &, $000058 *$ \\
\hline EUCAL & EN013 & $\{49\}$ &, 781017 &, 691395 &, $001703 *$ &, $000058 *$ \\
\hline EUCAL & ENO14 & $\{50\}$ & 1,000000 & 1,000000 & 843222 & 000058 * \\
\hline EUCAL & EN015 & $\{51\}$ & & 1,000000 & 999692 & .000058 * \\
\hline EUCAL & ENO23 & $\{52\}$ & 1,000000 & & 999936 & $000058 *$ \\
\hline EUCAL & EN026 & $\{53\}$ &, 999692 &, 999936 & & $000058 *$ \\
\hline EUCAL & M51 & $\{54\}$ &, $000058 *$ & $.000058 *$ &, $000058 *$ & \\
\hline
\end{tabular}

